US Army Corps of Engineers ${ }_{\circledast}$

Engineer Research and

Development Center

\title{
Laboratory Characterization of Cor-Tuf Baseline and UHPC-S
}

Dylan A. Scott, Steven S. Graham, Bradford P. Songer,

March 2021

Brian H. Green, Michael J. Grotke, and Tony N. Brogdon

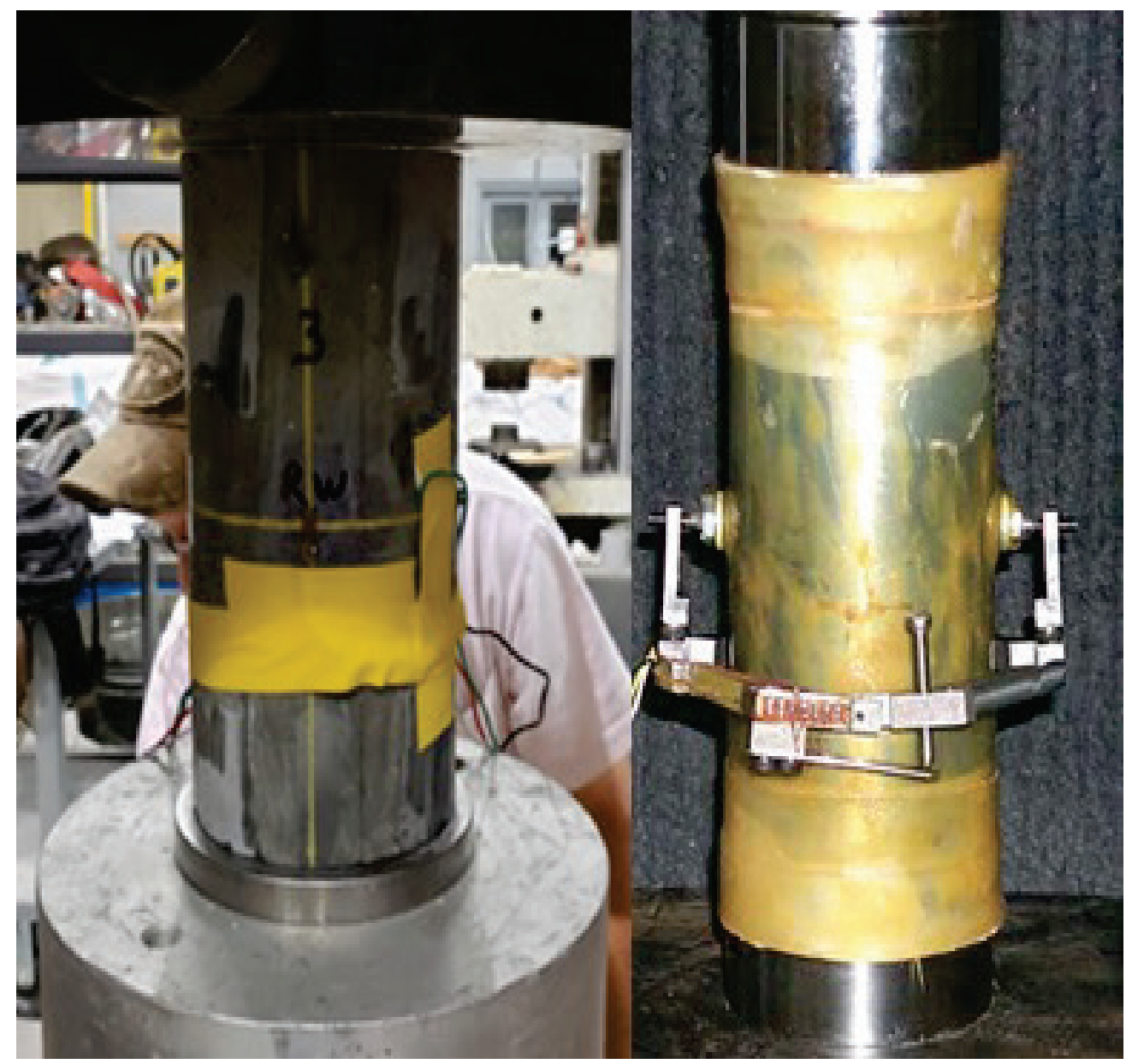


The U.S. Army Engineer Research and Development Center (ERDC) solves the nation's toughest engineering and environmental challenges. ERDC develops innovative solutions in civil and military engineering, geospatial sciences, water resources, and environmental sciences for the Army, the Department of Defense, civilian agencies, and our nation's public good. Find out more at www.erdc.usace.army.mil.

To search for other technical reports published by ERDC, visit the ERDC online library at https://erdclibrary.on.worldcat.org/discovery. 


\section{Laboratory Characterization of Cor-Tuf Baseline and UHPC-S}

Dylan A. Scott, Steven S. Graham, Bradford P. Songer, Brian H. Green, Michael J. Grotke, and Tony N. Brogdon

Geotechnical and Structures Laboratory

U.S. Army Engineer Research and Development Center

3909 Halls Ferry Road

Vicksburg, MS 39180-6199

Final report

Approved for public release; distribution is unlimited.

Prepared for Combating Terrorism Technical Support Office

Washington, DC 20314-1000

Under Project PS-3928, "Development of Ultra-High-Performance Concrete Tool," MIPR N4175618MP00321 


\section{Abstract}

This experimental effort is part of a larger program entitled Development of Ultra-High-Performance Concrete Tools and Design Guidelines. This program operates in accordance with an agreement concerning combating terrorism research and development between the United States of America Department of Defense and the Republic of Singapore Ministry of Defence. The objective of the program is to develop a better understanding of the potential benefits that may be achieved from the application of ultra-high-performance concrete (UHPC) materials for protective structures. The specific effort detailed in this report will provide insight into laboratory-scale mechanical properties of Cor-Tuf and a proprietary material termed UHPC-Singapore (UHPC-S).

DISCLAIMER: The contents of this report are not to be used for advertising, publication, or promotional purposes. Citation of trade names does not constitute an official endorsement or approval of the use of such commercial products. All product names and trademarks cited are the property of their respective owners. The findings of this report are not to be construed as an official Department of the Army position unless so designated by other authorized documents. 


\section{Contents}

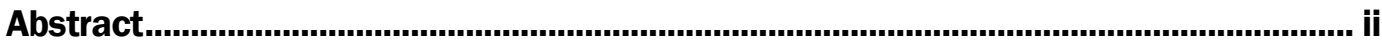

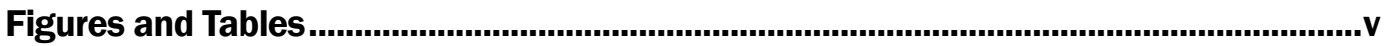

Preface

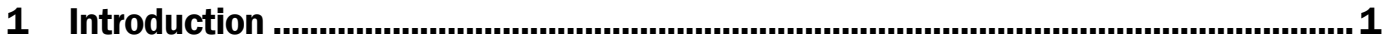

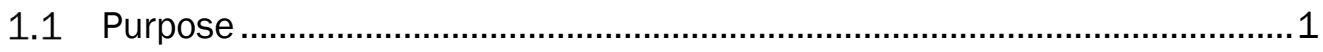

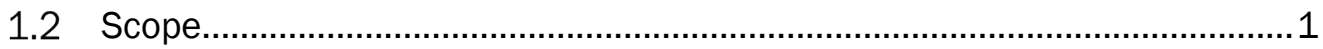

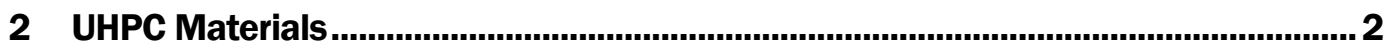

2.1 Ultra-High performance concrete ............................................................ 2

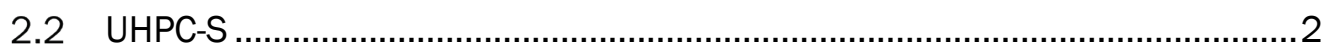

2.2.1 Cor-Tuf Baseline.............................................................................................. 3

2.2.2 Strength and constitutive property behavior of Cor-Tuf Baseline .......................... 3

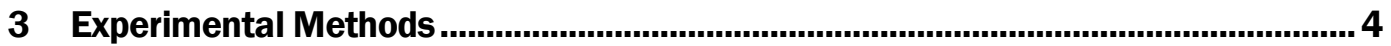

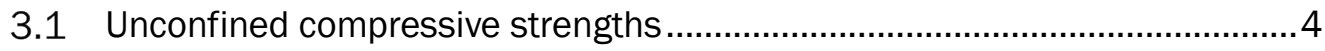

3.1.1 101.6-mm x 203.2-mm (4-in. x 8-in.) cylinders - ASTM C39 .................................. 4

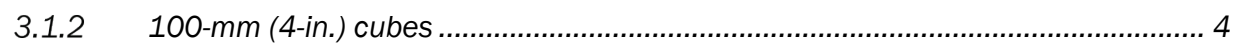

3.2 Flexural response ........................................................................... 4

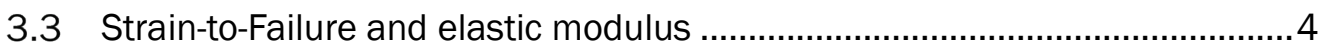

3.3.1 Strain gauge installation procedure................................................................... 5

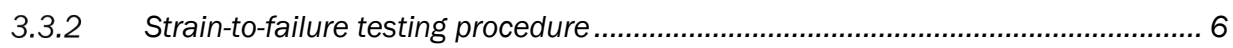

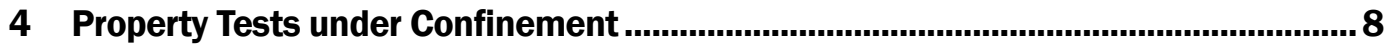

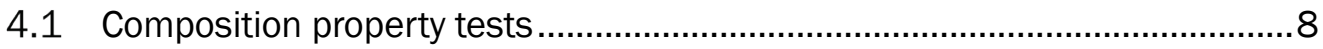

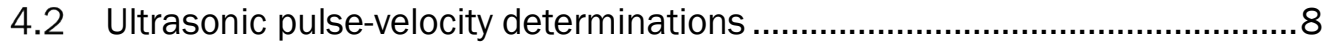

4.3 Mechanical property tests .................................................................

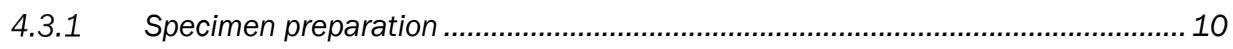

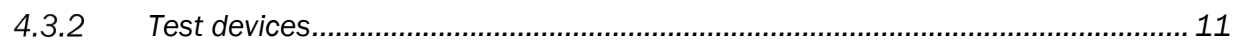

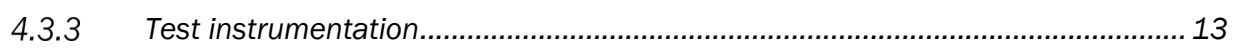

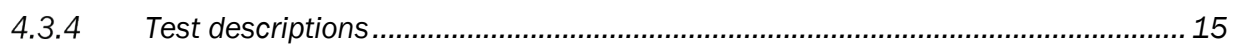

4.3.5 Definition of stresses and strains ................................................................ 16

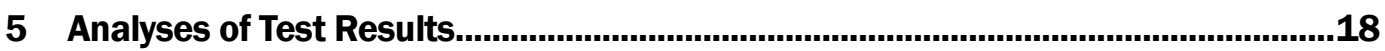

5.1 Unconfined compressive strength (ASTM C39 and BS-EN

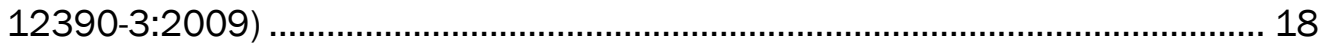

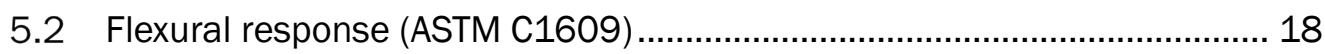

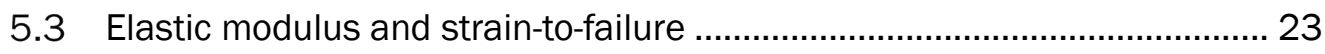

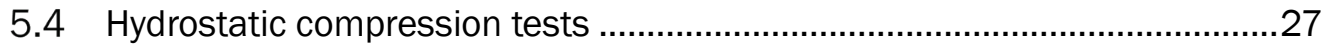

5.5 Triaxial compression tests...................................................................... 29

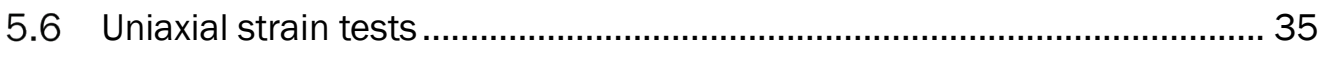

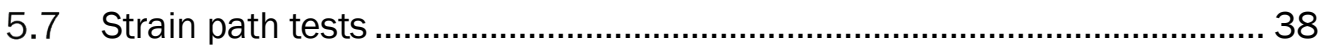




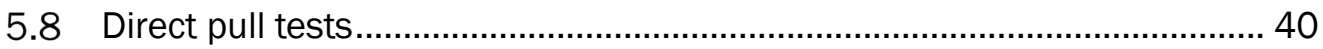

5.9 Comparison of UHPC-S and CT concretes................................................ 40

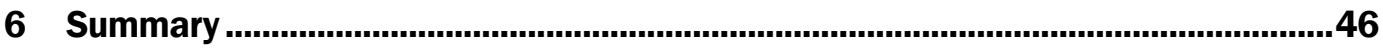

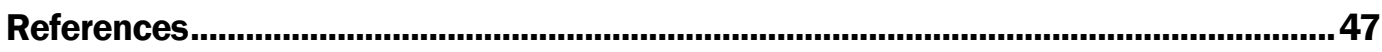

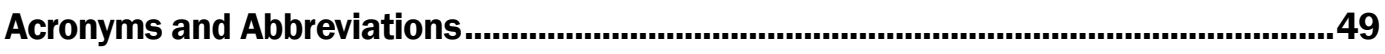

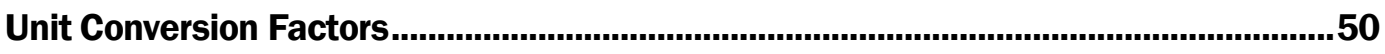

Report Documentation Page 


\section{Figures and Tables}

\section{Figures}

Figure 1. Four-inch by eight-inch cylinder instrumented with two transverse and two longitudinal strain gauges.

Figure 2. Stress vs. time detailing strain-to-failure loading conditions................................. 7

Figure 3. Strain-to-failure sample awaiting testing........................................................... 7

Figure 4. Typical test specimen setup........................................................................12

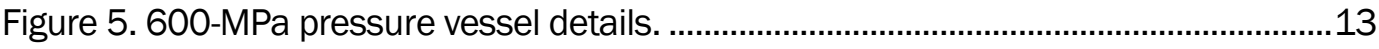

Figure 6. Spring-arm lateral deformeter mounted on test specimen...................................14

Figure 7. ASTM C39 UCS testing results for Cor-Tuf. .........................................................20

Figure 8 . Load vs. displacement of 4 -in. by 4 -in. by 16 -in. flexural response beams.

Figure 9. Load vs. displacement for 6 -in. by 6 -in. by 21 -in. flexural response beams

Figure 10. Flexural response stress vs. 'normalized' displacement.

Figure 11. Load vs. displacement of unconfined compressive tests conducted during strain-to-failure experiments.

Figure 12. Stress vs. absolute value of longitudinal strain................................................26

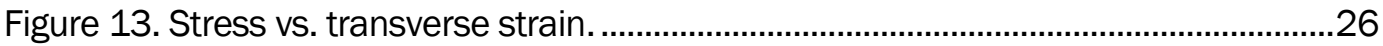

Figure 14. Transverse strain vs. Iongitudinal strain $(\mathrm{mm} / \mathrm{mm})$......................................... 27

Figure 15. Pressure-volume responses from HC tests...................................................28

Figure 16. Pressure-time histories from HC tests. ................................................................29

Figure 17. Stress-strain responses from UC tests. ............................................................31

Figure 18. Stress difference-volumetric strain during shear from UC tests. ......................32

Figure 19. Stress-strain responses from TXC tests at confining pressures of 10 , 20, and $50 \mathrm{MPa}$.

Figure 20. Stress difference-volumetric strain during shear from TXC tests at confining pressures of 10,20 , and $50 \mathrm{MPa}$.

Figure 21. Stress-strain responses from TXC tests at confining pressures of 100, 200, 300, and $400 \mathrm{MPa}$.

Figure 22. Stress difference-volumetric strain during shear from TXC tests at confining pressures of 100, 200,300, and $400 \mathrm{MPa}$.

Figure 23. Failure data from UC and TXC tests and recommended failure surface...........34

Figure 24. Stress-strain responses from UX tests............................................................36

Figure 25. Pressure-volume data from UX tests...........................................................36

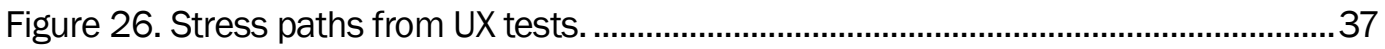

Figure 27. Comparison of pressure-volume data from $\mathrm{HC}$ and $\mathrm{UX}$ tests............................37

Figure 28. Stress paths from UX/CV tests. .......................................................................38

Figure 29. Pressure-volume responses from UX/CV tests...................................................39 
Figure 30. Stress-strain responses from UX/CV tests..........................................................39

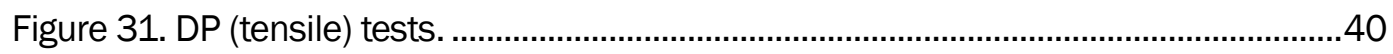

Figure 32. Comparison of pressure-volume responses from $\mathrm{HC}$ tests on UHPC-S and CT...

Figure 33. Comparison of stress-strain responses from UC tests on UHPC-S and CT.

Figure 34. Comparison of stress difference-volumetric strain during shear from UC tests on UHPC-S and CT. .43

Figure 35. Comparison of failure surfaces for UHPC-S and CT. .......................................44

Figure 36. Comparison of stress paths from UX tests on UHPC-S and CT...........................44

Figure 37. Comparison of stress-strain responses from UX tests on UHPC-S and

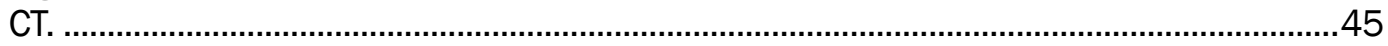

Figure 38. Comparison of pressure-volume data from UX tests on UHPC-S and CT.........45

\section{Tables}

Table 1. Physical and composition properties of UHPC-S. ..................................................

Table 2. Completed UHPC-S test matrix..........................................................................11

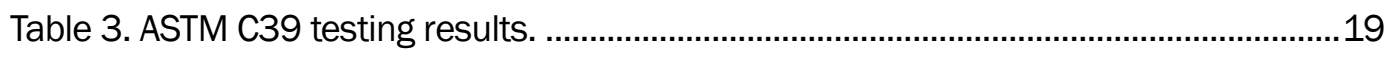

Table 4. BS EN 12390-3 UCS testing results..................................................................20

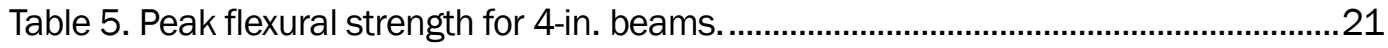

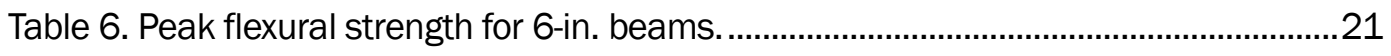

Table 7. Cor-Tuf unconfined compressive strength, elastic modulus, and

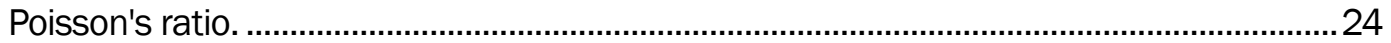

Table 8. UHPC-S unconfined compressive strength, elastic modulus, and Poisson's ratio. 


\section{Preface}

This study was conducted for the Combating Terrorism Technical Support Office (CTTSO) and the Defence Science \& Technology Agency (DSTA) in Singapore under Project Number PS-3928, "Development of Ultra-High-Performance Concrete Tool,” MIPR N4175618MPoo321. The technical monitor was Dr. Bradley W. Foust.

The work was performed by the Concrete and Materials Branch (CMB) and the Impact and Explosion Effects Branch (IEEB), both of the Engineering Systems and Materials Division (ESMD), and the Structural Mechanics Branch (SMB) of the Geosciences and Structures Division (GSD). Each Division resides within the Geotechnical and Structures Laboratory (GSL), U.S. Army Engineer Research and Development Center (ERDC). At the time of publication, Dr. Jameson Shannon was Chief, CMB; Mr. Jeffrey G. Averett was Chief, IEEB; Mr. Bradford Steed was Chief, SMB; and Mr. Justin S. Strickler was Chief, ESMD. Ms. Pamela G. Kinnebrew was the Technical Director for Military Engineering. The Deputy Director of GSL was Mr. Charles W. Ertle II, and the Director was Mr. Bartley P. Durst.

COL Teresa A. Schlosser was the Commander of ERDC, and Dr. David W. Pittman was the Director. 


\section{Introduction}

\subsection{Purpose}

The purpose of this report is to document the results from a laboratory characterization of two Ultra-High Performance Concretes (UHPCs) in support of a collaborative project entitled "Development of Ultra-HighPerformance Concrete Tools and Design Guidelines." The work presented herein is in accordance with the agreement between the Department of Defense of the United States of America and the Ministry of Defence of the Republic of Singapore concerning research and development for combating terrorism. All research and results presented within this manuscript were conducted by personnel of the Concrete and Materials Branch (CMB), the Impact and Explosives Effects Branch (IEEB), and the Structural Mechanics Branch (SMB) of the Geotechnical Structures Laboratory (GSL) of the Engineer Research and Development Center (ERDC). All Ultra-High-Performance Concrete-Singapore (UHPC-S) specimens were provided directly from the Defence Science and Technology Agency (DTSA) of Singapore through the Combating Terrorism Technical Support Office (CTTSO), which then provided specimens to the ERDC.

\subsection{Scope}

A full suite of quasi-static mechanical property tests, both unconfined and confined, were conducted on Cor-Tuf and UHPC-S specimens. This report quantitatively compares these results. Unconfined material property tests included unconfined compressive strength (UCS), two sizes of flexural response beams, Young's modulus, Poisson's ratio, and strain-to-failure.

Mechanical property tests under confinement were conducted on the UHPC-S specimens, and the results of nondestructive pulse-velocity measurements from each specimen were obtained. These results were compared to historical data for Cor-Tuf to provide programmatic efficiency and a cost savings to the overall program. The physical and composition properties, test procedures, and test descriptions are documented in Chapter 4, comparative plots and analyses of the experimental results are presented in Chapter 5, and a summary is provided in Chapter 6. 


\section{UHPC Materials}

\subsection{Ultra-High performance concrete}

The American Concrete Institute (ACI) defines ultra-high performance concrete (UHPC) as "concrete that has a minimum specified compressive strength of $150 \mathrm{MPa}(22,000 \mathrm{psi})$ with specified durability, tensile ductility, and toughness requirements; fibers are generally included to achieve specified requirements" (2018).

In order to obtain these properties, UHPCs are made with specific highquality materials including, but not limited to, oil-well or low-heat Portland cement, siliceous or aluminous fine aggregates, crushed quartz or some other micrometer-sized powder, silica fume, water, high-range water-reducing admixtures to control rheology, and other components that vary by manufacturer. Concrete tends to exhibit more brittle-like behavior with higher compressive strengths. This brittle behavior is offset by the inclusion of steel fibers that aid in delocalizing micro- and macro-cracking, which improves tensile strength.

\subsection{UHPC-S}

UHPC-S is a proprietary ultra-high-performance fiber-reinforced concrete (UHPFRC) from Southeast Asia. The product has been advertised to reach compressive strengths of up to $175 \mathrm{MPa}$ or 25,000 psi. It has been successfully used to construct and/or provide critical element construction of hundreds of bridges in Southeast Asia.

The constituent materials and proportions are proprietary and, therefore, unknown by the public at this juncture. However, this UHPC shares many of the same characteristics of other well-known UHPCs. The cement appears to be of high quality with relatively low thermal output. Aggregates consist of either a single well-graded sand or some combination of sands producing an optimal grain-size distribution. The use of silica fume and perhaps other supplementary cementitious materials is likely and within ranges to be expected for this class of concrete. Steel-fiber reinforcement consists of short brass-coated steel fibers at roughly two percent by volume. The steel-fiber reinforcement is similar to that which is widely used by DUCTAL and other well-known proprietary UHPCs (e.g., 13-mm by 0.2mm-diam straight brass-coated steel fibers). 


\subsubsection{Cor-Tuf Baseline}

Cor-Tuf (CT) is the nomenclature given to a family of UHPCs developed at the ERDC Geotechnical and Structures Laboratory. For the in-depth comparative study described here, an exact mixture proportion was determined based on fixed constitutive material lots and was designated "Cor-Tuf Baseline" as a reference material.

Cor-Tuf Baseline was developed to serve as, and is currently considered by ERDC to be, a "laboratory standard" UHPC mixture that can be reproduced for various projects and exhibits the same physical properties with minimal batch-to-batch variability. The goal of Cor-Tuf Baseline was to minimize batch-to-batch variations as much as possible and to supply other ERDC researchers with a UHPC mixture that would be the same no matter when it was produced. To that end, the constituent materials that comprise Cor-Tuf Baseline must be obtained from the same vendors, source material location, manufacturing facility, etc., to maintain this standardization goal. Another feature of Cor-Tuf Baseline is that a revolving-drum mixer can be used to produce the mixture. The use of the revolving-drum mixer greatly increases production and allows ERDC to produce the larger test articles from one batch instead of from multiple smaller batches by using a smaller high-shear mixer. This allows an expansion of the production of test articles to be produced for a variety of research projects within the ERDC (Green et al. 2015).

\subsubsection{Strength and constitutive property behavior of Cor-Tuf Baseline}

In 2009, a series of laboratory experiments was conducted by ERDC/GSL to investigate the strength and constitutive property behavior of Cor-Tuf Baseline with and without steel fibers. These mechanical property tests consisted of hydrostatic compression (HC), unconfined compression (UC), triaxial compression (TXC), unconfined direct pull (DP), uniaxial strain (UX), and uniaxial strain/constant volumetric strain (UX/CV) tests. The results were reported in Williams et al. (2009).

In 2010, seven experimental series were conducted by ERDC/GSL to characterize the flexural and splitting tensile properties of Cor-Tuf Baseline with and without distributed steel-fiber reinforcement. The objectives of these experiments were to determine relevant mechanical properties of the material when exposed to the specified loading conditions. The results were reported in Roth et al. (2010). 


\section{Experimental Methods}

\subsection{Unconfined compressive strengths}

\subsubsection{6-mm x 203.2-mm (4-in. x 8-in.) cylinders - ASTM C39}

The unconfined compressive strength (UCS) was determined in accordance with ASTM C39 (2018b) by using 101.6-mm-diam by 203.2-mm-tall cylinders. The Cor-Tuf cylinders were cast according to ASTM C192 (2018a) in plastic molds on a vibrating table. UHPC-S cylinders were delivered to the ERDC in a hardened state, and the casting method is not specifically known. Prior to testing, the ends of the cylinders were ground to ensure end planeness. Three replicates were tested at each age. These tests allowed a comparison between the matrices of each Cor-Tuf batch and a comparison to UHPC-S. Fiber content generally has little effect on the pre-cracking UCS.

\subsubsection{0-mm (4-in.) cubes}

The UCS was also determined by using 100-mm cubes in accordance with BS EN 12390-3 (2009). The Cor-Tuf cubes were cast according to ASTM C192 (2018a) on a vibrating table using high-density polyethylene molds. UHPC-S samples were tested as received, and placement technique is not specifically known. Three replicates were tested at each age.

\subsection{Flexural response}

The flexural response testing was performed according to ASTM C1609 (2019b). This test used a beam with four-point loading. Two different sized beams were tested. The smaller beams were 4 in. by 4 in. by 16 in. tested on a 12-in. span (101.6 by 101.6 by $457.2 \mathrm{~mm}$ by $406.4-\mathrm{mm}$ span) with the larger beams being 6 in. by 6 in. by 21 in. tested on an 18-in. span (152.4 by 152.4 by $533.4 \mathrm{~mm}$ by $457.2-\mathrm{mm}$ span) Cor-Tuf samples were cast according to ASTM C192 (2018a), and UHPC-S samples were tested as received. Linear variable differential transformers (LVDTs) were used to measure centerline displacement that was, in turn, paired with the corresponding load data to provide a plot of load versus displacement.

\subsection{Strain-to-Failure and elastic modulus}

Six samples of both UHPC materials (CT and UHPC-S) were instrumented with four strain gauges each (i.e., two in the longitudinal and two in the lateral directions) to allow direct measurement of Young's modulus, Poisson's 
ratio, and strain-to-failure via quasi-static compression. The procedure for installation of foil-type adhesive-mounted strain gauges is described in Section 3.3.1, and the testing procedure is described in Section 3.3.2.

\subsubsection{Strain gauge installation procedure}

When strain gauges are installed on concrete, the maximum size of the aggregate inside the mix usually needs to be available. Typically, the gauge length must be double the size of the aggregate for $3 / 4$-in. aggregate. This is not a concern with these specimens because both UHPCs consisted of only fine aggregate. The cylindrical specimens were 4 in. diam by 8 in. tall. Gauge length was still prevalent to ensure the measuring sensors covered a sufficient area. A 1-in. gauge was used to provide an adequate surface area for a measurement.

Prior to installing gauges, the specimens were cleaned with acetone to remove unwanted oils and/or grease left from handling the specimens. This was accomplished with a lint-free cloth dampened with acetone. The specimens were then ready for gauge location marks to be applied. A crosshair configuration was applied midway up the specimen's height at $90^{\circ}$ increments around the specimen's circumference. The gauge locations were laid out at the midline points of each crosshair. Two gauges were installed in the vertical (longitudinal) direction $180^{\circ}$ apart. The same was used for the two horizontal (transverse) gauges. The transverse and longitudinal gauge distributions are shown in Figure 1.

At this point, a layer of Devcon 5-Minute Epoxy was applied over the gauge location and spread thin by using a 1-in. putty knife. After the epoxy had cured, it was sanded to a paper thin layer. This ensured that no voids were present under any of the gauge areas. The specimens were then ready for the strain gauges to be placed. The gauges were held in place with a piece of Mylar tape until they could be glued in place. An adhesive accelerator, model number BCYo1, was used to expedite the curing time of the adhesive, thus ensuring the sensors were installed. 


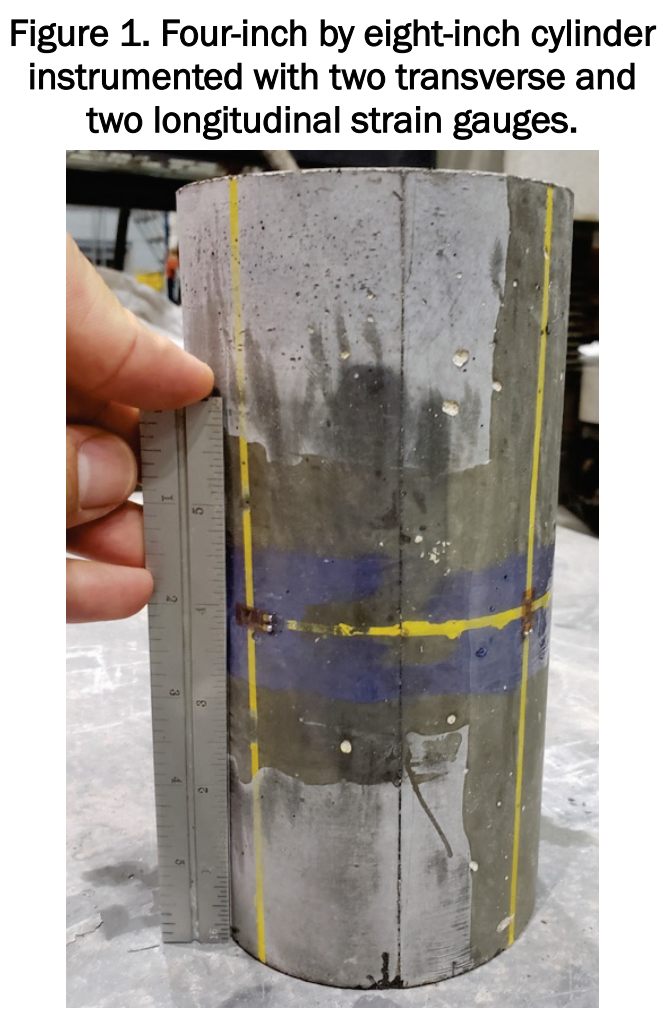

The gauges used were type 1-LY41-20/350 and were foil-backed. The adhesive used was $Z_{70}$, which is a cyanoacrylate low-viscosity super glue. The adhesive accelerator, the foil-backed gauges, and the adhesive were manufactured by the Hottinger Baldwin Messtechnik (HBM) company.

After the gauges were installed, a layer of moisture barrier material, model number Gage Kote \#8, was applied to the entire gauge surface excluding the solder tabs. This protected the adhesive against moisture ingression from ambient humidity and ensured the testing was not delayed. The model number CPF-10oc solder tabs, made of copper foil laminated on polyimide film (CPF), allowed the gauges to start with American Wire Gauge (AWG) 30-AWG-size flat ribbon cable and connect to the lead cable without any splicing. The lead cable was 22 AWG in size, providin greater durability in harsh environments (e.g., a test that fails the specimen). The moisture barrier material and the solder tabs were manufactured by Vishay Micro-Measurements.

\subsubsection{Strain-to-failure testing procedure}

Specimens were tested under a procedure similar to ASTM C469 (2014). However, strain gauges were used in lieu of the compressometer detailed in the method. Loading rates were kept at the prescribed $35 \pm 7 \mathrm{psi} / \mathrm{min}$ up to an 
estimated $40 \%$ of the average ultimate load determined during the ASTM $\mathrm{C} 39$ (2018b) compressive testing. The loading cycle was reduced from three $40 \%$ cycles to one $40 \%$ cycle with a subsequent loading to failure. This cycle is illustrated in Figure 2 as a stress-versus-time plot for CT and UHPC-S.

Figure 2. Stress vs. time detailing strain-to-failure loading conditions.

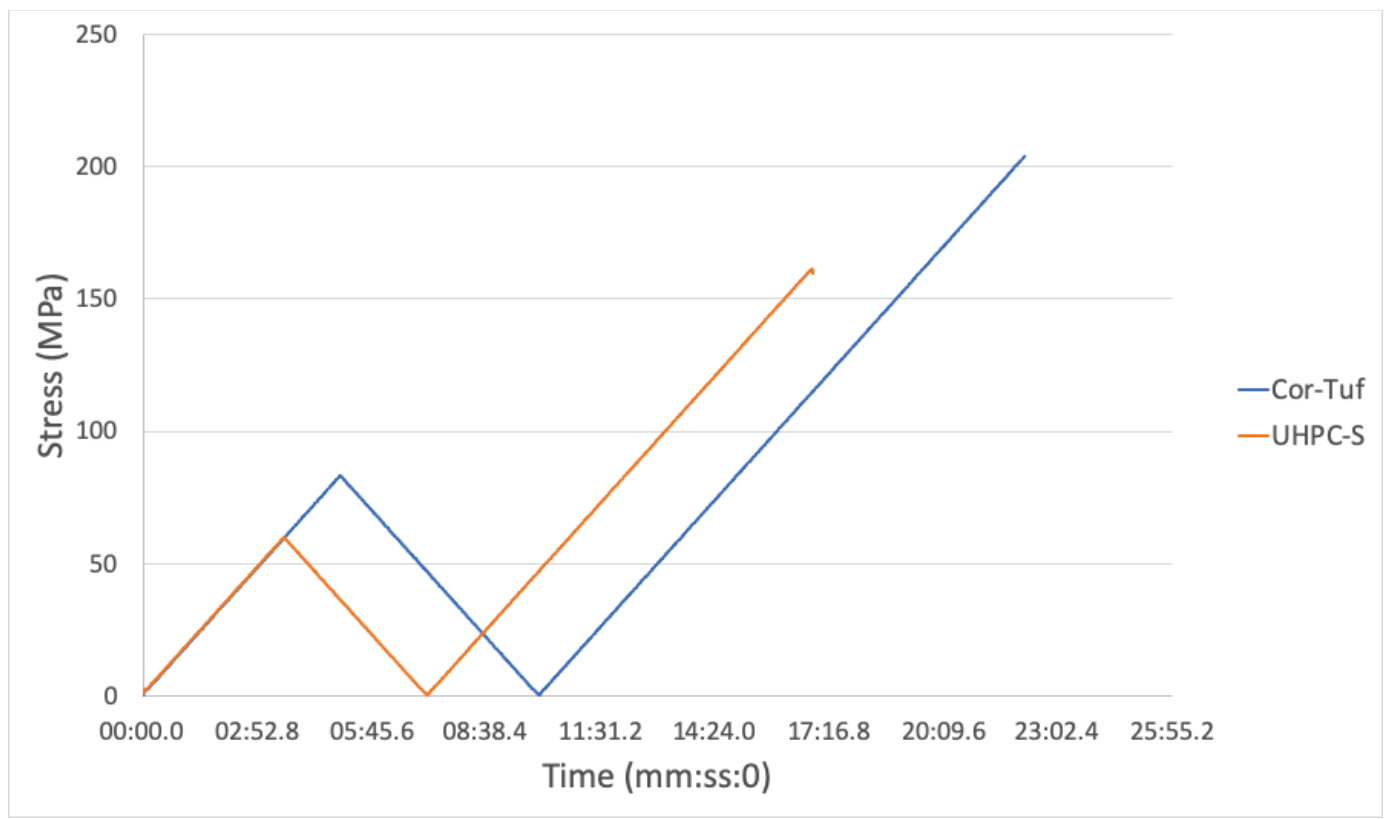

Figure 3 provides an image of the 4-in. by 8 -in. cylinder with strain gauges attached at the centerline and loaded into a one-million-pound capacity SATEC ${ }^{\text {TM }}$ hydraulic load frame awaiting testing.

Figure 3. Strain-to-failure sample awaiting testing.

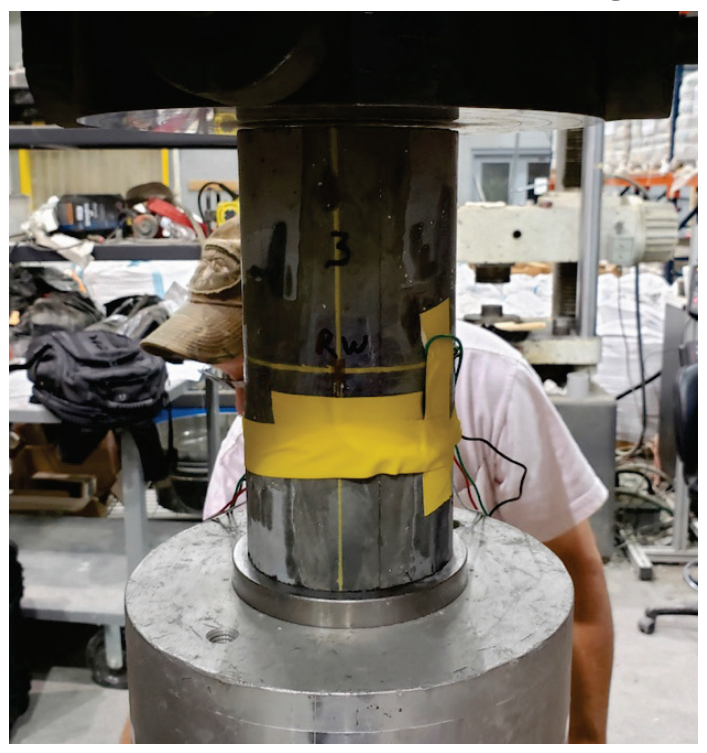




\section{Property Tests under Confinement}

\subsection{Composition property tests}

Prior to the performance of the mechanical property tests, the height, diameter, and weight of each test specimen were obtained. These measurements were used to compute the specimen's wet, bulk, or "as-tested" density. Measurements of posttest water content were conducted in accordance with procedures given in ASTM D2216-10 (2010). Based on the appropriate values of posttest water content and wet density and an estimated grain density of $2.92 \mathrm{Mg} / \mathrm{m}^{3}$, values of dry density, porosity, and degree of saturation and volumes of air, water, and solids were calculated (Table 1). Also listed in Table 1 are maximum, minimum, and mean values, as well as the standard deviation about the mean for each quantity. The concrete specimens had a mean wet density of $2.512 \mathrm{Mg} / \mathrm{m}^{3}$, a mean water content of $4.42 \%$, and a mean dry density of $2.406 \mathrm{Mg} / \mathrm{m}^{3}$.

\subsection{Ultrasonic pulse-velocity determinations}

Prior to the performance of the mechanical property tests, ultrasonic pulse-velocity measurements were obtained for each test specimen. This involved measuring the transit distance and time for each $\mathrm{P}$-wave (compressional) or S-wave (shear) pulse to propagate through a given specimen. The velocity was then computed by dividing the transit distance by the transit time. A matching pair of $1-\mathrm{MHz}$ piezoelectric transducers was used to transmit and receive the ultrasonic $\mathrm{P}$-waves while a pair of 2.25-MHz piezoelectric transducers was used to transmit and receive the ultrasonic S-waves. The transit time was measured with a 100-MHz digital oscilloscope, and the transit distance with a digital micrometer. All of the velocity determinations were made under atmospheric conditions (i.e., no prestress was applied to the specimen). The tests were conducted in accordance with procedures given in ASTM C597 (2016). 
Table 1. Physical and composition properties of UHPC-S.

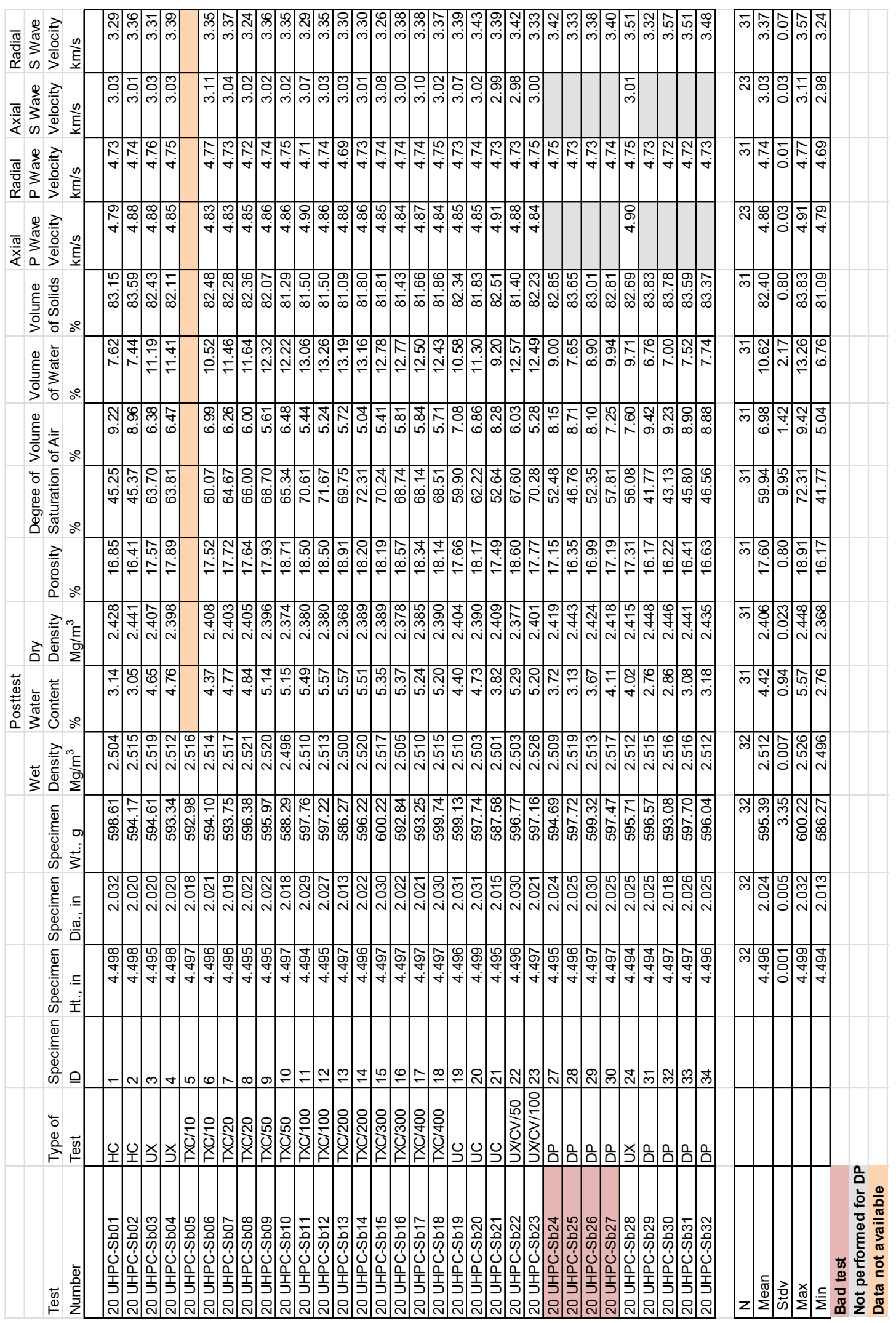


One compressional-wave and one shear-wave velocity were determined axially for each specimen. Six radial P-wave velocities were determined. Two measurements were taken transverse to each other at elevations of $1 / 4,1 / 2$, and $3 / 4$ of the specimen height. Two radial S-wave velocities were measured. These determinations were made at approximately $1 / 4$ and $3 / 4$ of the specimen height. The various $P$ - and S-wave velocities determined for the test specimens are provided in Table 1 . The radialwave velocities listed in Table 1 are the average values.

\subsection{Mechanical property tests}

Twenty-seven mechanical property tests were successfully conducted on the UHPC-S specimens to characterize the strength and constitutive properties of the material. All of the mechanical property tests were conducted quasi-statically with axial strain rates on the order of $10^{-4}$ to $10^{-5}$ per second and times to peak load on the order of 5 to $30 \mathrm{~min}$. Mechanical property data were obtained under several stress and strain paths. Undrained compressibility data were obtained from two $\mathrm{HC}$ tests and the hydrostatic loading phases of the TXC tests. Shear and failure data were obtained from UC tests and unconsolidated, undrained TXC tests. Onedimensional compressibility data were obtained from undrained UX, or $\mathrm{K}_{\mathrm{o}}$, tests with lateral stress measurements. The terms "undrained" and "unconsolidated" signify that no pore fluid (liquid or gas) was allowed to escape or drain from the membrane-enclosed specimens. The completed test matrix is in Table 2, which lists the test types, number of tests, test numbers for each test type, and the nominal peak radial stress applied to specimens prior to shear loading or during the HC or UX loading.

\subsubsection{Specimen preparation}

The mechanical property test specimens were cored from solid UHPC-S blocks using a diamond-bit core barrel, following the procedures provided in ASTM C42 (2018c). Once the test specimens were cut to the correct length, the ends were ground flat and parallel to each other as well as perpendicular to the sides of the core in accordance with procedures in ASTM D4543 (2008). The prepared test specimens had a mean diameter of $51 \mathrm{~mm}$ and a mean height of $110 \mathrm{~mm}$. 
Table 2. Completed UHPC-S test matrix.

\begin{tabular}{|l|l|l|l|}
\hline \multicolumn{1}{|c|}{ Type of test } & $\begin{array}{c}\text { Number of } \\
\text { tests }\end{array}$ & \multicolumn{1}{|c|}{$\begin{array}{c}\text { Test } \\
\text { number }\end{array}$} & $\begin{array}{c}\text { Nominal peak } \\
\text { radial stress } \\
(\mathrm{MPa})\end{array}$ \\
\hline $\begin{array}{l}\text { Hydrostatic Compression } \\
\text { (HC) }\end{array}$ & 2 & 1,2 & 400 \\
\hline \multirow{5}{*}{ Triaxial Compression (TXC) } & 3 & $19,20,21$ & 0 \\
\cline { 2 - 4 } & 2 & 5,6 & 10 \\
\cline { 2 - 4 } & 2 & 7,8 & 20 \\
\cline { 2 - 4 } & 2 & 9,10 & 50 \\
\cline { 2 - 4 } & 2 & 11,12 & 100 \\
\cline { 2 - 4 } & 2 & 13,14 & 200 \\
\cline { 2 - 4 } & 2 & 15,16 & 300 \\
\hline Uniaxial Strain (UX) & 2 & 17,18 & 400 \\
\hline \multirow{2}{*}{$\begin{array}{l}\text { Uniaxial Strain/Constant } \\
\text { Volumetric Strain (UX/CV) }\end{array}$} & 1 & 22 & 400 \\
\cline { 2 - 4 } & 1 & 23 & 50 \\
\hline \multirow{3}{*}{ Direct Pull (DP) } & 4 & 29,30, & \\
\hline Total No. of Tests: & 27 & 31,32 & 0 \\
\hline
\end{tabular}

Prior to testing, each specimen was placed between hardened steel top and base caps. With the exception of the UC test specimens, two o.6-mm-thick membranes and an AquaSeal ${ }^{\circledR}$ membrane were placed around each specimen. The exterior of the outer membrane was coated with a liquid synthetic rubber to inhibit deterioration caused by the confining fluid (Figure 4). The confining fluid used was a 50/50 mixture of kerosene and hydraulic oil. Finally, the specimen, along with its topand base-cap assembly, was placed on the instrumentation stand of the test apparatus, and the instrumentation setup was initiated.

\subsubsection{Test devices}

All tests were conducted in a 600-MPa-capacity pressure vessel (Figure 5), and the axial load was provided by an 8.9-MN loader. With this loader, the application of load, pressure, and axial displacement were regulated by a servo-controlled data acquisition system. This servo-controlled system allowed the user to program rates of load, pressure, and axial displacement in order to achieve the desired stress or strain path. Confining pressure was measured externally to the pressure vessel by a 
pressure transducer mounted in the confining fluid line. A load cell mounted in the base of the specimen pedestal was used to measure the applied axial loads inside the pressure vessel (Figure 4).

Outputs from the various instrumentation sensors were electronically amplified and filtered, and the conditioned signals were recorded by computer-controlled, 16-bit, analog-to-digital converters. The data acquisition system was programmed to sample the data channels every 1 to $5 \mathrm{sec}$, convert the measured voltages to engineering units, and store the data for further processing.

Figure 4. Typical test specimen setup.

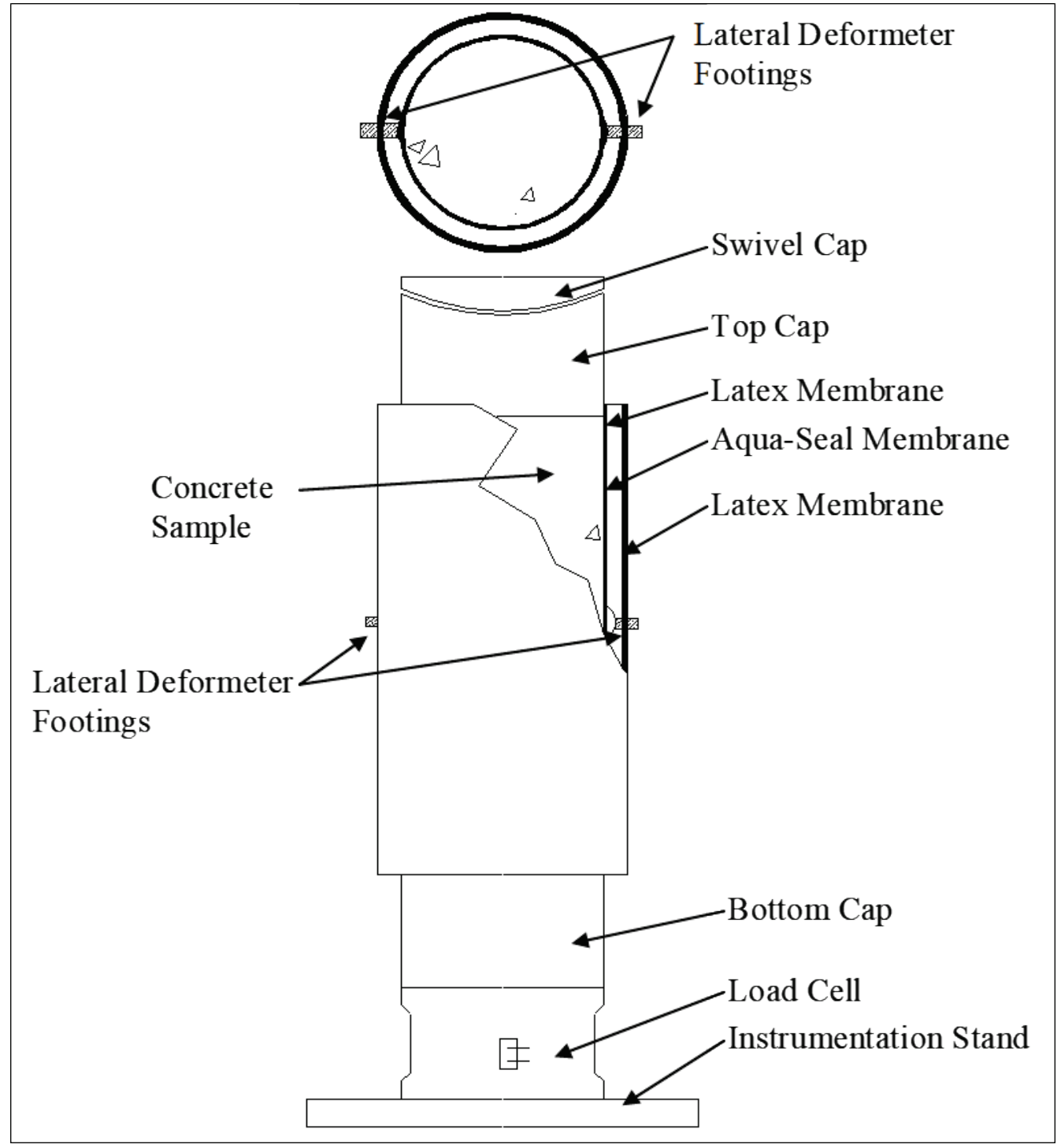


Figure 5. 600-MPa pressure vessel details.

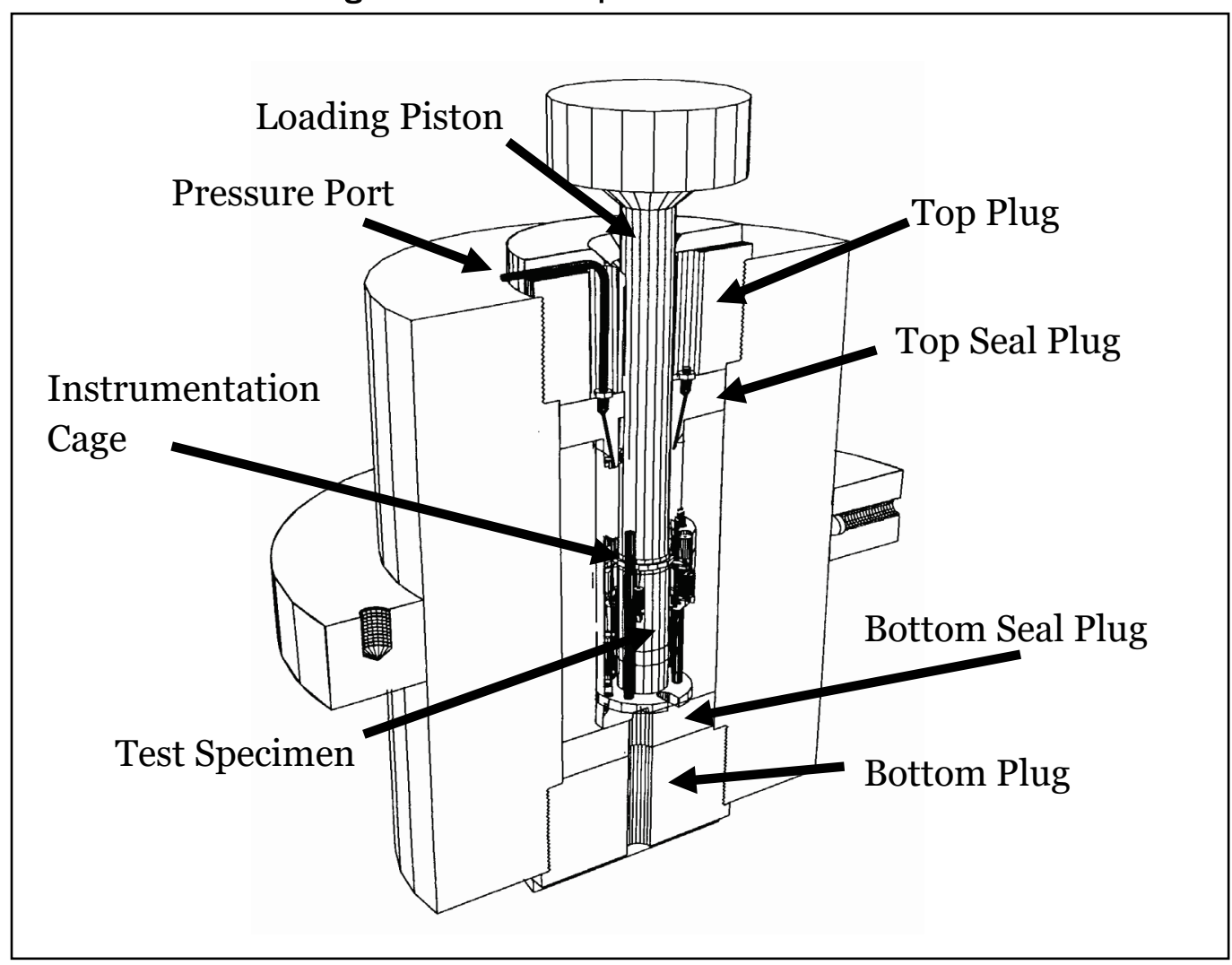

\subsubsection{Test instrumentation}

The vertical deflection measurement system consisted of two LVDTs mounted vertically on the instrumentation stand and positioned $180^{\circ}$ apart. They were oriented to measure the displacement between the top and base caps, thus providing a measure of the axial deformation of the specimen. For the confined tests, a linear potentiometer was mounted externally to the pressure vessel to measure the displacement of the piston through which axial loads were applied. This provided a backup to the vertical LVDTs in the event they exceeded their calibrated range or malfunctioned.

Two types of radial deflection measurement systems (lateral deformeters) were used in this test program. The output of each deformeter was calibrated to the radial displacement of the two footings glued to the sides of the test specimen (Figure 4). These two small steel footings were placed $180^{\circ}$ apart at the specimen's midheight. The footing faces were machined to match the curvature of the test specimen. A threaded post extended from each footing and protruded through the membranes. Once the membranes were in place, steel caps were screwed onto the threaded posts to seal the membranes to each footing. The lateral deformeter ring was 
then attached to the steel footings with set screws. The completed specimen lateral deformeter setup is shown in Figure 6.

Figure 6. Spring-arm lateral deformeter mounted on test specimen.

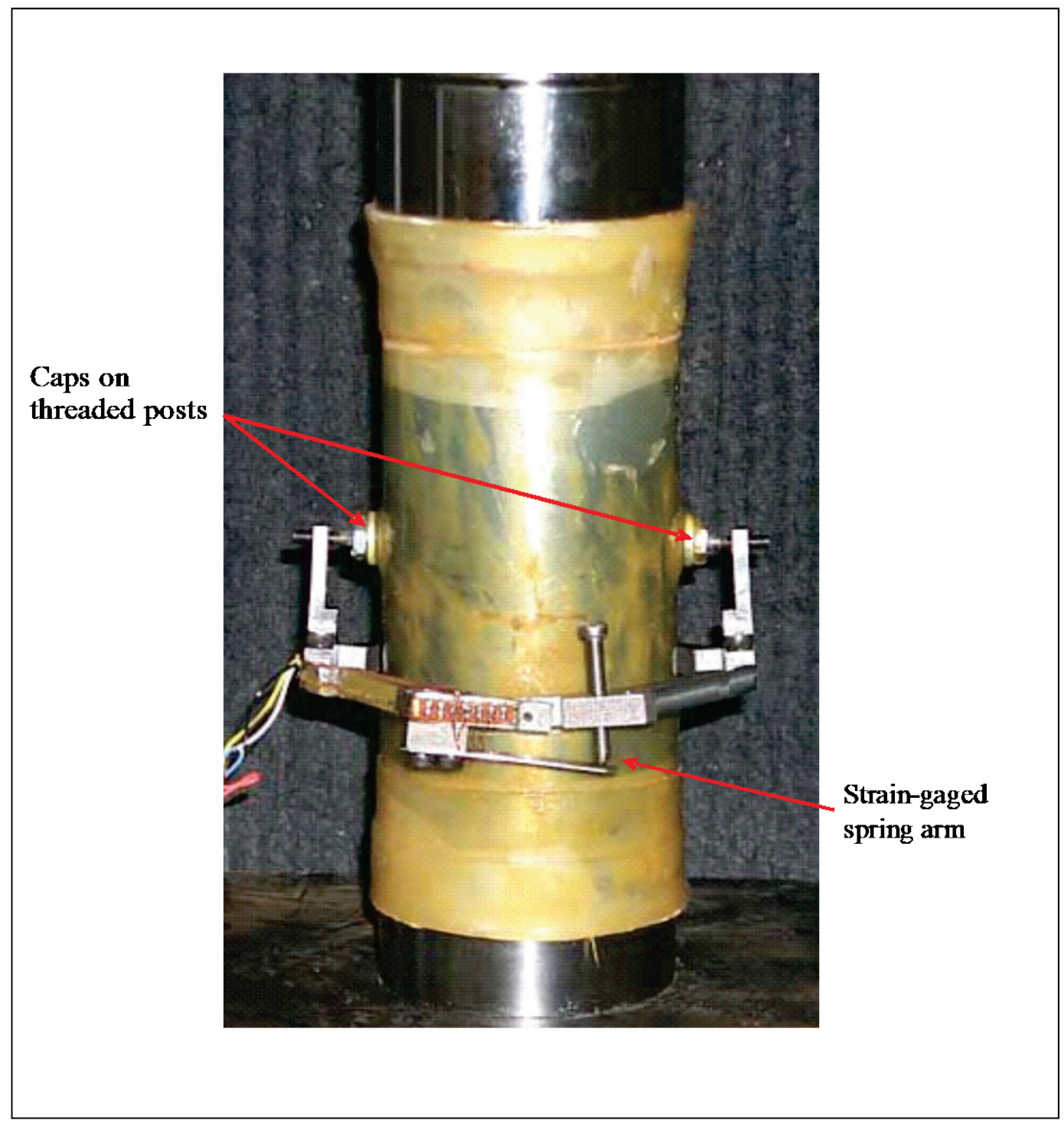

One of the two types of lateral deformeters used consisted of an LVDT mounted on a hinged ring; the LVDT measured the expansion or contraction of the ring. This lateral deformeter was used over smaller ranges of radial deformation when the greatest measurement accuracy was required. This lateral deformeter was used for all of the HC and UX tests. This design is similar to the radial deformeter design provided by Bishop and Henkel (1962). When the specimen expanded (or contracted), the hinged-deformeter ring opened (or closed), causing a change in the electrical output of the horizontally mounted LVDT. 
The second type of lateral deformeter, used for all of the UC and TXC tests, consisted of two strain-gauged, spring-steel arms mounted on a doublehinged ring. The strain-gauged arms deflected as the ring expanded or contracted. When the specimen laterally expanded or contracted, the rigid deformeter ring flexed about its hinges, causing a change in the electrical output of the strain gauge circuit. This deformeter was used when the greatest radial deformation range was required and was slightly less accurate than the LVDT-type deformeter. The output of the strain gauge circuit was calibrated to measure the specimen's lateral deformation.

\subsubsection{Test descriptions}

TXC tests were conducted in two phases. During the initial or hydrostaticcompression phase, the cylindrical test specimen was subjected to an increase in hydrostatic pressure while measurements of the specimen's height and diameter changes were recorded. The data from this phase are typically plotted as pressure versus volumetric strain, the slope of which, assuming elastic theory, is the bulk modulus, $K$. The second phase of the TXC test, the shear-loading phase, was conducted after the desired confining pressure was reached during the $\mathrm{HC}$ phase. While the desired confining pressure was held constant, axial load was increased, and measurements of the changes in the specimen's height and diameter were made. The axial (compressive) load was increased until the specimen failed. The shear data are generally plotted as principal stress difference versus axial strain, the slope of which represents Young's modulus, $E$. The maximum principal stress difference that a given specimen can support, or the principal stress difference at $15 \%$ axial strain during shear (whichever occurs first) is defined as the peak strength of the material.

UC tests were performed in accordance with ASTM C39 (2018b). The UC test is a type of TXC test in which no confining pressure is applied. The maximum principal stress difference observed during a UC test is defined as the unconfined compressive strength of the material.

UX tests were conducted by applying axial load and confining pressure simultaneously so that, as the cylindrical specimen shortened, its diameter remained unchanged (i.e., zero radial strain boundary conditions were maintained). The data are generally plotted as axial stress versus axial strain, the slope of which is the constrained modulus, $M$. The data are also plotted as principal stress difference versus mean normal stress, the slope 
of which is twice the shear modulus, $\mathrm{G}$, divided by the bulk modulus, $K$, (i.e., $2 G / K$ ), or in terms of Poisson's ratio, $v, 3(1-2 v) /(1+v)$.

The strain-path tests in this test program were conducted in two phases. Initially, the specimens were subjected to a uniaxial-strain loading up to a desired level of mean normal, radial, or axial stress. At the end of the UX loading, a constant axial-to-radial-strain ratio (ARSR) of -2.0 was applied; these tests were identified earlier as UX/CV tests. In order to conduct these tests, the software controlling the servo-controls had to correct the measured inputs for the system compressibility and for the nonlinear calibrations of specific transducers.

Tension shear data were obtained for the concrete mixture by performing direct pull (DP) tests. The DP tests have no confining pressure during the tests. To conduct the DP tests, end caps were attached with epoxy to the specimens. The end caps were then screwed into the direct pull apparatus, and the specimen was pulled apart vertically when pressure was applied to the piston.

\subsubsection{Definition of stresses and strains}

During the mechanical property tests, measurements were typically made of the axial and radial deformations of the specimen as confining pressure and/or axial load was applied or removed. These measurements, along with the pretest measurements of the height and diameter of the specimen, were used to convert the measured test data to true stresses and engineering strains. ${ }^{2}$

Axial strain, $\varepsilon_{a}$, was computed by dividing the measured axial deformation, $\Delta h$ (change in height), by the original height, $h_{o}$ (i.e., $\varepsilon_{a}=\Delta h / h_{o}$ ). Similarly, radial strain, $\varepsilon r$, was computed by dividing the measured radial deformation, $\Delta d$ (change in diameter), by the original diameter, $d_{o}$ (i.e., $\left.\varepsilon_{r}=\Delta d / d_{o}\right)$. For this report, volumetric strain, $\varepsilon v$, was assumed to be the sum of the axial strain and twice the radial strain (i.e., $\varepsilon_{v}=\varepsilon_{a}+2 \varepsilon_{r}$ ).

\footnotetext{
2 Compressive stresses and strains are positive in this report.
} 
The principal stress difference, $q$, was calculated by dividing the axial load, $P$, by the cross-sectional area of the specimen, $A$, which is equal to the original cross-sectional area, $A_{0}$, multiplied by $\left(1-\varepsilon_{\mathrm{r}}\right)^{2}$. In equation form,

$$
q=\left(\sigma_{a}-\sigma_{r}\right)=\frac{P}{A_{o}\left(1-\varepsilon_{r}\right)^{2}}
$$

where $\sigma_{a}$ is the axial stress and $\sigma_{r}$ is the radial stress. The axial stress is related to the confining pressure and the principal stress difference by

$$
\sigma_{a}=\mathrm{q}+\sigma_{r}
$$

The mean normal stress, $p$, is the average of the applied principal stresses. In cylindrical geometry,

$$
p=\frac{\left(\sigma_{a}+2 \sigma_{r}\right)}{3}
$$




\section{Analyses of Test Results}

\subsection{Unconfined compressive strength (ASTM C39 and BS-EN 12390-3:2009)}

Table 3 shows the results for ASTM C39 (2018b) testing. The Cor-Tuf specimens achieved compressive strengths above $207 \mathrm{MPa}$ (30 ksi) at 28 days, which is typical for this mixture. The UCS of the Cor-Tuf at 90 days can be compared to the UCS of UHPC-S at 130 days. The age variance should have little effect on test results. Cor-Tuf specimens achieved compressive strengths over $69 \mathrm{MPa}$ (10 ksi) higher than the UHPC-S mixture. UHPC-S specimens had much lower deviation between replicates.

UCS tests were performed on Cor-Tuf specimens at four different ages. The UCSs at these different ages are shown in Figure 7. The curing protocol for Cor-Tuf consists of 7 days inside a fog room at $21^{\circ} \mathrm{C}\left(70^{\circ} \mathrm{F}\right)$ in compliance with ASTM $\mathrm{C}_{511}$ (2019a) followed by steam curing for 7 days at $90^{\circ} \mathrm{C}$ $\left(194^{\circ} \mathrm{F}\right)$. After steam curing, specimens were kept indoors at $23^{\circ} \mathrm{C}\left(73^{\circ} \mathrm{F}\right)$.

BS EN 12390-3 (2009) UCS testing results are in Table 4. Once again, the Cor-Tuf specimens have higher deviation among replicates. Cor-Tuf performed at higher compressive strengths than UHPC-S, but the difference between the two mixtures was less than observed through ASTM C39 (2018b) testing.

\subsection{Flexural response (ASTM C1609)}

Two sizes of beams were tested for flexural response according to ASTM C1609 (2019b) in both CT and UHPC-S: 4 by 4 by 16 in. (101.6 x $101.6 \mathrm{x}$ $406.4 \mathrm{~mm}$ ) and 6 by 6 by 21 in. (152.4 x $152.4 \times 533.4 \mathrm{~mm})$. Span was set to three times the beam depth. The peak flexural stresses are presented in Tables 5 and 6 . Stress was calculated using formula 1 presented in ASTM C1609 (2019b),

$$
f=\frac{P L}{b d^{2}}
$$

where $f$ is the strength, $P$ is the load, $L$ is the span length, $b$ is the beam width, and $d$ is the beam thickness. Table 5 presents the maximum flexural strength calculated for the smaller 4-in. flexural response beams. 
Table 3. ASTM C39 testing results.

\begin{tabular}{|c|c|c|c|c|c|}
\hline $\begin{array}{l}\text { Mixture } \\
\text { ID }\end{array}$ & $\begin{array}{c}\text { Age } \\
\text { (Days) }\end{array}$ & $\begin{array}{l}\text { Compressive } \\
\text { Strength } \\
\text { (psi) }\end{array}$ & $\begin{array}{l}\text { Compressive } \\
\text { Strength } \\
\text { (MPa) }\end{array}$ & $\begin{array}{l}\text { Average } \\
\text { Compressive } \\
\text { Strength } \\
\text { (MPa) }\end{array}$ & $\begin{array}{c}\text { Standard } \\
\text { Deviation } \\
(\mathrm{MPa})\end{array}$ \\
\hline \multirow{12}{*}{ Cor-Tuf 1} & \multirow{3}{*}{15} & 32,516 & 224.19 & \multirow{3}{*}{218.18} & \multirow{3}{*}{5.98} \\
\hline & & 30,782 & 212.23 & & \\
\hline & & 31,637 & 218.13 & & \\
\hline & \multirow{3}{*}{28} & 30,562 & 210.72 & \multirow{3}{*}{213.85} & \multirow{3}{*}{6.73} \\
\hline & & 30,350 & 209.26 & & \\
\hline & & 32,137 & 221.58 & & \\
\hline & \multirow{3}{*}{56} & 30,585 & 210.88 & \multirow{3}{*}{216.91} & \multirow{3}{*}{13.01} \\
\hline & & 33,625 & 231.84 & & \\
\hline & & 30,170 & 208.01 & & \\
\hline & \multirow{3}{*}{90} & 34,495 & 237.83 & \multirow{3}{*}{236.58} & \multirow{3}{*}{11.51} \\
\hline & & 32,560 & 224.49 & & \\
\hline & & 35,885 & 247.42 & & \\
\hline \multirow{12}{*}{ Cor-Tuf 2} & \multirow{3}{*}{15} & 34,214 & 235.90 & \multirow{3}{*}{224.65} & \multirow{3}{*}{9.77} \\
\hline & & 31,879 & 219.80 & & \\
\hline & & 31,657 & 218.27 & & \\
\hline & \multirow{3}{*}{28} & 32,690 & 225.39 & \multirow{3}{*}{227.58} & \multirow{3}{*}{13.52} \\
\hline & & 31,226 & 215.30 & & \\
\hline & & 35,109 & 242.07 & & \\
\hline & \multirow{3}{*}{56} & 29,575 & 203.91 & \multirow{3}{*}{219.82} & \multirow{3}{*}{21.08} \\
\hline & & 30,720 & 211.81 & & \\
\hline & & 35,350 & 243.73 & & \\
\hline & \multirow{3}{*}{90} & 34,580 & 238.42 & \multirow{3}{*}{226.57} & \multirow{3}{*}{27.16} \\
\hline & & 35,650 & 245.80 & & \\
\hline & & 28,355 & 195.50 & & \\
\hline \multirow{3}{*}{ UHPC-S } & \multirow{3}{*}{130} & 21,365 & 147.31 & \multirow{3}{*}{149.13} & \multirow{3}{*}{1.42} \\
\hline & & 21,655 & 149.31 & & \\
\hline & & 21,870 & 150.79 & & \\
\hline
\end{tabular}


Figure 7. ASTM C39 UCS testing results for Cor-Tuf.

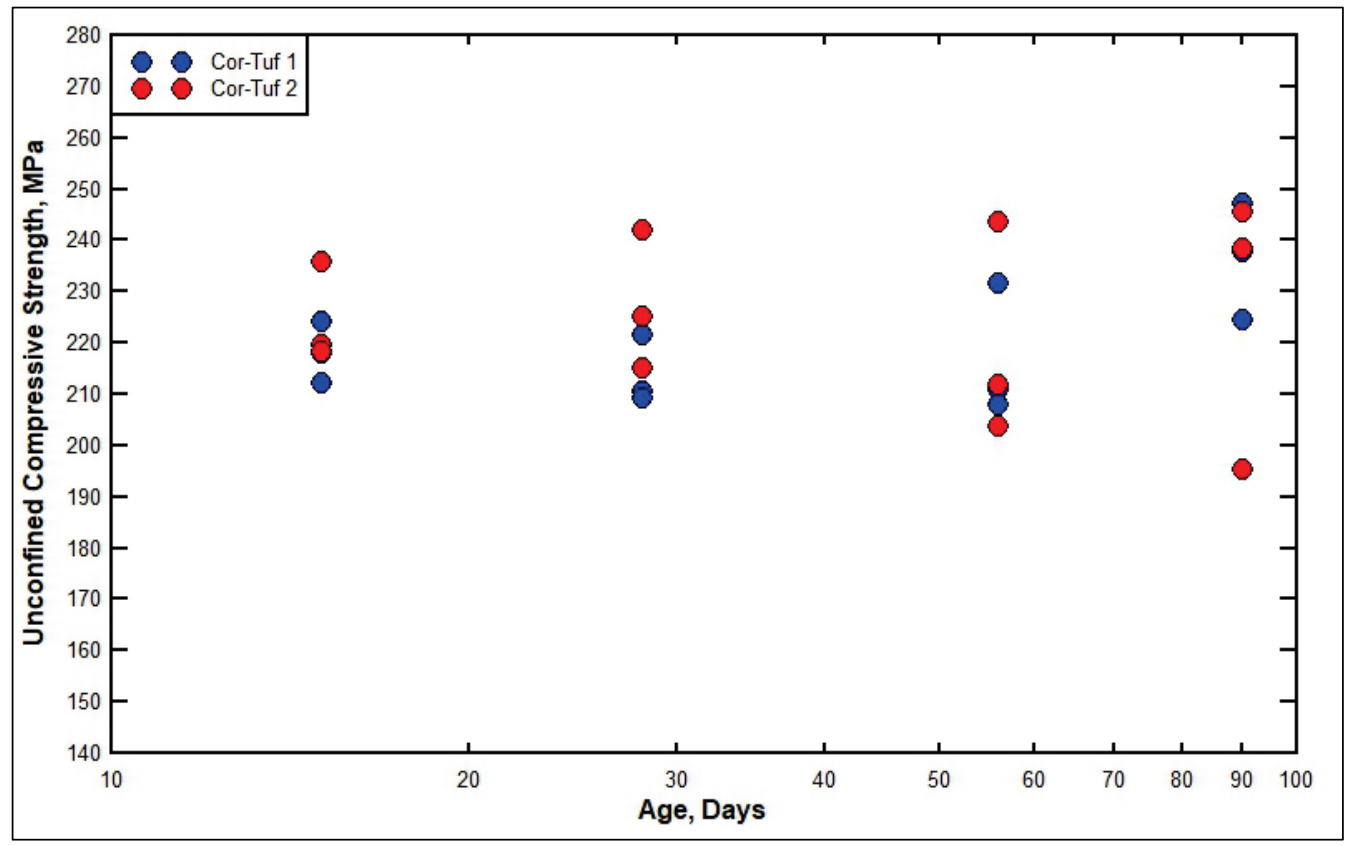

Table 4. BS EN 12390-3 UCS testing results.

\begin{tabular}{|c|c|c|c|c|c|}
\hline $\begin{array}{l}\text { Mixture } \\
\text { ID }\end{array}$ & $\begin{array}{l}\text { Age } \\
\text { (days) }\end{array}$ & $\begin{array}{l}\text { Compressive } \\
\text { Strength } \\
\text { (psi) }\end{array}$ & $\begin{array}{l}\text { Compressive } \\
\text { Strength } \\
(\mathrm{MPa})\end{array}$ & $\begin{array}{c}\text { Average } \\
\text { Compressive } \\
\text { Strength } \\
\text { (MPa) }\end{array}$ & $\begin{array}{c}\text { Standard } \\
\text { Deviation } \\
\text { (MPa) }\end{array}$ \\
\hline \multirow{3}{*}{ Cor-Tuf 1} & 28 & 31,788 & 219.17 & \multirow{3}{*}{188.90} & \multirow{3}{*}{29.59} \\
\hline & 28 & 23,212 & 160.04 & & \\
\hline & 28 & 27,192 & 187.48 & & \\
\hline \multirow{3}{*}{ Cor-Tuf 2} & 28 & 28,356 & 195.51 & \multirow{3}{*}{208.52} & \multirow{3}{*}{15.29} \\
\hline & 28 & 29,686 & 204.68 & & \\
\hline & 28 & 32,686 & 225.36 & & \\
\hline \multirow{3}{*}{ UHPC-S } & 130 & 19,736 & 136.07 & \multirow{3}{*}{136.43} & \multirow{3}{*}{4.15} \\
\hline & 130 & 20,414 & 140.75 & & \\
\hline & 130 & 19,213 & 132.47 & & \\
\hline
\end{tabular}


Table 5. Peak flexural strength for 4-in. beams.

\begin{tabular}{|c|c|c|c|c|c|c|}
\hline Specimen & Type & $\begin{array}{l}\text { Age } \\
\text { (days) }\end{array}$ & $\begin{array}{c}\text { Flexural } \\
\text { Strength } \\
\text { (psi) }\end{array}$ & $\begin{array}{c}\text { Flexural } \\
\text { Strength } \\
(\mathrm{MPa})\end{array}$ & $\begin{array}{c}\text { Average } \\
\text { Flexural } \\
\text { Strength } \\
\text { (MPa) }\end{array}$ & $\begin{array}{c}\text { Standard } \\
\text { Deviation } \\
\text { (MPa) }\end{array}$ \\
\hline 346-18 CT SNG T2 & Cor-Tuf & 28 & 4,933 & 34.01 & \multirow{3}{*}{36.11} & \multirow{3}{*}{1.87} \\
\hline 346-18 CT SNG T2 & Cor-Tuf & 28 & 5,456 & 37.62 & & \\
\hline 346-18 CT SNG T2 & Cor-Tuf & 28 & 5,324 & 36.71 & & \\
\hline 21-2-19 USACAO 2 & UHPC-S & 130 & 3,323 & 22.91 & \multirow{4}{*}{21.04} & \multirow{4}{*}{2.24} \\
\hline 21-2-19 USACAO 2 & UHPC-S & 130 & 3,229 & 22.26 & & \\
\hline 21-2-19 USACAO 2 & UHPC-S & 130 & 2,593 & 17.88 & & \\
\hline 21-2-19 USACAO 3 & UHPC-S & 130 & 3,061 & 21.11 & & \\
\hline
\end{tabular}

Table 6 presents a similar set of data for the 6-in. flexural response beams. Note the excess data points for the UHPC-S specimens. Initial plans were to conduct three tests. However, due to technician error, the tests with red font in both Tables 5 and 6 were stopped after a $5 \%$ drop in load instead of a more desired continued load until complete failure. This did not affect the peak stress results. Extra beams were tested correctly and are presented with the standard black font.

Table 6. Peak flexural strength for 6-in. beams.

\begin{tabular}{|c|c|c|c|c|c|c|}
\hline Specimen & Type & $\begin{array}{l}\text { Age } \\
\text { (days) }\end{array}$ & $\begin{array}{c}\text { Flexural } \\
\text { Strength } \\
\text { (psi) }\end{array}$ & $\begin{array}{c}\text { Flexural } \\
\text { Strength } \\
(\mathrm{MPa})\end{array}$ & $\begin{array}{c}\text { Average } \\
\text { Flexural } \\
\text { Strength } \\
\text { (MPa) }\end{array}$ & $\begin{array}{c}\text { Standard } \\
\text { Deviation } \\
(\mathrm{MPa})\end{array}$ \\
\hline 346-18 CT SNG T2 & Cor-Tuf & 28 & 4,074 & 28.09 & \multirow{3}{*}{28.64} & \multirow{3}{*}{3.99} \\
\hline 346-18 CT SNG T2 & Cor-Tuf & 28 & 4,769 & 32.88 & & \\
\hline 346-18 CT SNG T2 & Cor-Tuf & 28 & 3,620 & 24.96 & & \\
\hline 21-2-19 USACAO 2 & UHPC-S & 130 & 1,796 & 12.38 & \multirow{6}{*}{17.34} & \multirow{6}{*}{2.78} \\
\hline 21-2-19 USACAO 2 & UHPC-S & 130 & 2,597 & 17.91 & & \\
\hline 21-2-19 USACAO 2 & UHPC-S & 130 & 2,658 & 18.33 & & \\
\hline 21-2-19 USACAO 2 & UHPC-S & 130 & 2,560 & 17.65 & & \\
\hline 21-2-19 USACAO 2 & UHPC-S & 130 & 2,452 & 16.91 & & \\
\hline 21-2-19 USACAO 2 & UHPC-S & 130 & 3,026 & 20.86 & & \\
\hline
\end{tabular}

Overall, CT demonstrated about 1.7 times higher peak flexural strengths than UHPC-S. In terms of stress, average strengths were higher for the 4 -in. beams than for the 6-in. beams for both CT and UHPC-S. This is 
likely due to an increased fiber alignment along the longitudinal axis in the narrower 4-in. beams.

Figure 8 is a load-versus-displacement chart for CT and UHPC-S 4-in. flexural response beams. The UHPC-S tests plotted in green show the three prematurely ended tests. Only one extra 4-in. UHPC-S specimen was available for full testing to failure. That test is also presented here in green.

Figure 9 is the same load-versus-displacement plot but for the 6-in. specimens. In both figures, it can be seen that CT had higher peak strengths and outperformed UHPC-S under the prescribed quasi-static loading rates detailed in ASTM C1609 (2019b).

Figure 8. Load vs. displacement of 4-in. by 4 -in. by 16 -in. flexural response beams.

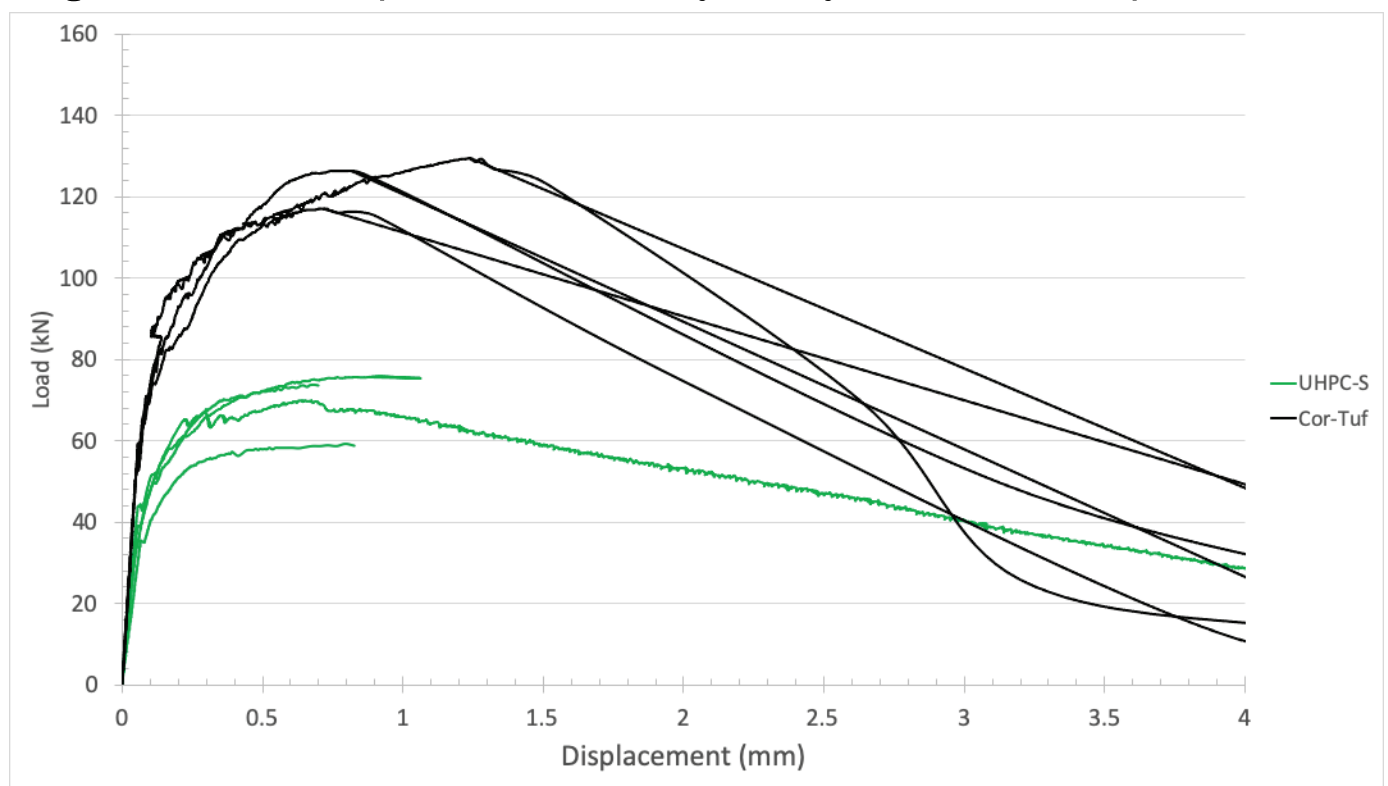

Figure 10 presents the same data set in a different way. A stress-versus'normalized' displacement plot is presented in an effort to present the two beam sizes on the same plot. In this instance, 'normalized' is defined as the displacement divided by the span. Strain could not be measured due to an inability to measure and calculate the strain at the fracture location. This plot is meant to allow comparisons between the 4-in. and 6-in. beam sizes. The 4-in. specimens reached higher stresses, which is likely due to fiber alignment, as mentioned previously. 
Figure 9. Load vs. displacement for 6-in. by 6-in. by 21-in. flexural response beams.

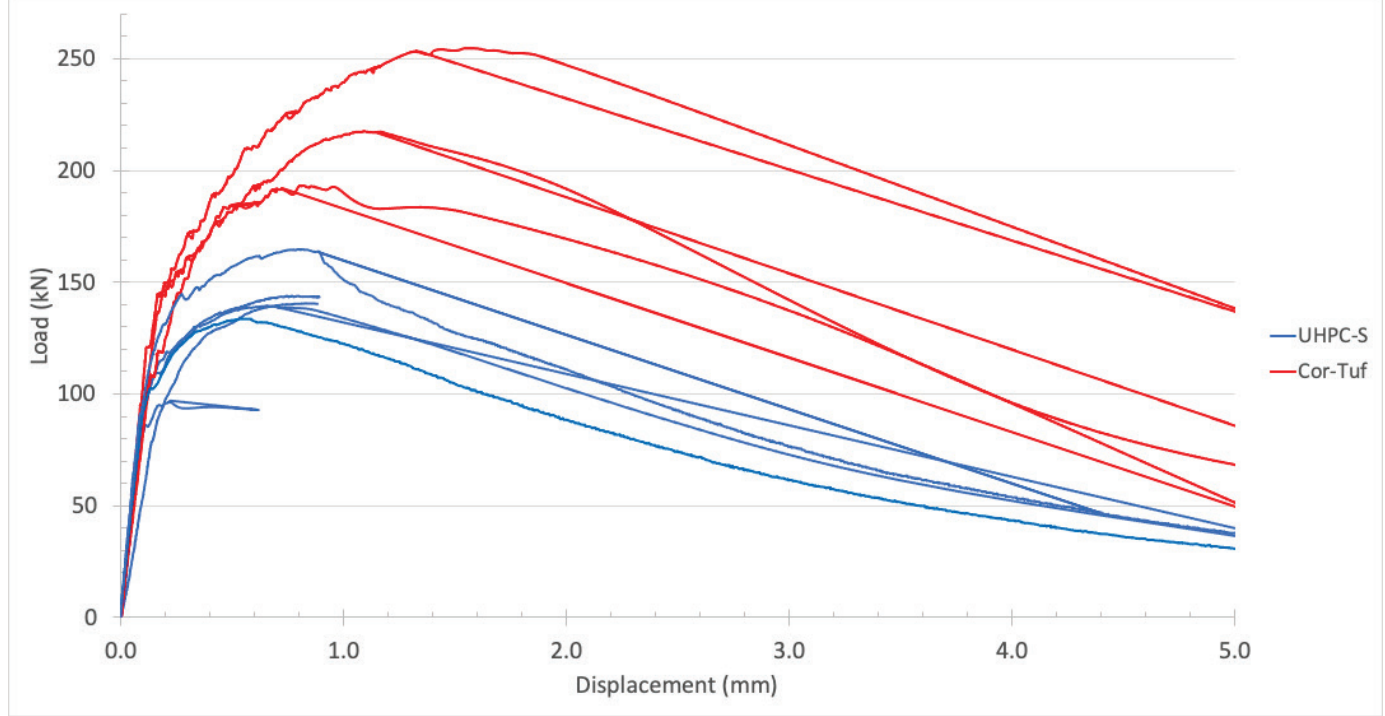

Figure 10. Flexural response stress vs. 'normalized’ displacement.

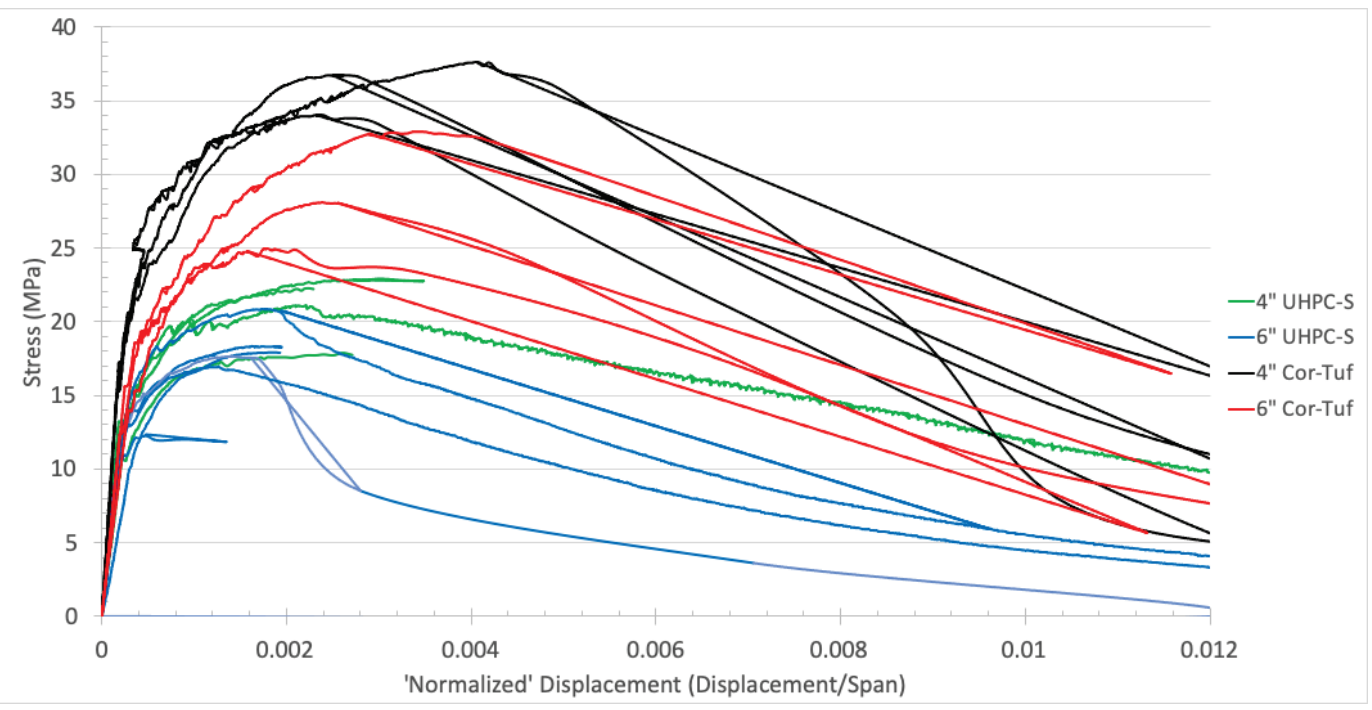

\subsection{Elastic modulus and strain-to-failure}

Six samples each of CT and UHPC-S were tested for elastic modulus and strain-to-failure according to modified and combined versions of ASTM C39 (2018b) and ASTM C1609 (2019b). Table 7 presents the maximum compressive strength reached during strain-to-failure, modulus, and Poisson's ratio for six CT specimens. 
Table 7. Cor-Tuf unconfined compressive strength, elastic modulus, and Poisson's ratio.

\begin{tabular}{|l|l|l|l|l|l|}
\hline \multicolumn{1}{|c|}{ Specimen } & \multicolumn{1}{|c|}{$\begin{array}{c}\text { Max UCS } \\
(\mathbf{p s i})\end{array}$} & $\begin{array}{c}\text { Max UCS } \\
(\mathrm{MPa})\end{array}$ & $\begin{array}{c}\text { Modulus } \\
(\mathbf{p s i})\end{array}$ & $\begin{array}{c}\text { Modulus } \\
(\mathrm{GPa})\end{array}$ & $\begin{array}{c}\text { Poisson's } \\
\text { ratio }\end{array}$ \\
\hline CT-1 & 29,690 & 205 & $8.23 \mathrm{E}+06$ & 56.7 & 0.195 \\
\hline CT-2 & 33,420 & 230 & $8.80 \mathrm{E}+06$ & 60.7 & 0.188 \\
\hline CT-3 & 31,435 & 217 & $8.31 \mathrm{E}+06$ & 57.3 & 0.174 \\
\hline CT-4 & 29,630 & 204 & $8.43 \mathrm{E}+06$ & 58.1 & 0.176 \\
\hline CT-5 & 30,608 & 211 & $8.24 \mathrm{E}+06$ & 56.8 & 0.171 \\
\hline CT-6 & 29,935 & 206 & $8.35 \mathrm{E}+06$ & 57.6 & 0.190 \\
\hline CT Avg. & 30,786 & 212 & $8.39 \mathrm{E}+06$ & 57.9 & 0.182 \\
\hline CT StDev & 1,459 & 10.0 & $2.15 \mathrm{E}+05$ & 1.5 & 0.010 \\
\hline
\end{tabular}

The same data set for UHPC-S is presented in Table 8. Average compressive strengths for CT and UHPC-S were $30.7 \mathrm{ksi}$ and $23.6 \mathrm{ksi}$, respectively. CT exhibited a higher stiffness with an elastic modulus of $8.39 \times 10^{6}$ psi versus UHPC-S with an elastic modulus of $7.02 \times 10^{6} \mathrm{psi}$. Poisson's ratio was slightly higher for UHPC-S at 0.206 on average versus $\mathrm{CT}$ with an average of $\mathbf{0 . 1 8 2}$. The measured values of Poisson's ratio are consistent with those in literature. The load data associated with specimen UHPC-S-6 malfunctioned and were not recorded after cycling between modulus and load-to-failure loadings.

Table 8. UHPC-S unconfined compressive strength, elastic modulus, and Poisson's ratio.

\begin{tabular}{|l|l|l|l|l|l|}
\hline \multicolumn{1}{|c|}{ Specimen } & \multicolumn{1}{c|}{$\begin{array}{c}\text { Max UCS } \\
(\mathbf{p s i})\end{array}$} & $\begin{array}{c}\text { Max UCS } \\
(\mathrm{MPa})\end{array}$ & $\begin{array}{c}\text { Modulus } \\
(\mathbf{p s i})\end{array}$ & $\begin{array}{c}\text { Modulus } \\
(\mathrm{GPa})\end{array}$ & $\begin{array}{c}\text { Poisson's } \\
\text { ratio }\end{array}$ \\
\hline UHPC-S-1 & 23,394 & 161 & $7.09 \mathrm{E}+06$ & 48.9 & 0.177 \\
\hline UHPC-S-2 & 22,325 & 154 & $7.91 \mathrm{E}+06$ & 54.6 & 0.222 \\
\hline UHPC-S-3 & 24,985 & 172 & $7.28 \mathrm{E}+06$ & 50.2 & 0.245 \\
\hline UHPC-S-4 & 22,355 & 154 & $6.45 \mathrm{E}+06$ & 44.5 & 0.178 \\
\hline UHPC-S-5 & 24,800 & 171 & $6.83 \mathrm{E}+06$ & 47.1 & 0.206 \\
\hline UHPC-S-6 & 8,722 & 60 & $6.53 \mathrm{E}+06$ & 45.1 & 0.158 \\
\hline UHPC-S Avg. & 2,3572 & 163 & $7.02 \mathrm{E}+06$ & 48.4 & 0.206 \\
\hline $\begin{array}{l}\text { UHPC-S St. } \\
\text { Dev. }\end{array}$ & 1,281 & 8.83 & $5.40 \mathrm{E}+05$ & 3.73 & 0.033 \\
\hline
\end{tabular}

Load versus displacement was measured for the load-to-failure cycle and is presented in Figure 11. The displacement presented is the 
crosshead displacement. Peak loads reached up to approximately 1,700 $\mathrm{kN}$ and $1,300 \mathrm{kN}$ for CT and UHPC-S, respectively.

Figure 11. Load vs. displacement of unconfined compressive tests conducted during strain-to-failure experiments.

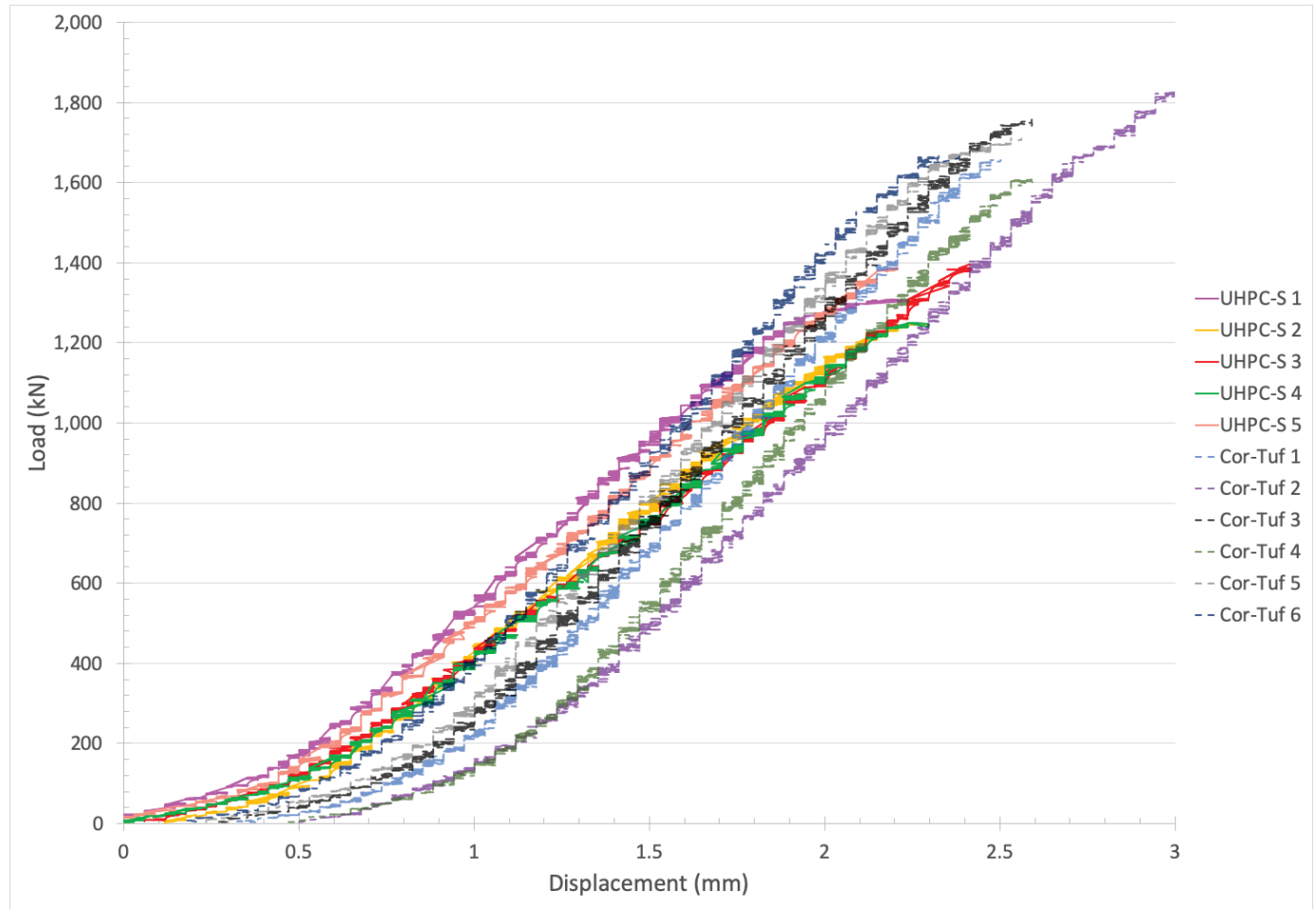

Figures 12 and 13 present cylinder stress versus the absolute value of longitudinal and transverse strain, respectively. In Figure 12, the longitudinal strain is presented as the absolute value to provide a more aesthetic plot for analysis. Both UHPC types underwent brittle failure upon fracture with little to no descending or strain softening after the peak compression point. This type of failure is expected for UHPC. Upon failure, the relatively small strain gauges either relaxed, reducing the strain measurement, or expanded, depending on fracture locations of the cylinder. CT exhibited a higher stiffness (illustrated by the slopes in this figure). UHPC-S presents a relatively more rounded curve as expected for lower strength concretes.

Figure 13 presents stress-versus-transverse strain for the same UHPC-S and CT samples. Similar trends to those in the previous figure were observed. Brittle failure modes were observed for both UHPCs, with UHPC-S exhibiting a more rounded curve and CT exhibiting an almost perfectly linear curve up to failure. 
Figure 12. Stress vs. absolute value of longitudinal strain.

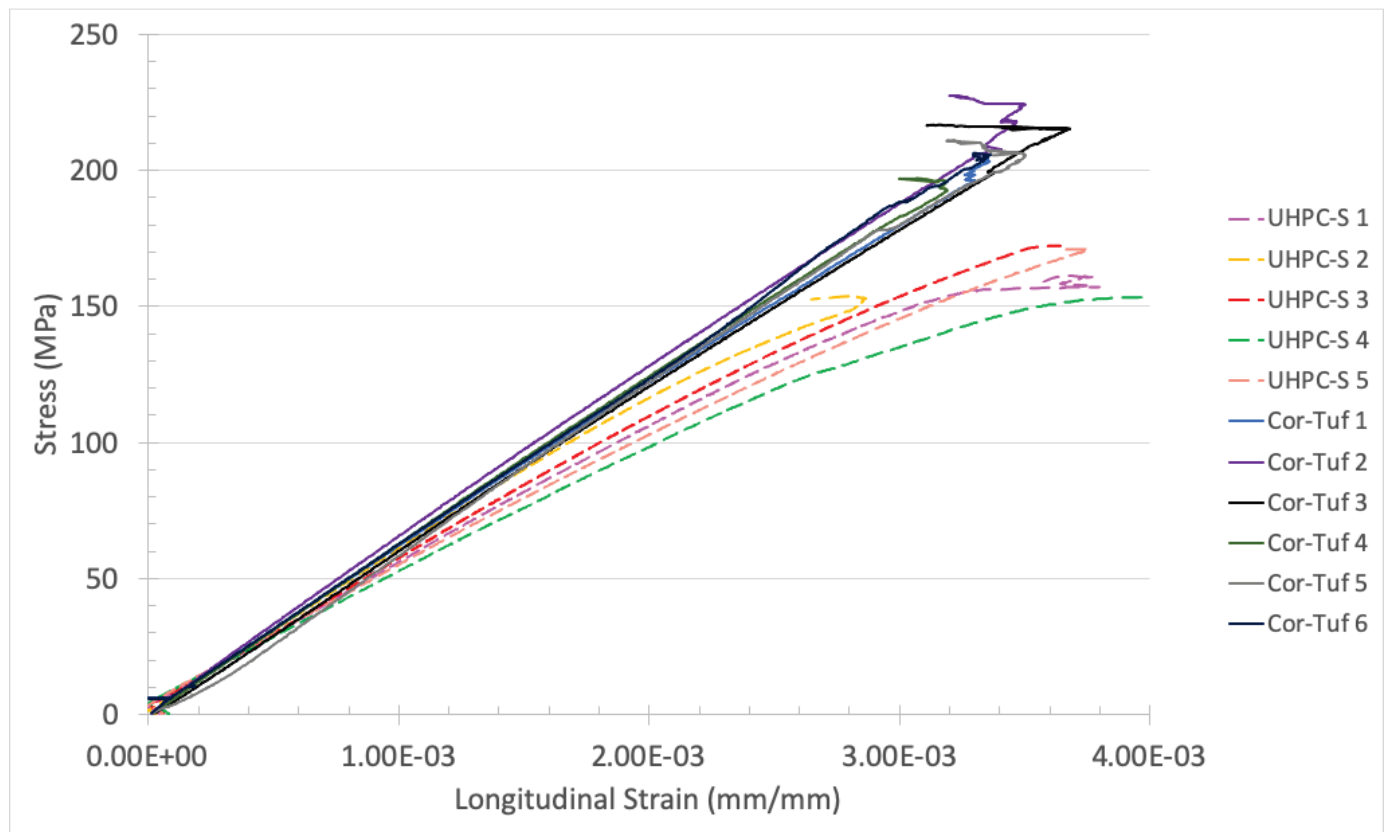

Figure 13. Stress vs. transverse strain.

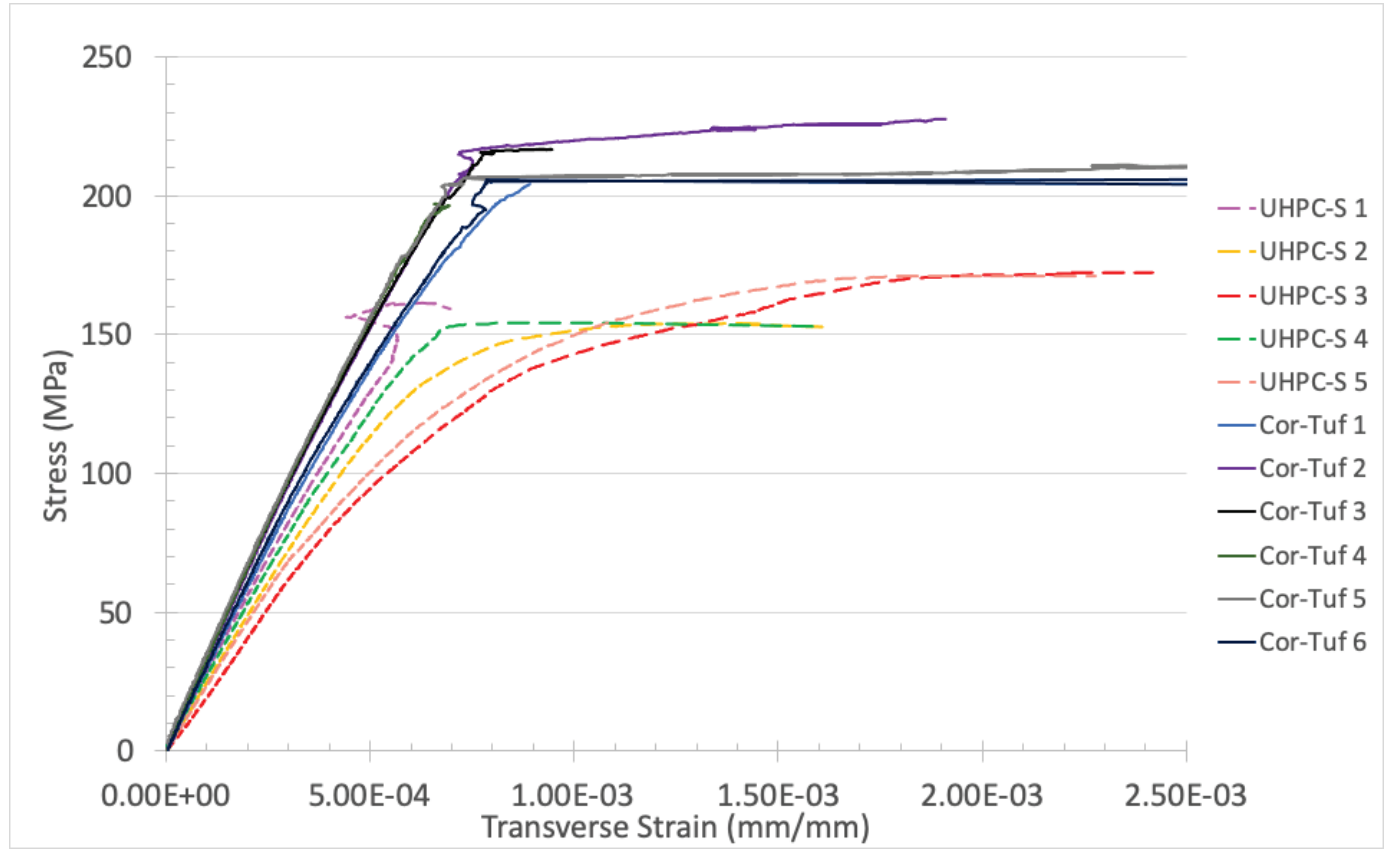

Transverse strain versus longitudinal strain is presented in Figure 14. This plot shows a linear relationship between the two strain types. As the cylinders were compressed in the longitudinal axis, the transverse axis expanded proportionally up to $40 \%$ of the expected maximum load. Any deviation from this linear relationship is likely due to defects in the glued bond between the 
strain gauge and the UHPC or defects in the surface of the concrete. In this plot, longitudinal strain is presented as negative for compression.

Figure 14. Transverse strain vs. longitudinal strain $(\mathrm{mm} / \mathrm{mm})$.

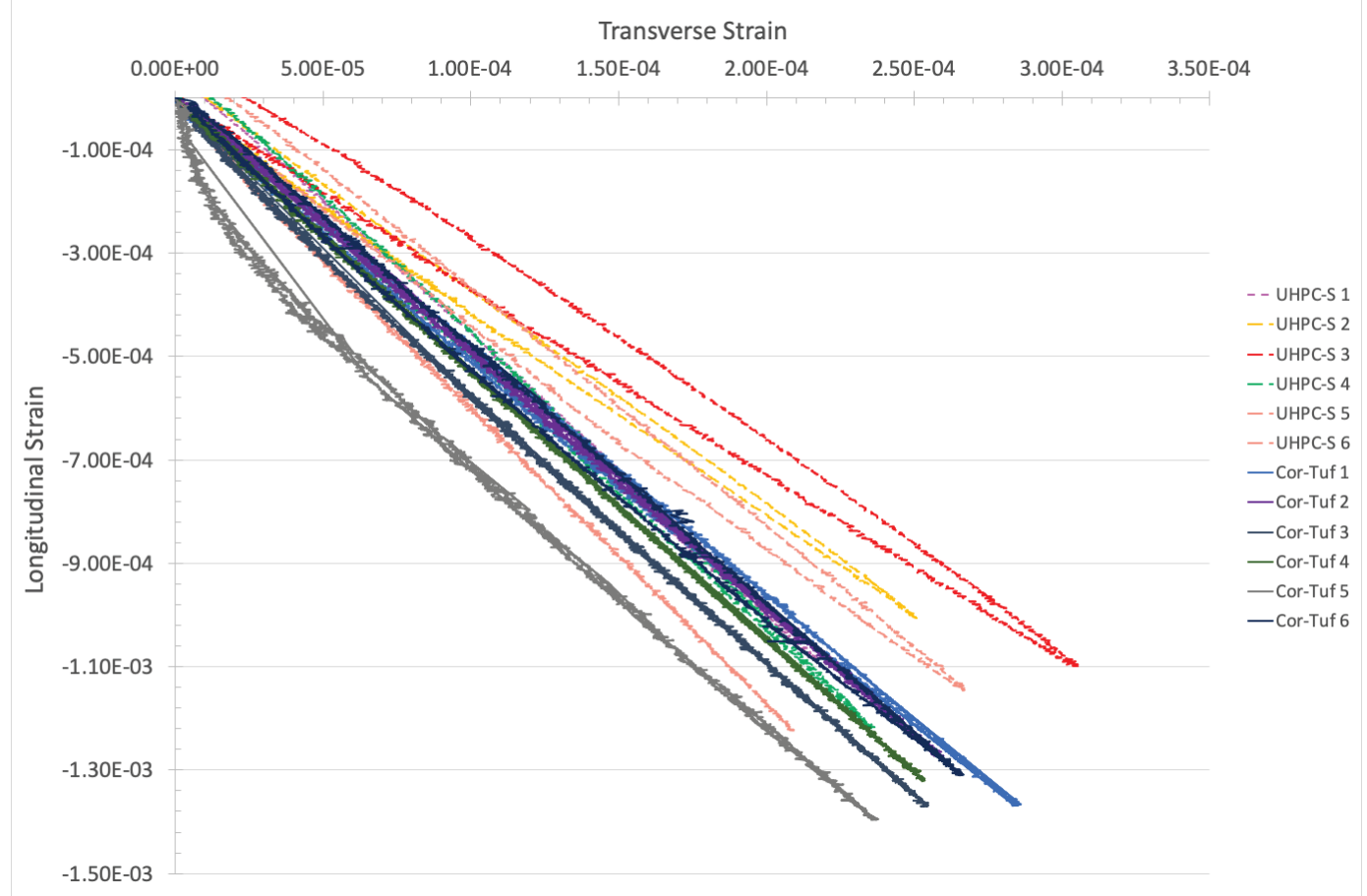

\subsection{Hydrostatic compression tests}

Undrained bulk compressibility data were obtained from two $\mathrm{HC}$ tests and from the hydrostatic loading phases of the 14 TXC tests. The pressure-volume data from the two HC tests are plotted in Figure 15. The initial dry densities of $\mathrm{HC}$ test specimens 1 and 2 were 2.428 and $2.441 \mathrm{Mg} / \mathrm{m}^{3}$, respectively. The specimens for test numbers 1 and 2 have nearly the same initial dry densities and exhibit very similar compressibilities. These test specimens also have very similar P- and S-wave velocities with only minor differences between the two. However, the effects of these differences are normally at very low stress levels and should not affect the data, as plotted in Figure 15. Figure 16 presents the pressure-time histories for the $\mathrm{HC}$ tests. Once each $\mathrm{HC}$ test reached the maximum prescribed pressure, the pressure was intentionally held constant for a period of time.

During the pressure hold, the volumetric strains continued to increase, indicating that UHPC-S is susceptible to creep (Figure 15 and Figure 16). The pressure for test specimen 1 was held at $400 \mathrm{MPa}$ for $42 \mathrm{sec}$, during which time a volumetric strain of $0.11 \%$ occurred. For test specimen 2, the 
pressure was held at $400 \mathrm{MPa}$ for $70 \mathrm{sec}$, during which time a volumetric strain of $0.17 \%$ occurred. Based on the data from the HC tests, the initial bulk modulus $(K)$ of UHPC-S was calculated to be $22.5 \mathrm{GPa}$.

Figure 15. Pressure-volume responses from HC tests.

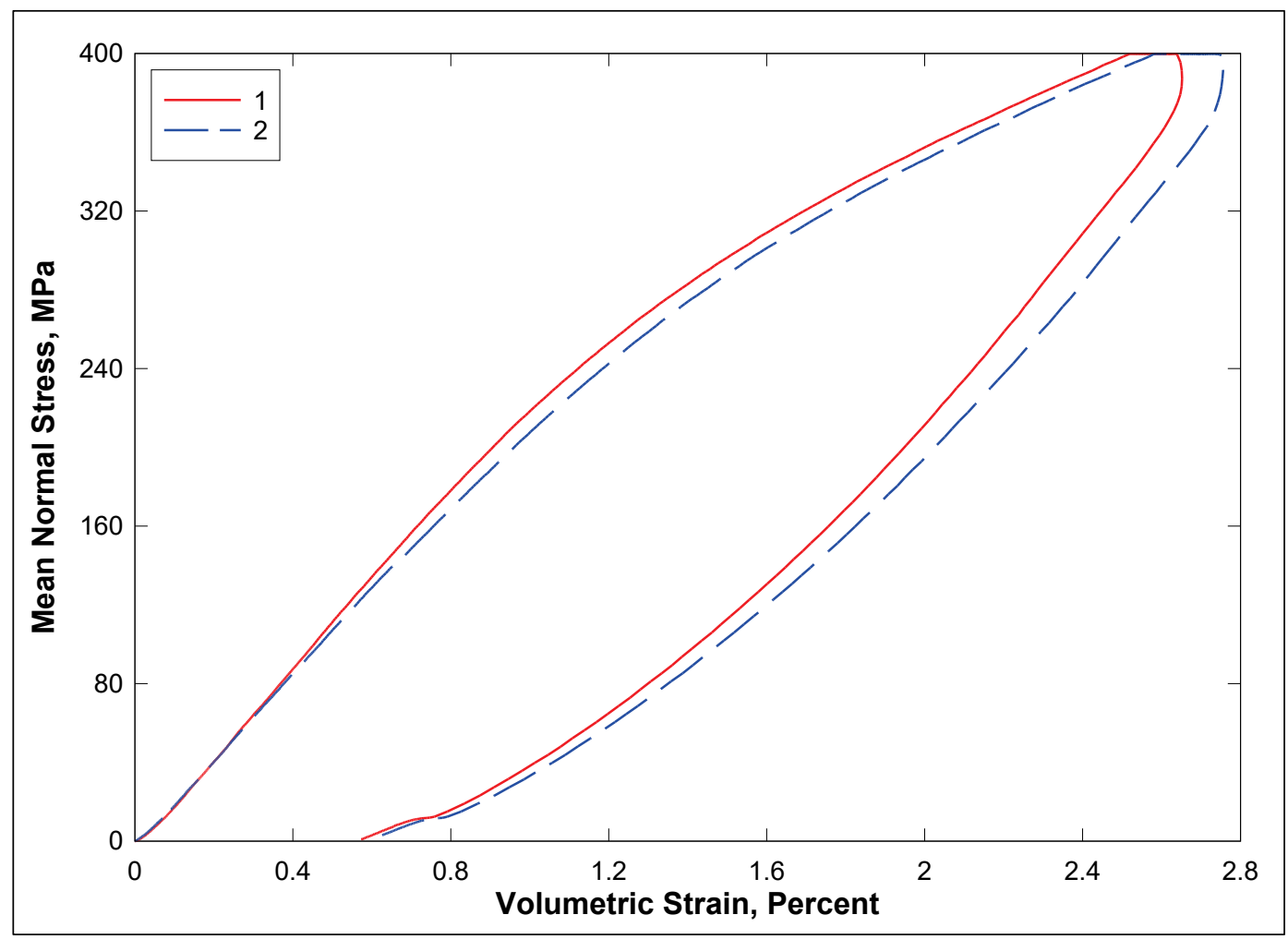


Figure 16. Pressure-time histories from HC tests.

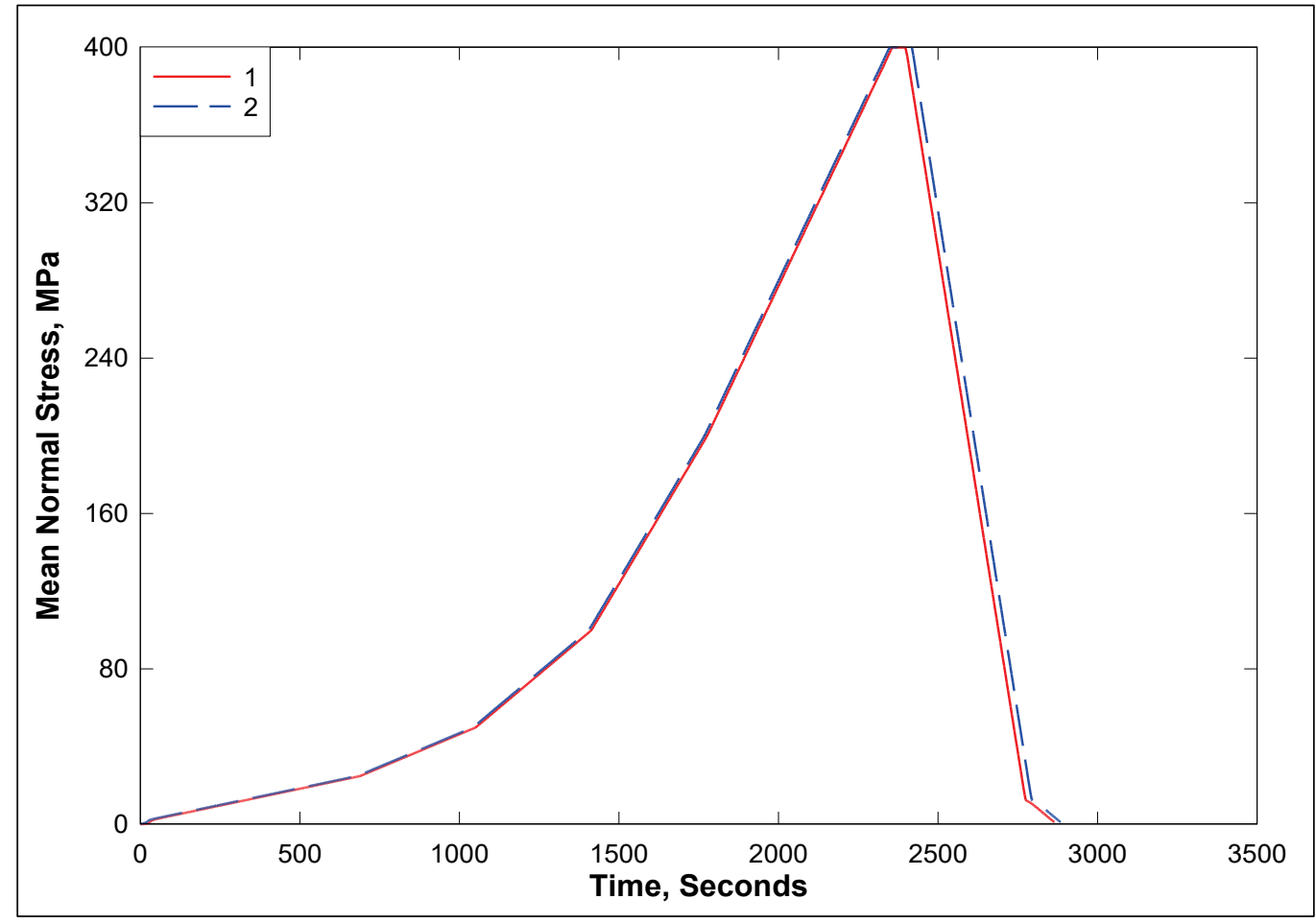

\subsection{Triaxial compression tests}

Shear and failure data were successfully obtained from three unconfined compression tests and 14 unconsolidated, undrained TXC tests. Recall from Chapter 2 that the second phase of the TXC test, the shear-loading phase, was conducted after the desired confining pressure was applied during the HC phase. The UC tests are a special type of TXC test without the application of confining pressure. Results from the UC tests are plotted in Figures 17 and 18, and results from the TXC tests are plotted in Figures 1922. In all figures, the axial and volumetric strains were set to zero at the start of the shear phase: only the strains during shear are plotted.

Stress-strain data from the three UC tests in Figures 17 and 18 are plotted as principal stress difference versus axial strain during shear and as principal stress difference versus volumetric strain during shear. During the UC tests, no attempt was made to capture the post-peak (or softening) stress-strain behavior of this material. The mean unconfined compressive strength of UHPC-S determined from the three UC tests was 78.o MPa. The dry densities of the specimens ranged from $2.390 \mathrm{Mg} / \mathrm{m}^{3}$ to $2.409 \mathrm{Mg} / \mathrm{m}^{3}$. Specimens 19 and 21 had nearly identical initial dry densities (2.404 and $2.409 \mathrm{Mg} / \mathrm{m}^{3}$, respectively). 
Specimen 20 had a slightly lower initial dry density and failed at a slightly lower peak stress compared to specimens 19 and 21.

Figures 19-22 present the results from the TXC tests conducted at nominal confining pressures of 10, 20,50, 100, 200, 300, and $400 \mathrm{MPa}$. The TXC test results are plotted as principal stress difference versus axial strain during shear and as principal stress difference versus volumetric strain during shear. The results show very little scatter over repeated loading paths. The wet densities of the TXC specimens ranged from 2.496 to $2.521 \mathrm{Mg} / \mathrm{m}^{3}$, the dry densities ranged from 2.368 to $2.408 \mathrm{Mg} / \mathrm{m}^{3}$, and the water contents ranged from $4.37 \%$ to $5.57 \%$.

Results of TXC tests conducted at constant confining pressures of 10, 20, and $50 \mathrm{MPa}$ are shown in Figures 19 and 20. The initial wet densities ranged from 2.496 to $2.521 \mathrm{Mg} / \mathrm{m}^{3}$. The initial dry densities ranged from 2.374 to $2.408 \mathrm{Mg} / \mathrm{m}^{3}$. The initial dry density of specimen 5 could not be determined due to a postfailure fluid leak into the specimen. The volumetric responses of these test specimens display compressive volumetric strains prior to dilating (Figure 20).

Results of TXC tests conducted at constant confining pressures of 100, 200, 300, and $400 \mathrm{MPa}$ are shown in Figures 21 and 22. The initial wet densities for these specimens ranged from 2.500 to $2.520 \mathrm{Mg} / \mathrm{m}^{3}$. The initial dry densities ranged from 2.368 to $2.390 \mathrm{Mg} / \mathrm{m}^{3}$. Figure 21 displays postpeak softening in all specimens tested. The volumetric responses in Figure 22 indicate that the specimens compacted until just prior to the peak principal stress difference, after which the specimens dilated. The tests performed at 300 and $400 \mathrm{MPa}$ exhibited only small increases in peak strengths compared to the peak strengths observed from the $200 \mathrm{MPa}$ tests.

The failure points from all the UC and TXC tests are plotted in Figure 23 as principal stress difference versus mean normal stress. A recommended failure surface is also plotted with the failure data. The overall quality of the failure data is good and exhibits very little scatter. It is important to note that, in general, the failure points exhibited a continuous increase in principal stress difference with increasing values of mean normal stress. The rate of increase is reduced after reaching a mean normal stress of approximately $400 \mathrm{MPa}$. The volumetric strain data from the HC and TXC tests indicate that at a mean normal stress of approximately $450 \mathrm{MPa}$, the material is approaching void closure. 
Materials such as concrete can continue to gain strength with increasing pressure until all of the specimen's air porosity is forced out.

Figure 17. Stress-strain responses from UC tests.

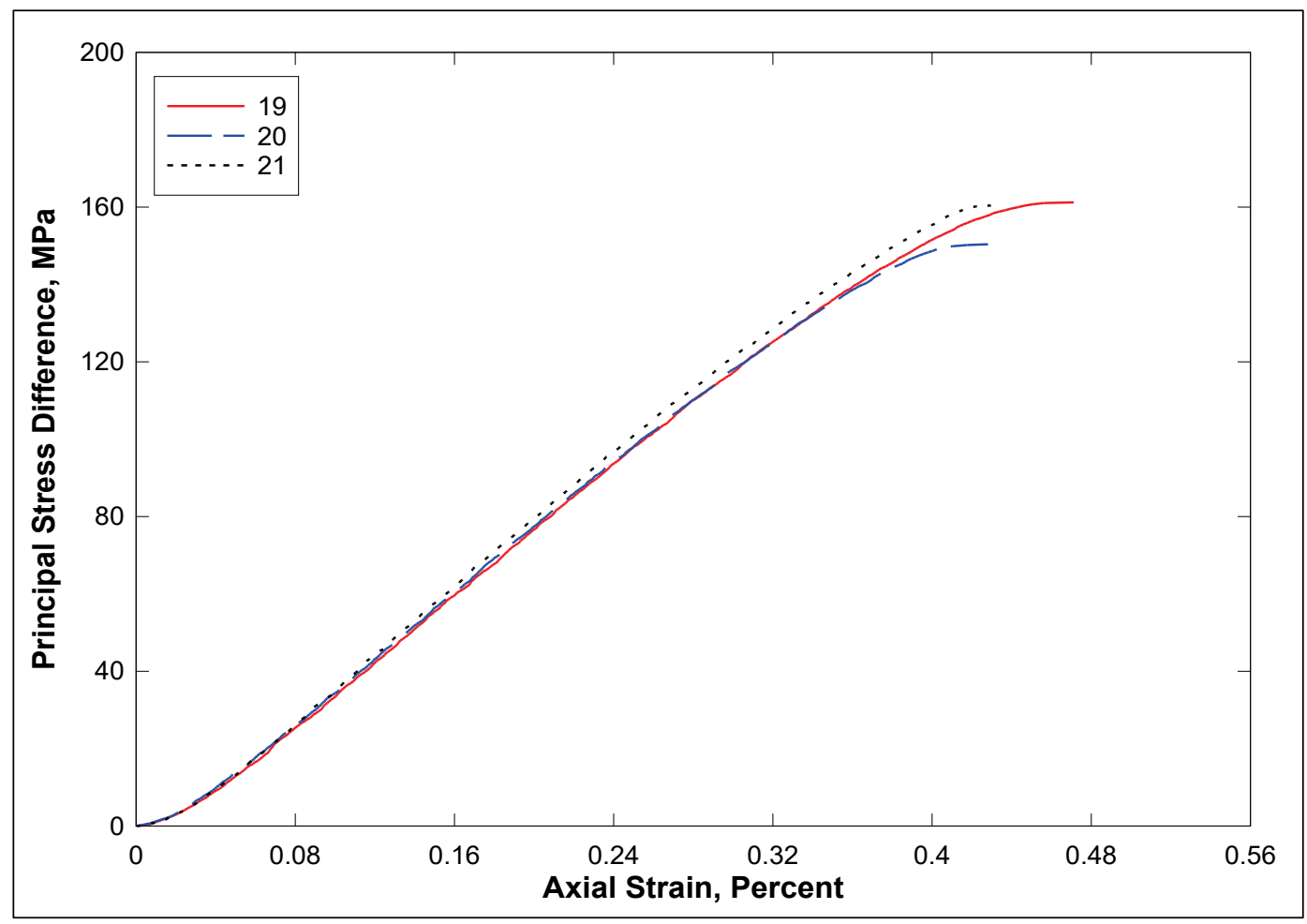


Figure 18. Stress difference-volumetric strain during shear from UC tests.

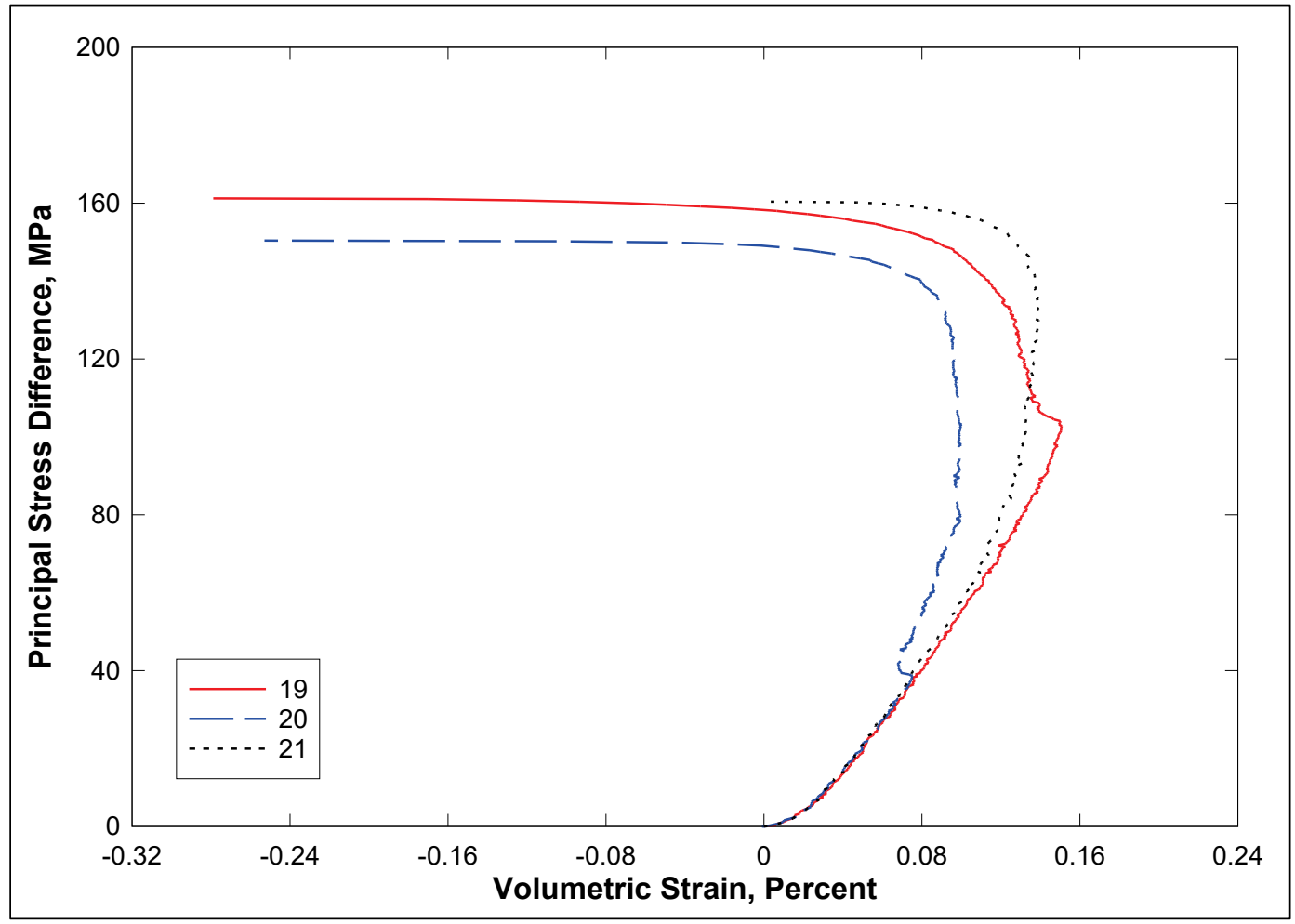

Figure 19. Stress-strain responses from TXC tests at confining pressures of 10, 20, and $50 \mathrm{MPa}$.

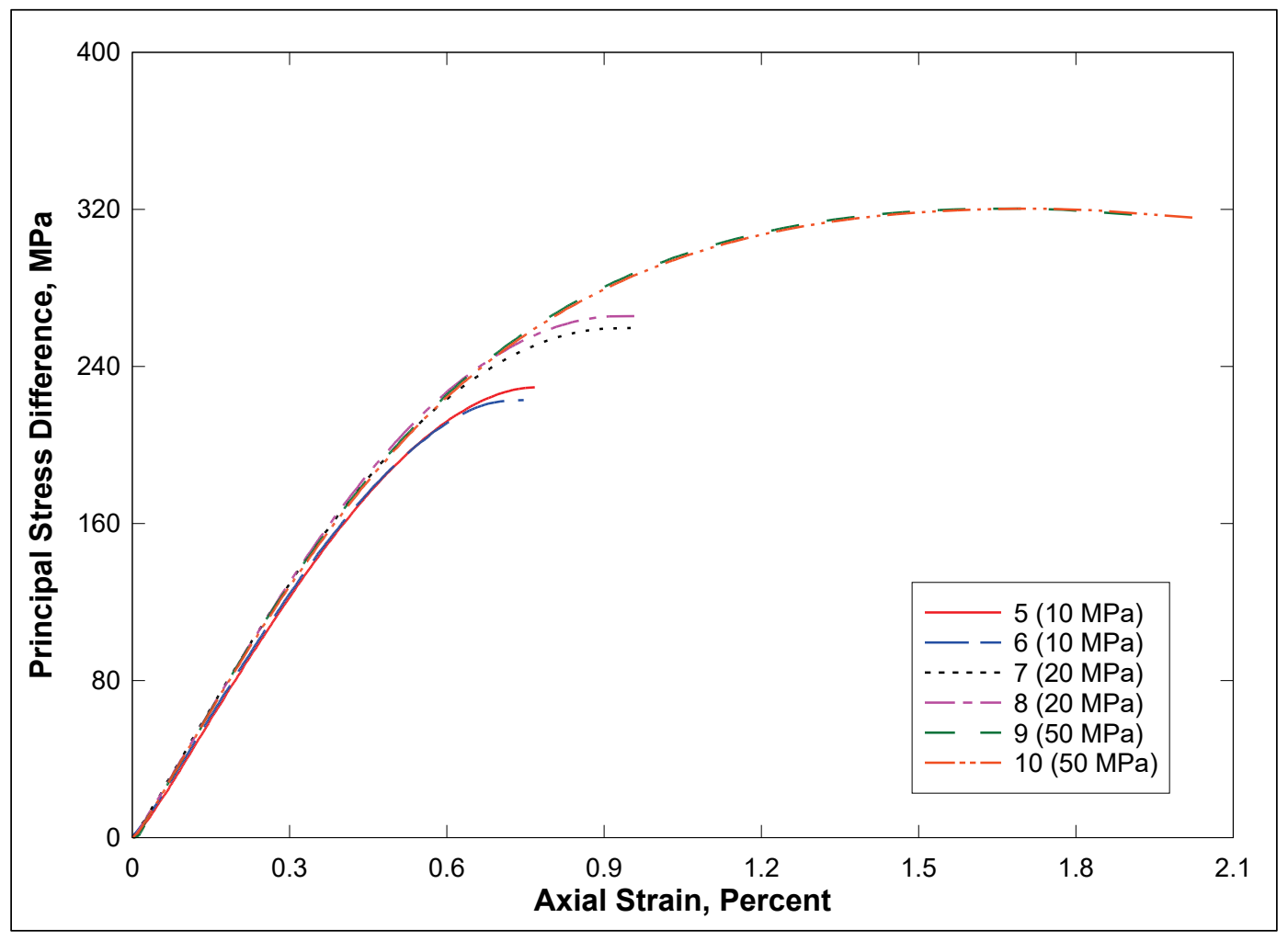


Figure 20. Stress difference-volumetric strain during shear from TXC tests at confining pressures of 10,20 , and $50 \mathrm{MPa}$.

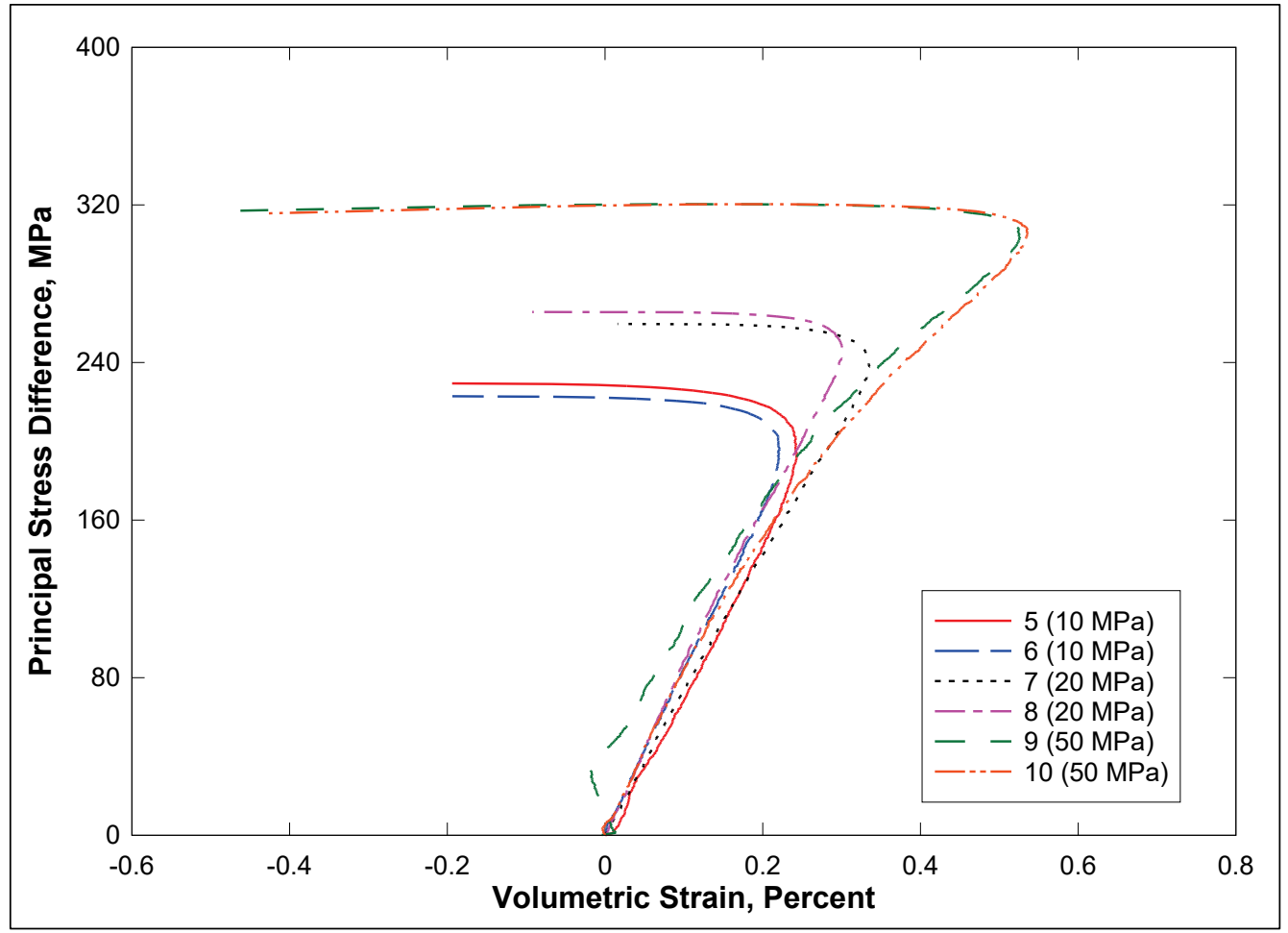

Figure 21. Stress-strain responses from TXC tests at confining pressures of 100, 200, 300 , and $400 \mathrm{MPa}$.

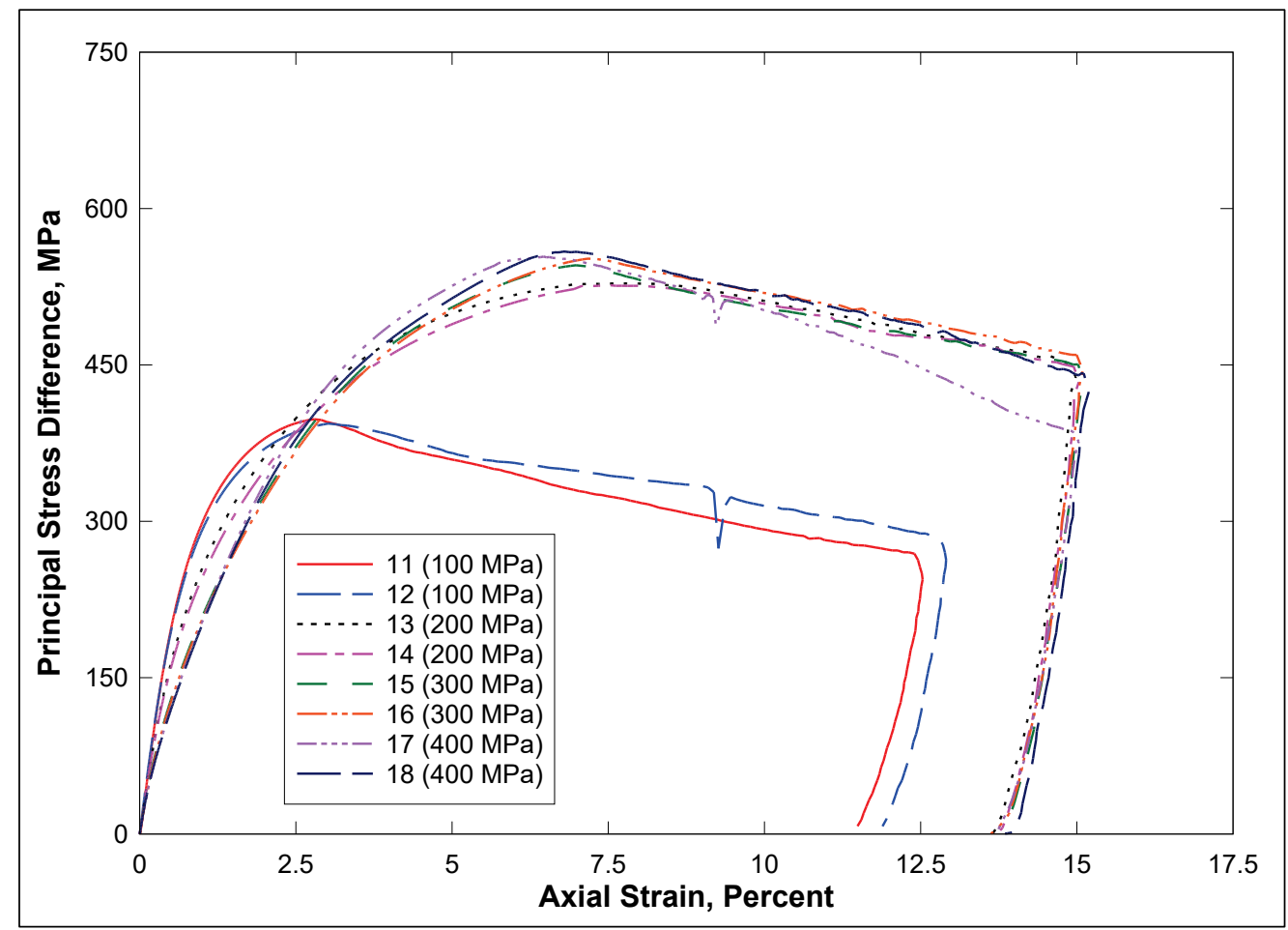


Figure 22. Stress difference-volumetric strain during shear from TXC tests at confining pressures of $100,200,300$, and $400 \mathrm{MPa}$.

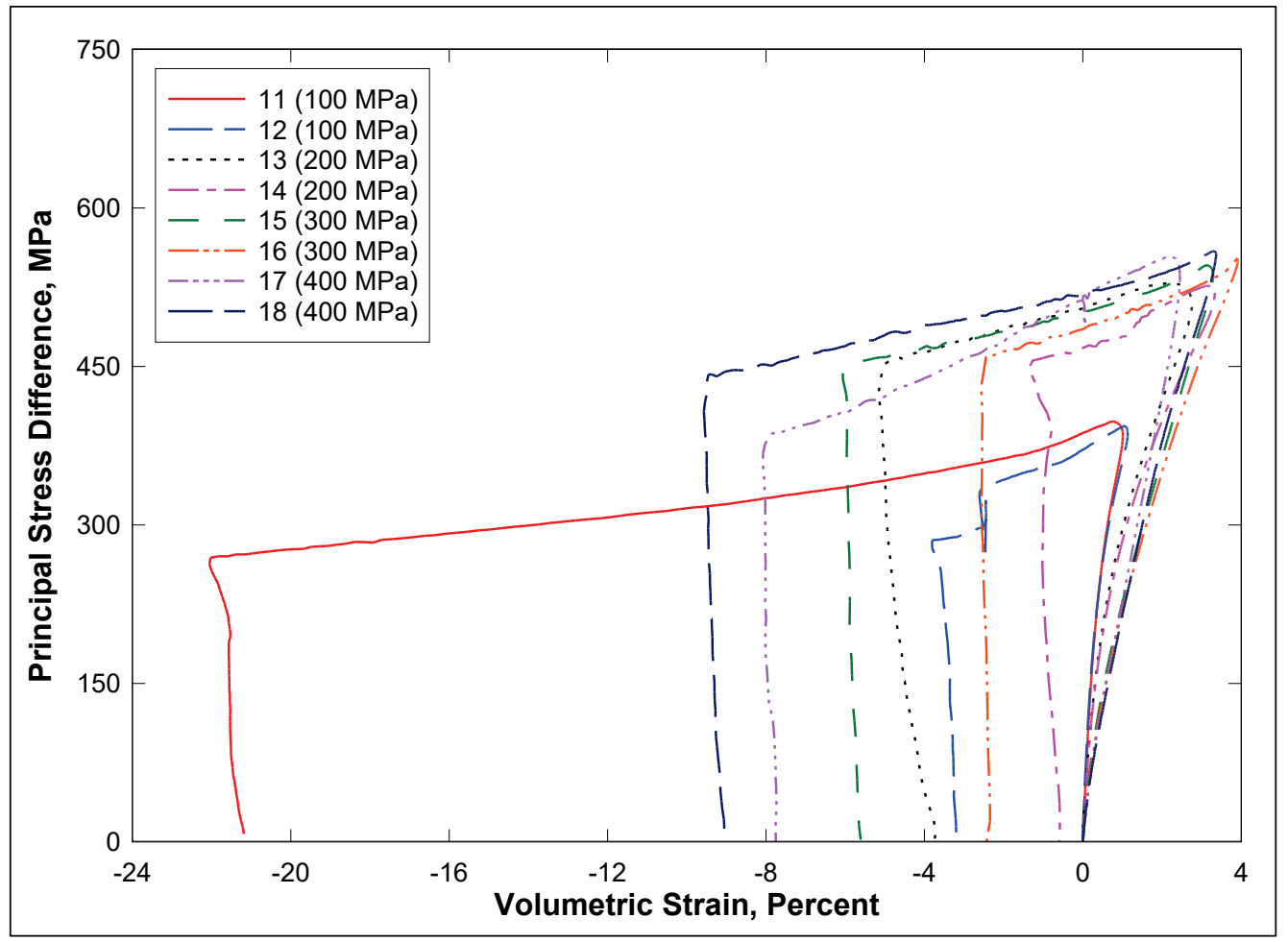

Figure 23. Failure data from UC and TXC tests and recommended failure surface.

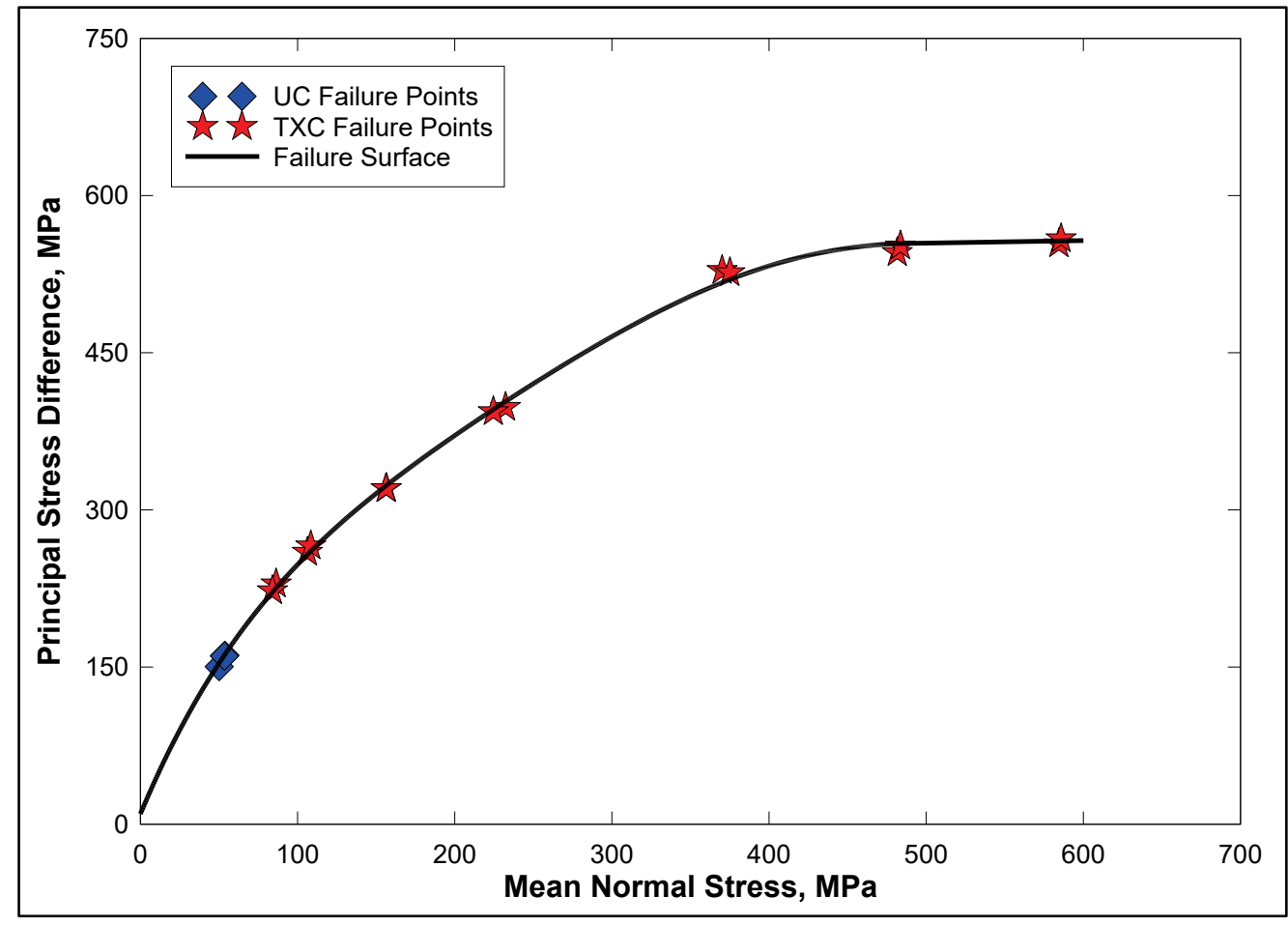




\subsection{Uniaxial strain tests}

One-dimensional compressibility data were obtained from two undrained, uniaxial strain tests with lateral stress measurements. Data from the tests are plotted in Figures 24-26. The stress-strain data from the UX tests are plotted in Figure 24, the pressure-volume data in Figure 25, and the stress paths in Figure 26. The UX responses indicate that the test specimens did not reach a saturated state: the volumetric strains achieved during the tests were less than the volumes of air in the specimens.

From the UX stress-strain loading data (Figure 24), an initial constrained modulus (M) of 47.0 GPa was calculated. The UX test data may also be plotted as principal stress difference versus mean normal stress (Figure 25), the slope of which is twice the shear modulus divided by the bulk modulus $(2 \mathrm{G} / \mathrm{K})$. An initial shear modulus of $18.3 \mathrm{GPa}$ was calculated from the constrained modulus and the initial bulk modulus, $\mathrm{K}$. These two values may be used to calculate other elastic constants, such as an initial Young's modulus of $43.2 \mathrm{GPa}$ and a Poisson's ratio of 0.18 .

The UX stress paths plotted in Figure 26 trend below the recommended TXC failure surface even at low stresses. The initial dry densities for test specimens 4 and 28 were 2.398 and $2.415 \mathrm{Mg} / \mathrm{m}^{3}$, respectively. The pressure-volume responses from the $\mathrm{HC}$ and UX tests are compared in Figure 27. Comparing UX and HC test results, shear-induced compaction is evident as seen by the greater volumetric strain experienced by UX specimens at equal values of mean normal stress. 
Figure 24. Stress-strain responses from UX tests.

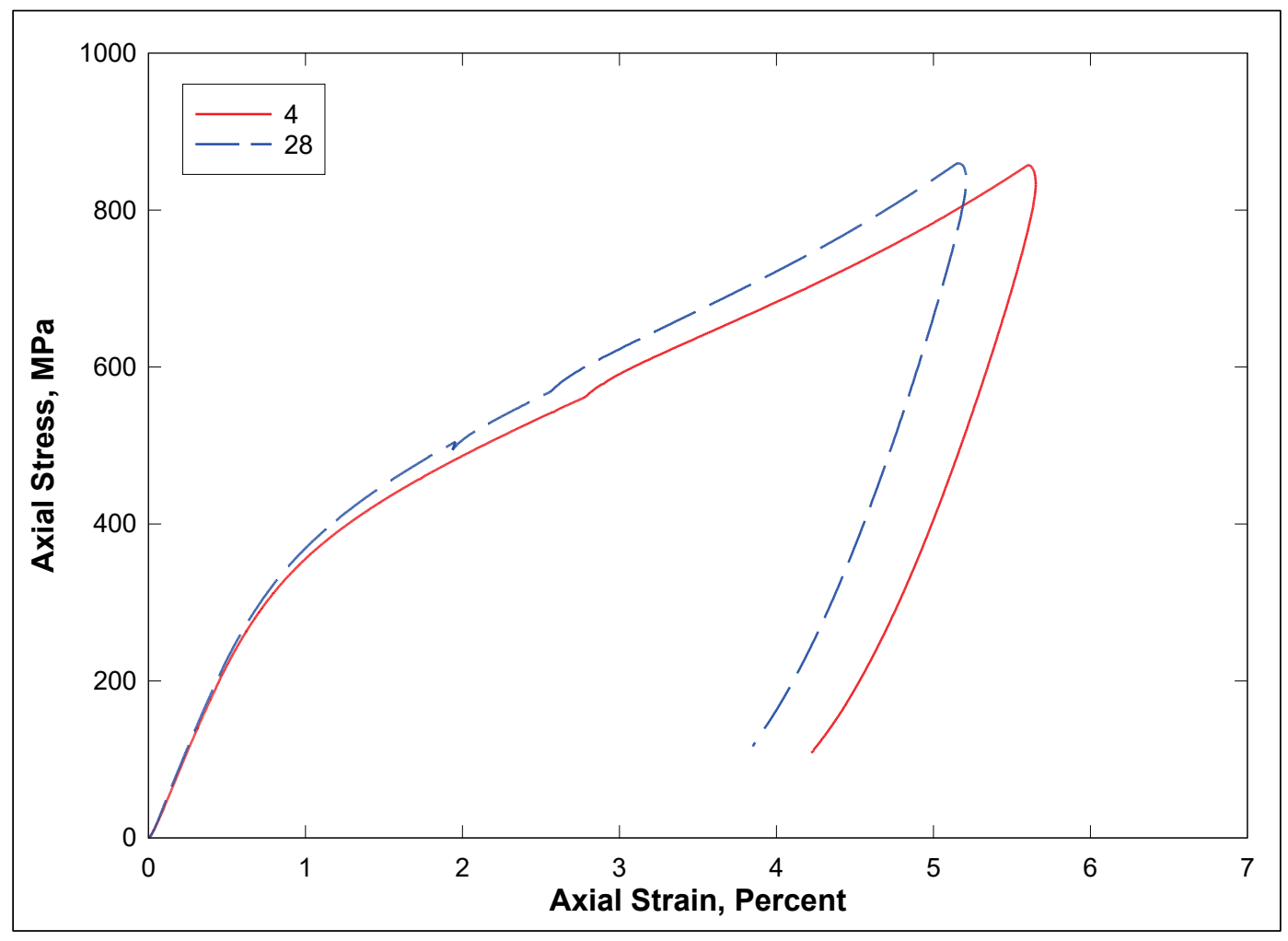

Figure 25. Pressure-volume data from UX tests.

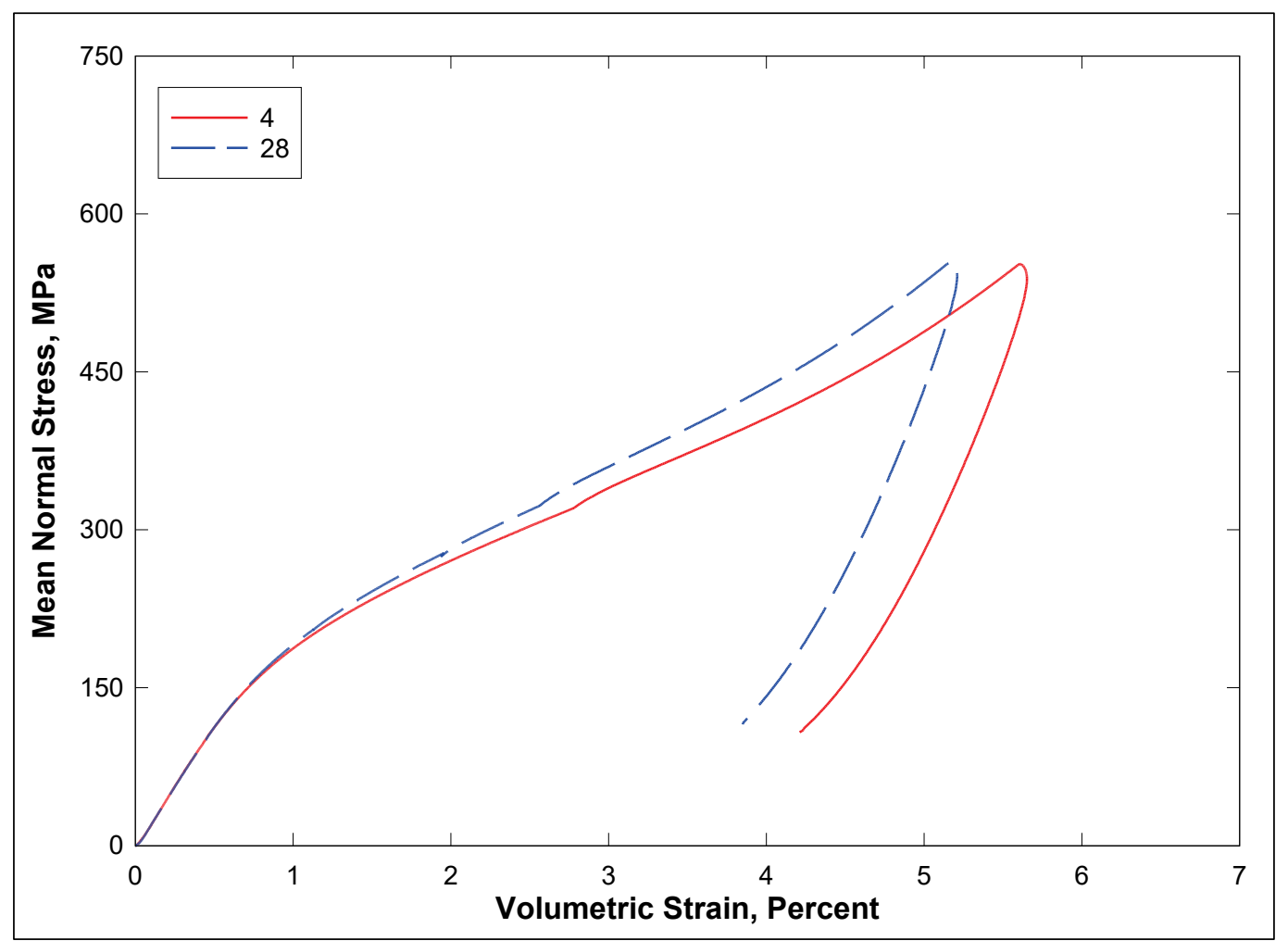


Figure 26. Stress paths from UX tests.

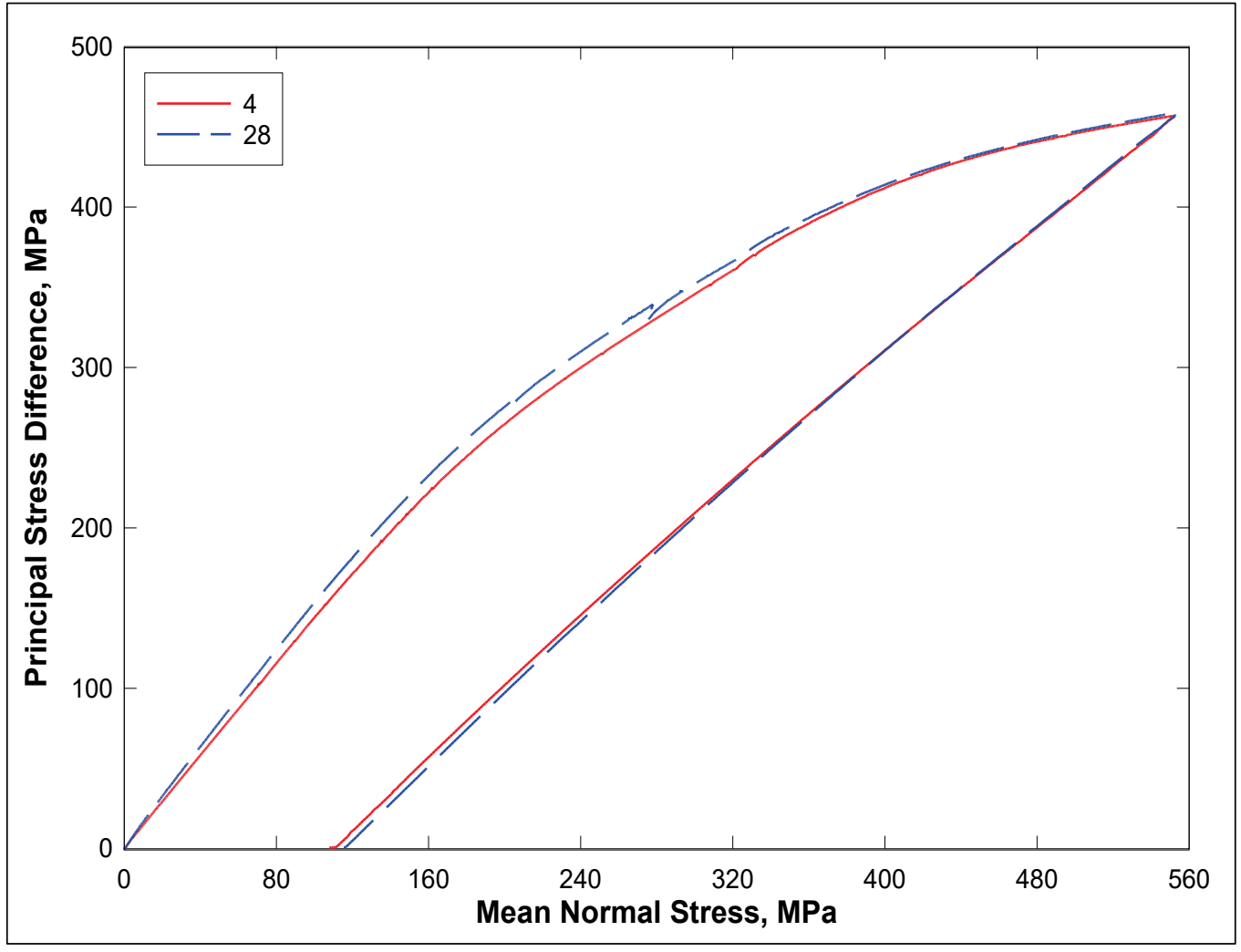

Figure 27. Comparison of pressure-volume data from HC and UX tests.

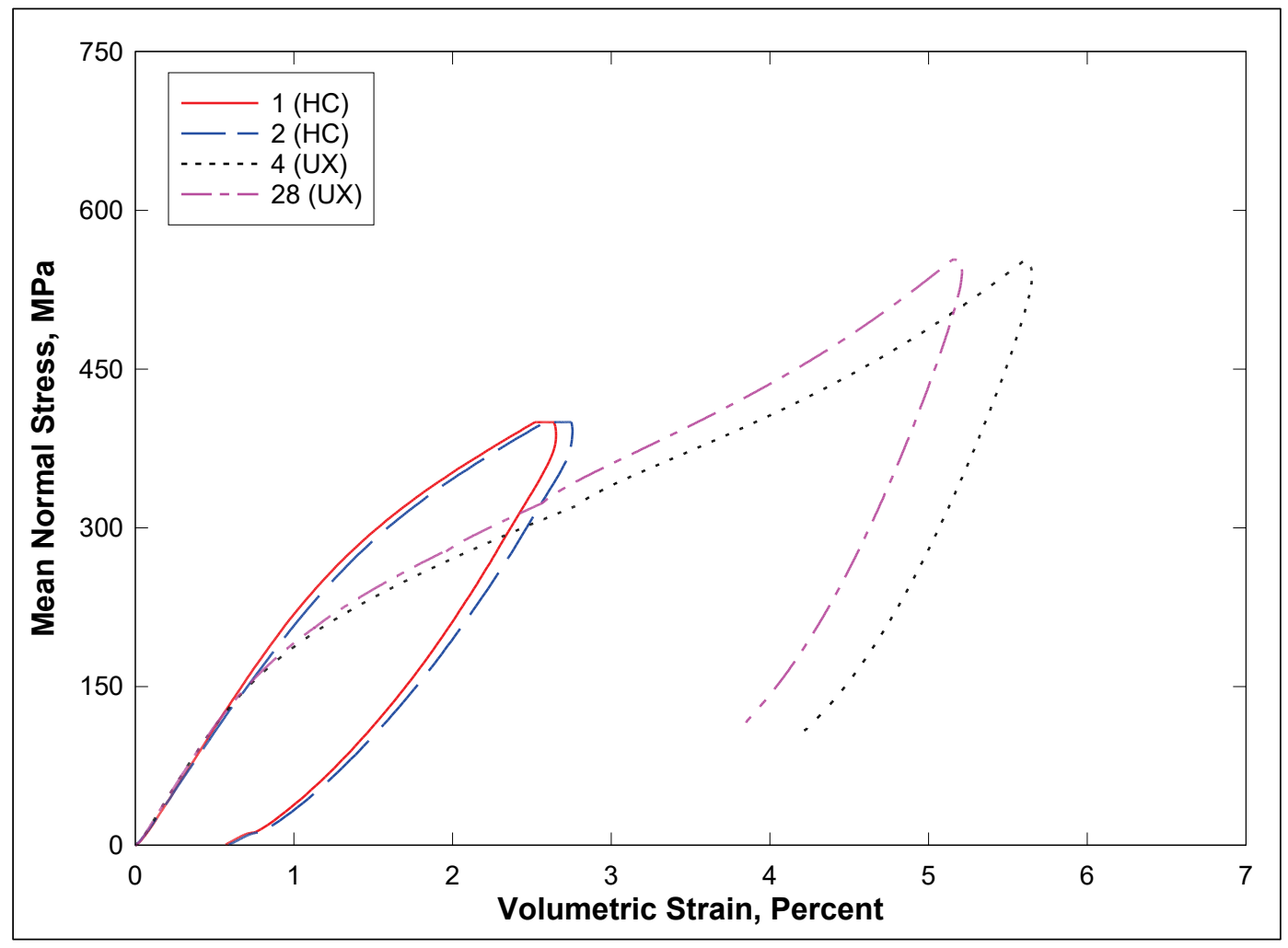




\subsection{Strain path tests}

One type of strain-path test was conducted in this test program. Uniaxial strain/constant volumetric strain (UX/CV) refers to tests with uniaxial strain loading followed by constant volumetric strain loading. Results from $\mathrm{UX} / \mathrm{CV}$ tests conducted at two levels of peak radial stress during the initial UX phase are shown in Figures 28-30. The CV portions of the stress path data in Figure 28 initially exhibit an increase in principal stress difference, then a slight decrease in mean normal stress, followed by an increase of both the principal stress difference and the mean normal stress. At some point during the $\mathrm{CV}$ loading, the data contact and follow along the failure surface developed from the TXC tests. Figures 29 and 30 show the constant volumetric strain loading and stress-strain responses, respectively.

Figure 28. Stress paths from UX/CV tests.

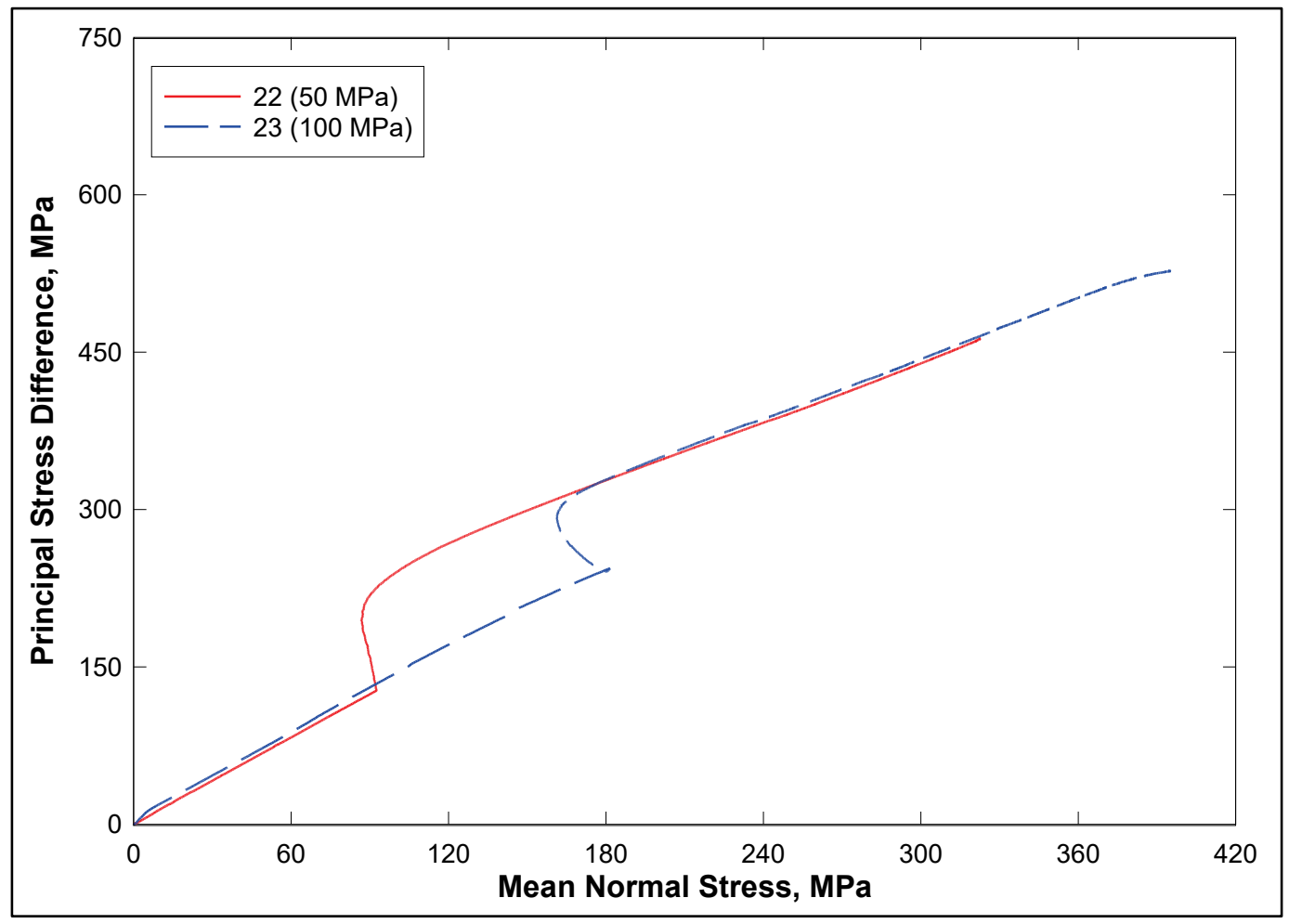


Figure 29. Pressure-volume responses from UX/CV tests.

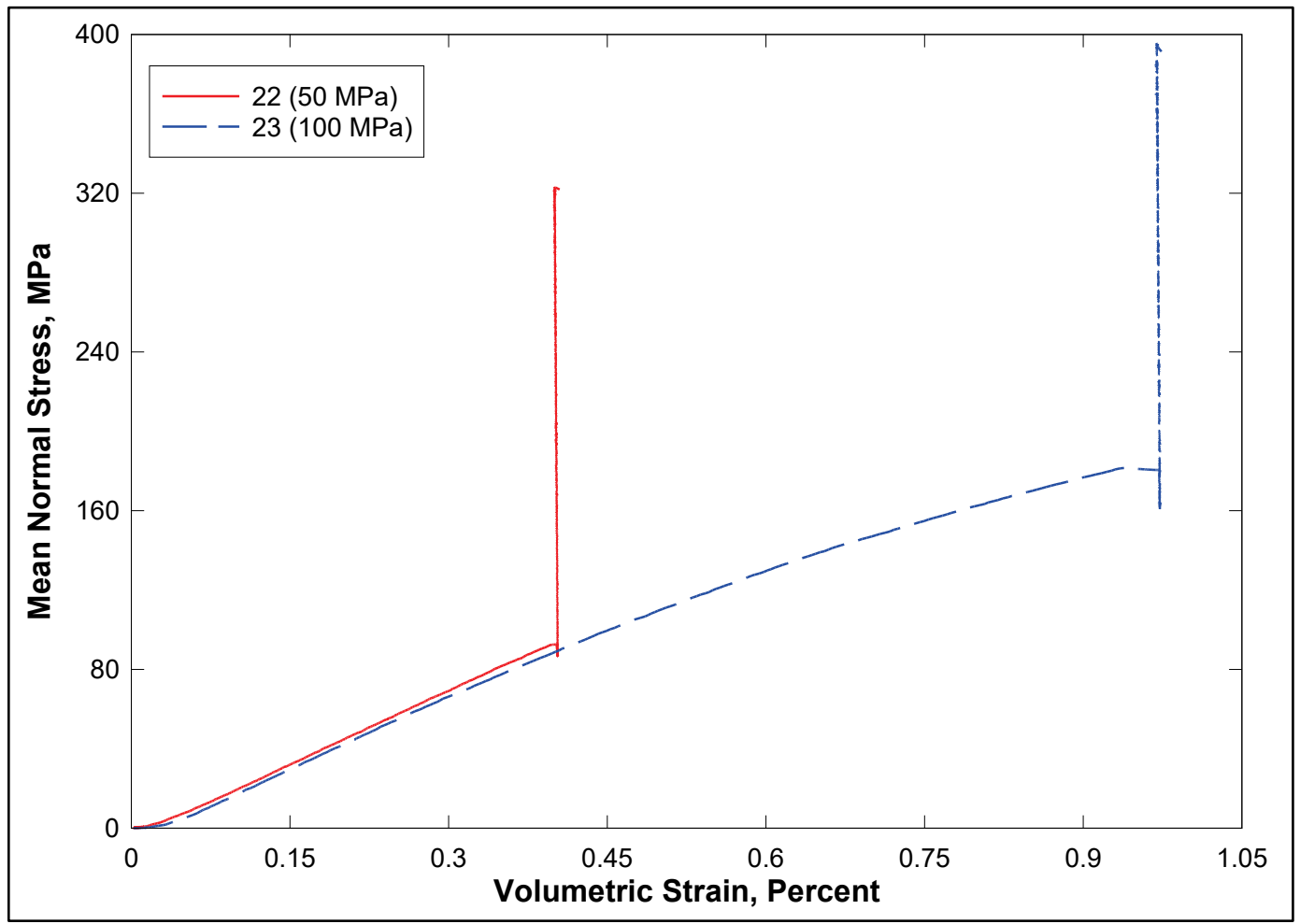

Figure 30. Stress-strain responses from UX/CV tests.

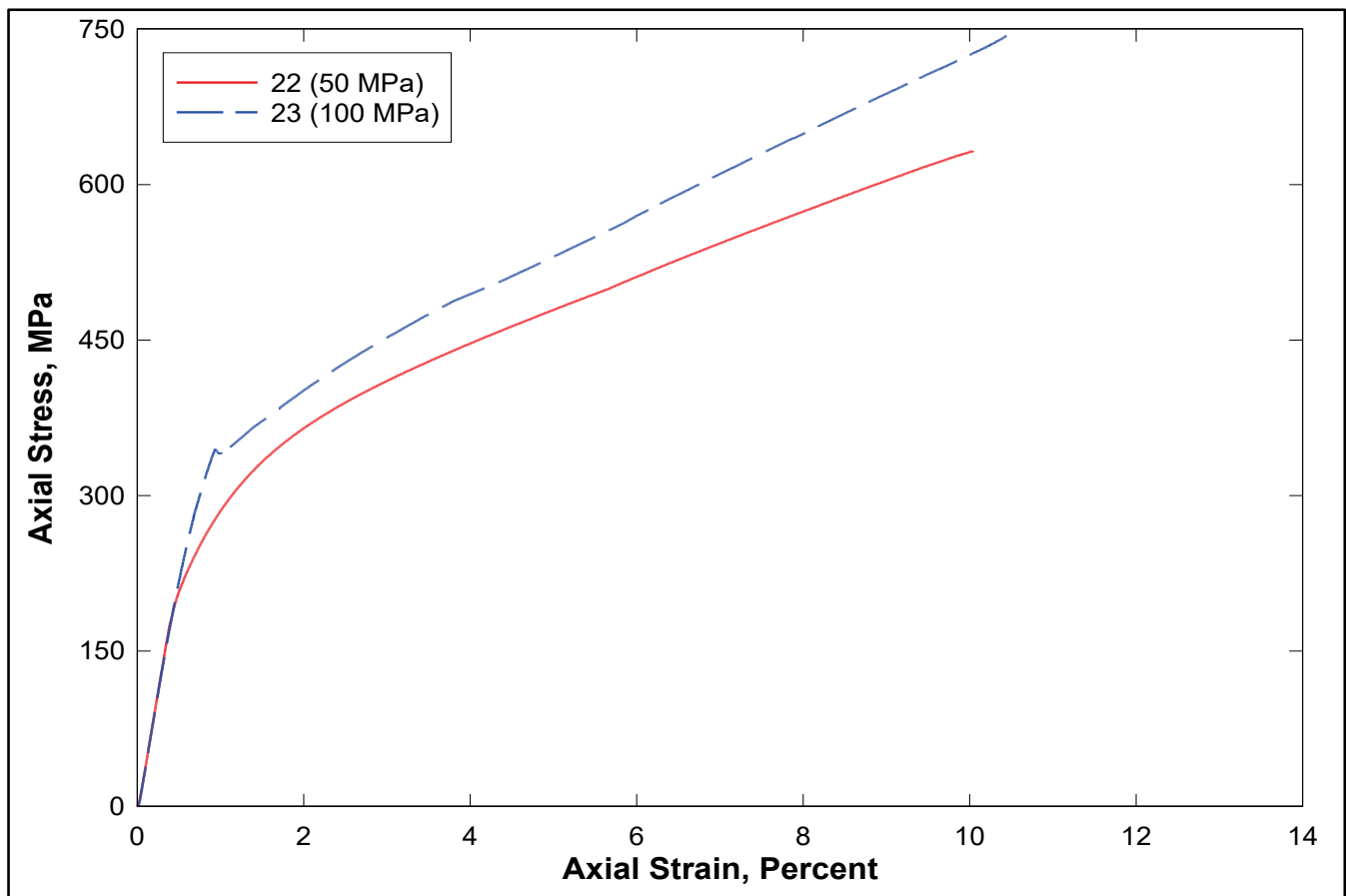




\subsection{Direct pull tests}

Tension shear and failure data were successfully obtained from four direct pull (DP) tests. The DP tests are performed without the application of confining pressure. Results from the DP tests are plotted in Figure 31. Failure from the DP tests occurred at an average mean normal stress of approximately -2.27 MPa and an average principal stress difference of approximately -6.81 MPa. The absolute value of the tensile strength of UHPC-S concrete is 4.3 percent of the unconfined compressive strength (approximately $157 \mathrm{MPa}$ ). According to the American Concrete Institute (ACI 2018), tensile strength of concrete is about $10 \%$ to $15 \%$ of the compressive strength. In this case, the DP test results produced a lower value than would generally be assumed.

Figure 31. DP (tensile) tests.

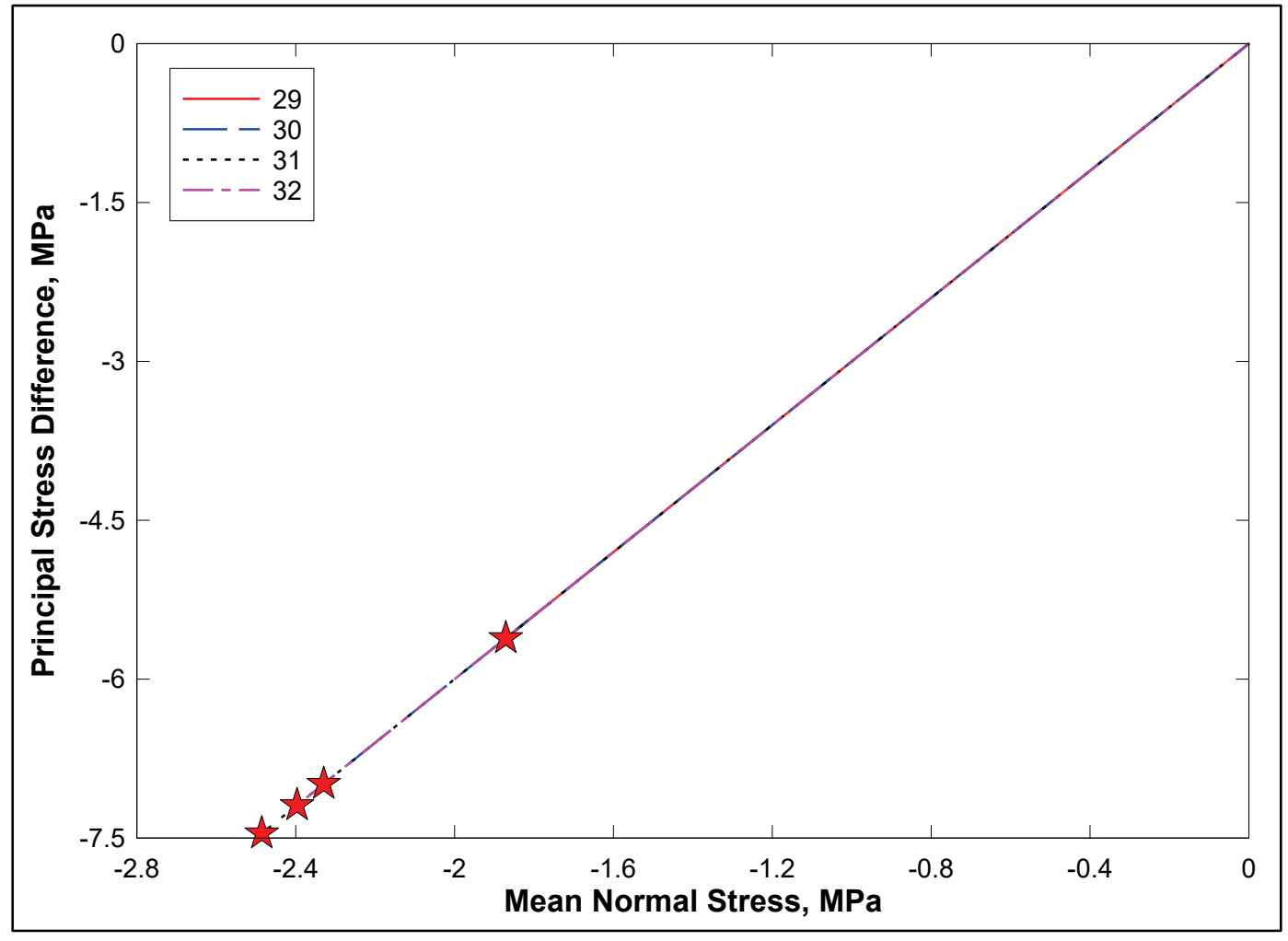

\subsection{Comparison of UHPC-S and CT concretes}

Results from selected historical tests conducted on CT specimens were compared below with results from this study's tests conducted on UHPC-S specimens to investigate any differences in the mechanical responses of the two materials. In Figures 32-38, test results are plotted together to compare the behaviors of each material. Each data plot is labeled 
according to the individual test series and the specimen number during that series, so some specimen numbers may be repeated.

The pressure-volume data from the $\mathrm{HC}$ tests conducted on each concrete are compared in Figure 32. Based on the tests performed, the compressibilities of the two materials show some differences, with UHPCS displaying approximately 50\% more compressibility than CT at 400 MPa. The average wet density and air void content for the CT HC specimens were $2.558 \mathrm{Mg} / \mathrm{m}^{3}$ and $8.84 \%$, respectively; and the average wet density and air void content for the UHPC-S HC specimens were 2.510 $\mathrm{Mg} / \mathrm{m}^{3}$ and $9.09 \%$, respectively. The lower dry density of UHPC-S contributed to its higher compressibility. Both CT and UHPC-S display a susceptibility to creep (Figure 32). Based on the data from the HC tests, the initial bulk modulus, $K$, for CT is $25.2 \mathrm{GPa}$ and $22.5 \mathrm{GPa}$ for UHPC-S.

Results from the UC tests conducted on the two concretes are plotted in Figures 33 and 34, and the failure results from the UC and TXC tests at confining pressures ranging from 10-400 MPa are plotted in Figure 35. In all figures, the axial and volumetric strains were set to zero at the beginning of the shear phase. Only the strains occurring during the shear phase are plotted in the figures. The small variations in the stress-strain and strength data for each material are primarily due to variations in the specimens' initial dry densities. The mean unconfined strengths of CT and UHPC-S were determined to be $237 \mathrm{MPa}$ and $157 \mathrm{MPa}$, respectively. CT specimens were not tested at $400 \mathrm{MPa}$ confining pressure due to the loads observed during the 300-MPa triaxial compression tests. Since the material had not reached void closure during the 300-MPa test, the necessary compressive load to fail a CT specimen at 400-MPa confining pressure would have likely exceeded the capacity of the load cell inside the pressure vessel. The CT material exhibited greater peak strength at each level of confining pressure, and the difference in peak strength tended to increase as confining pressure was increased (Figure 35).

Comparisons of the UX test results for the two concretes are shown in Figures 36-38. The stress path data displayed in Figure 36 show each UHPC-S specimen plotting slightly below the CT specimen data for the duration of the test. The UHPC-S and CT materials display identical stressstrain behaviors up to an axial stress level of approximately $200 \mathrm{MPa}$, at which point the slope of the UHPC-S test data softens and plots below the CT data for the remainder of the test (Figure 37). The pressure-volume data 
shown in Figure 38 display a similar trend. The initial constrained moduli for CT and UHPC-S are 47.4 GPa and 47.0 GPa, respectively.

Figure 32. Comparison of pressure-volume responses from HC tests on UHPC-S and CT.

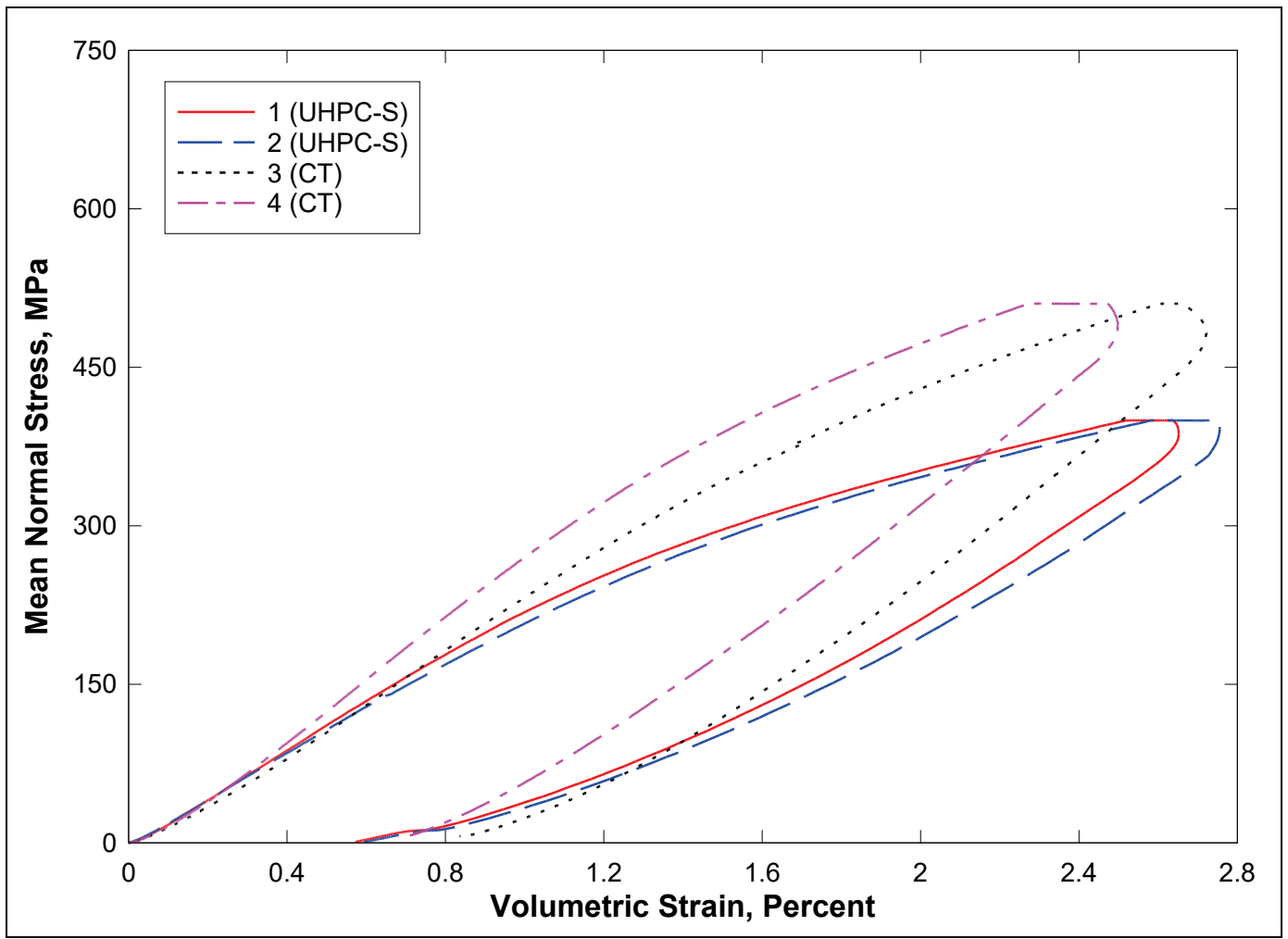


Figure 33. Comparison of stress-strain responses from UC tests on UHPC-S and CT.

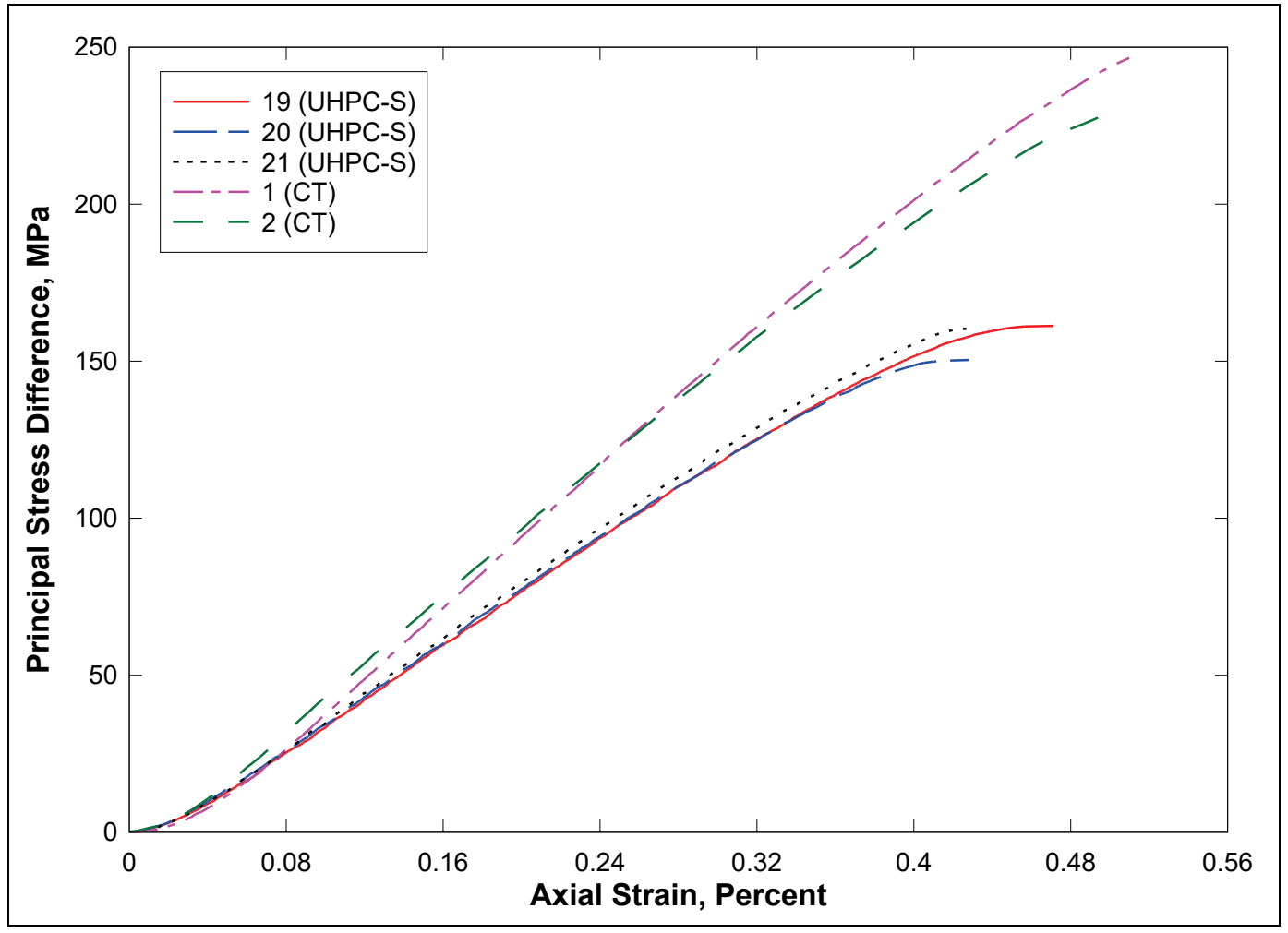

Figure 34. Comparison of stress difference-volumetric strain during shear from UC tests on UHPC-S and CT.

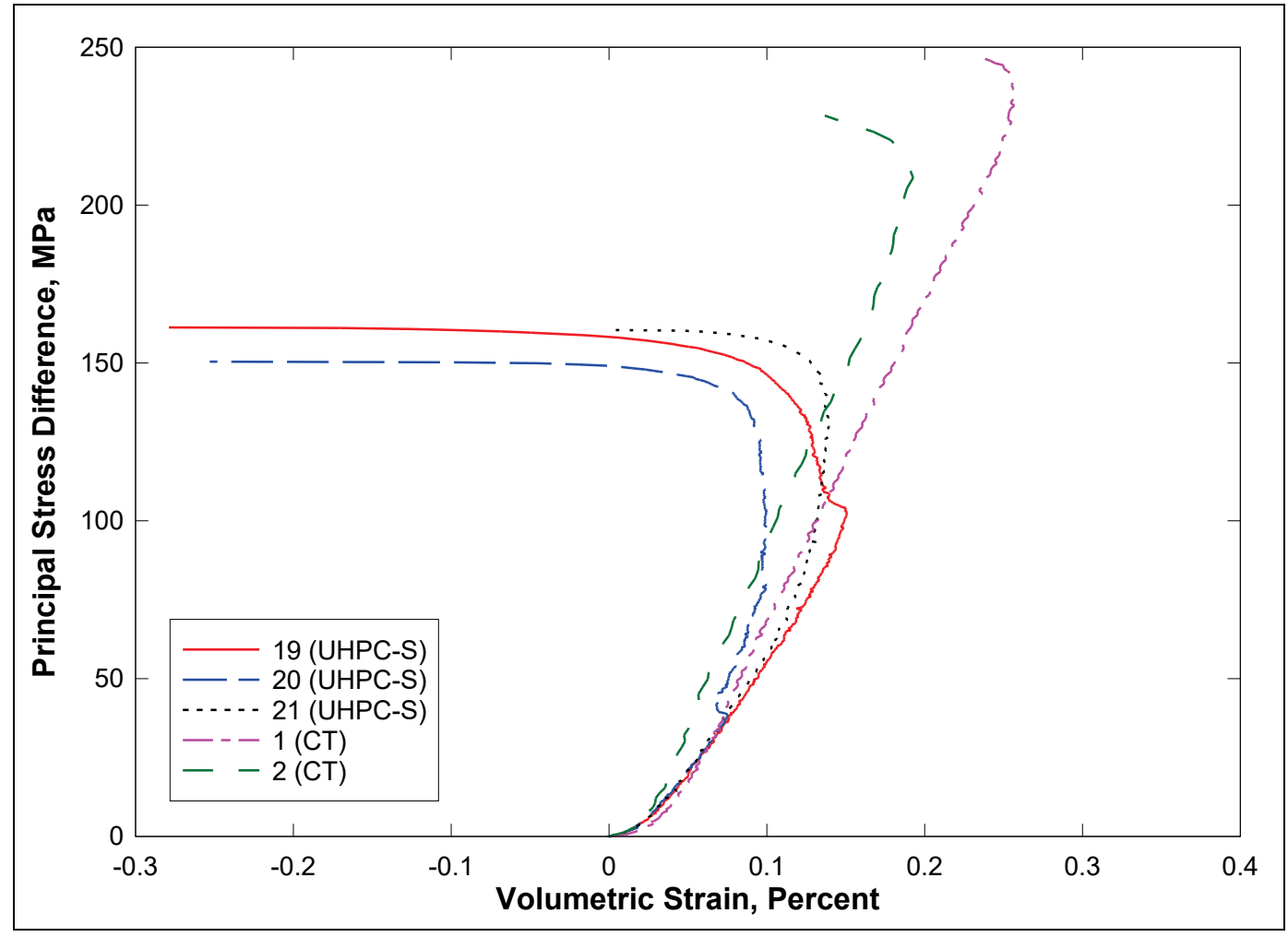


Figure 35. Comparison of failure surfaces for UHPC-S and CT.

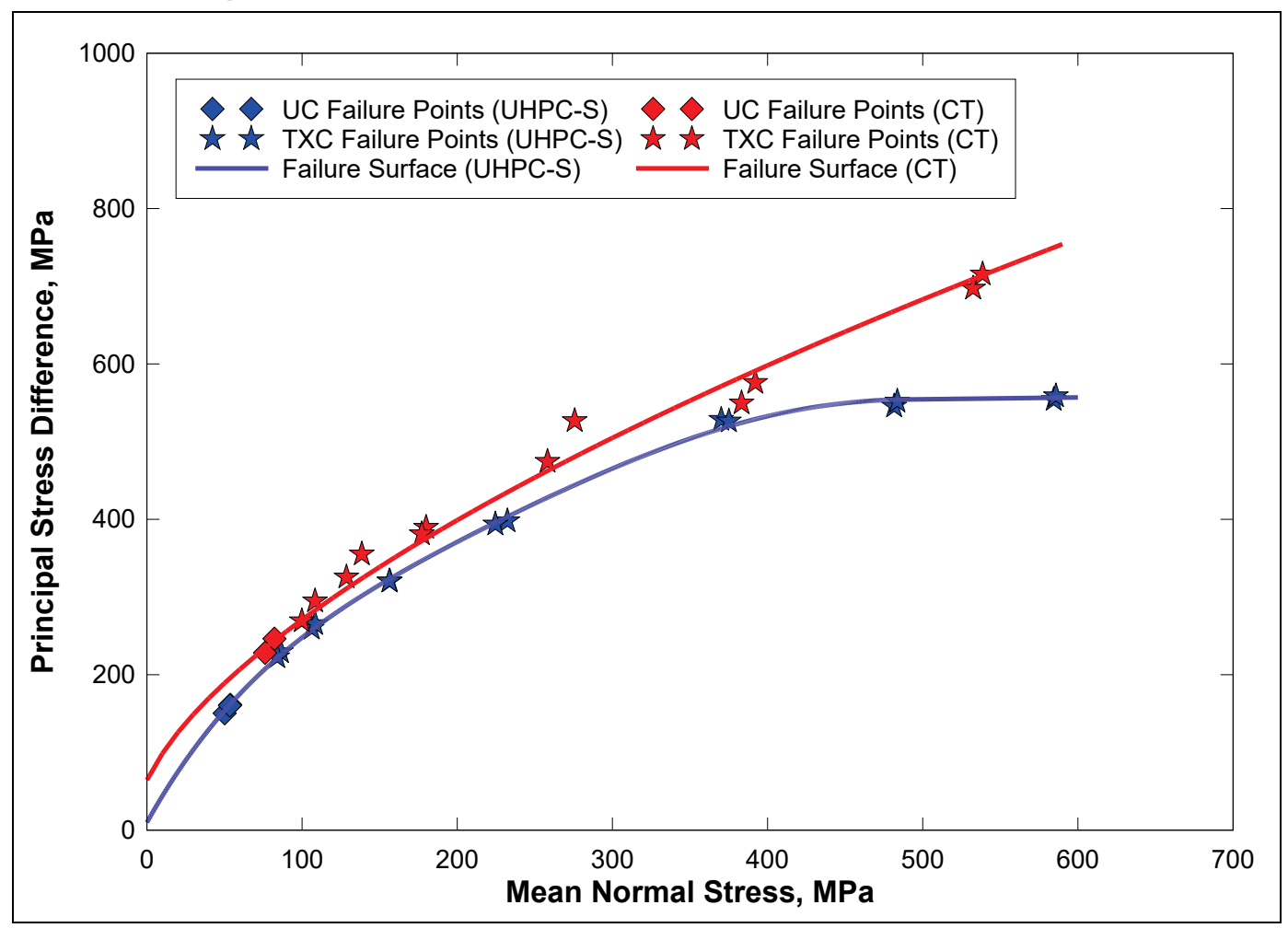

Figure 36. Comparison of stress paths from UX tests on UHPC-S and CT.

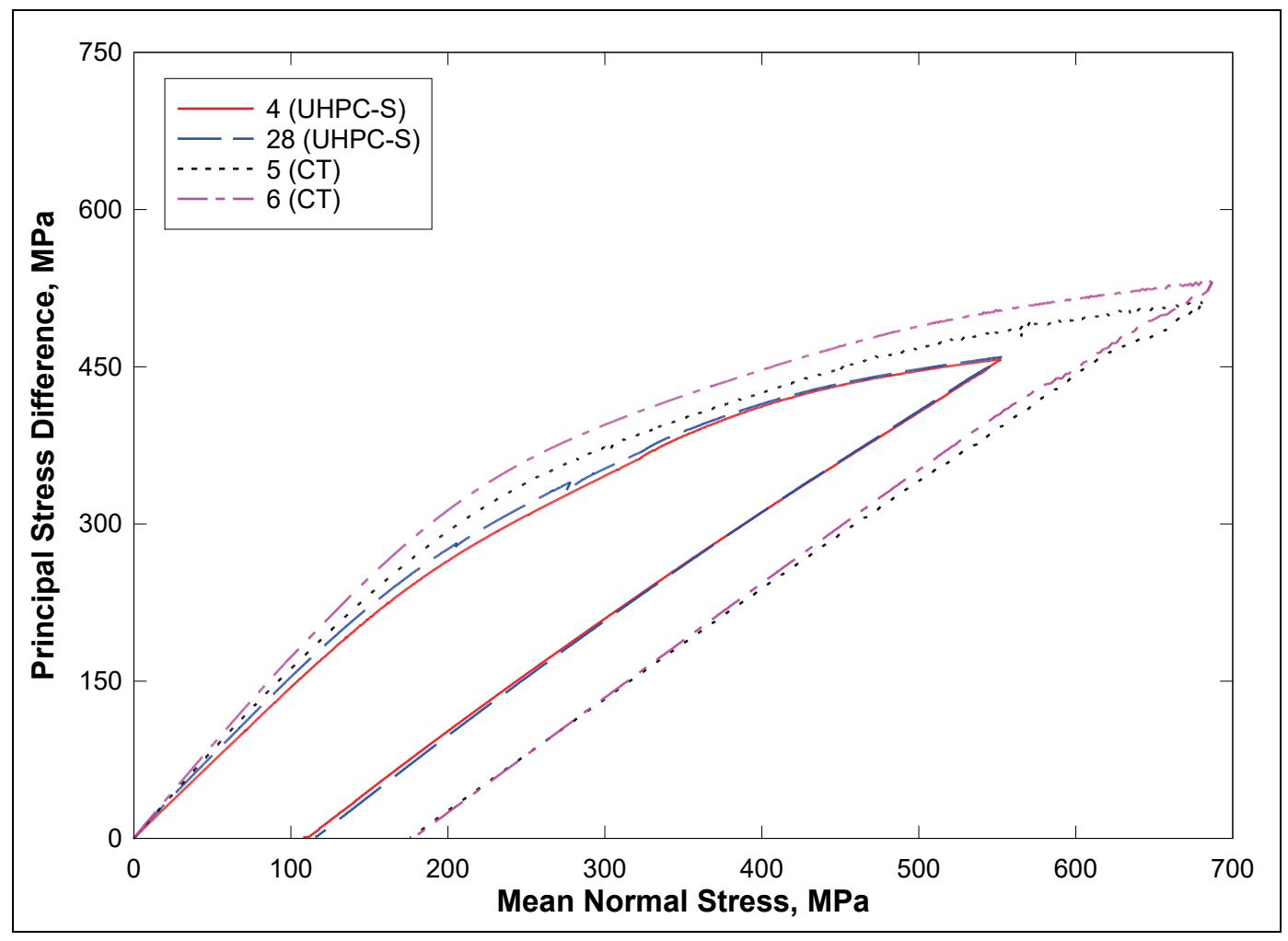


Figure 37. Comparison of stress-strain responses from UX tests on UHPC-S and CT.

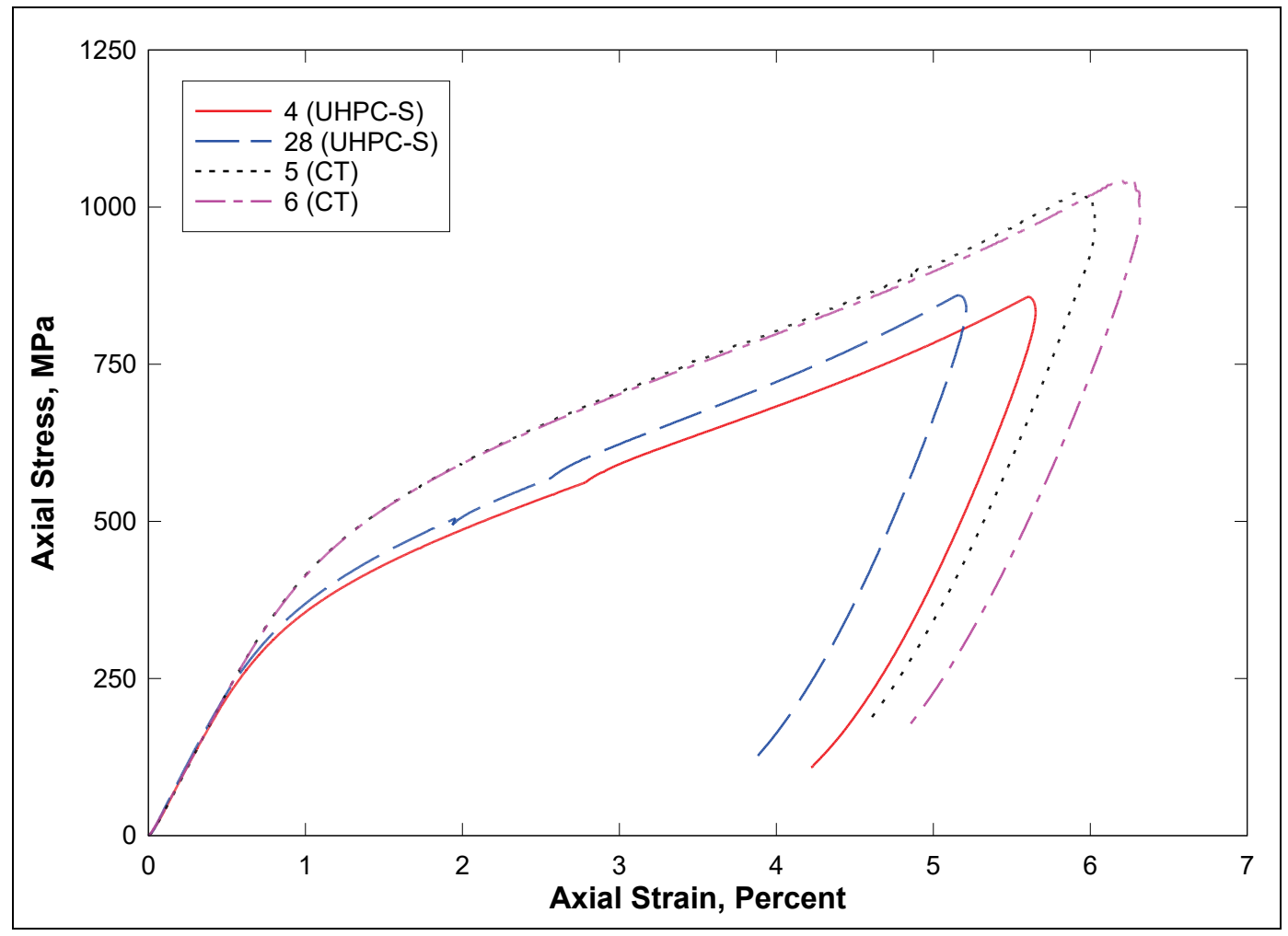

Figure 38. Comparison of pressure-volume data from UX tests on UHPC-S and CT.

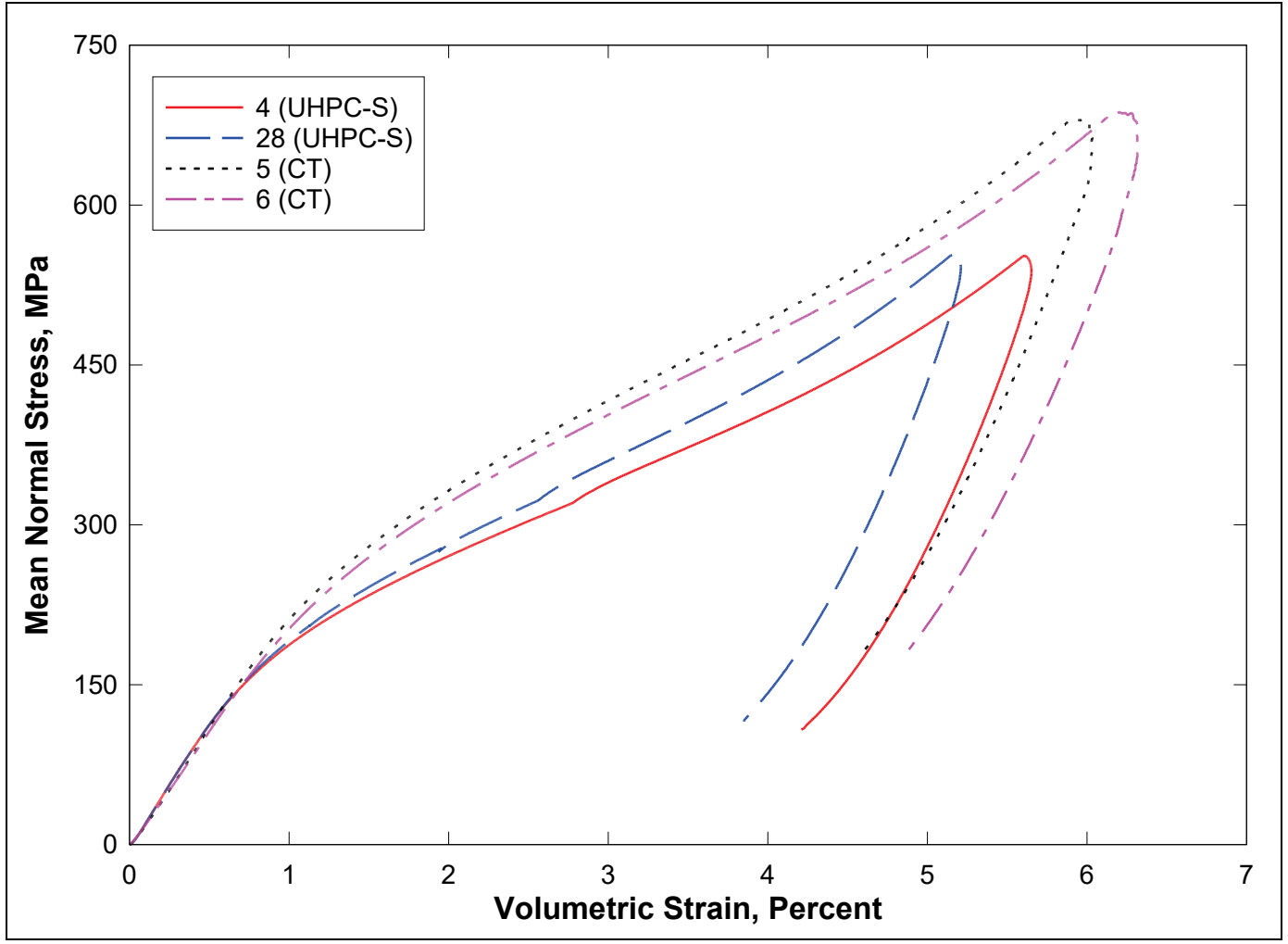




\section{Summary}

Personnel of the ERDC Geotechnical and Structures Laboratory conducted a laboratory investigation to characterize the strength and constitutive property behavior of two ultra-high-performance concretes (UHPCs), Cor-Tuf and UHPC-S.

Quasi-static unconfined characterization tests were conducted. CT and UHPC-S yielded unconfined compressive strengths of 212.3 MPa and 162.5 MPa, respectively. Both materials were instrumented with strain gauges for Young's modulus, strain-to-failure, and Poisson's ratio testing. CT had an elastic modulus of $57.9 \mathrm{GPa}$ and a Poisson's ratio of 0.182 . UHPC-S's modulus was 48.4 GPa and Poisson's ratio was 0.206. Flexural response was tested on two different beam sizes. CT peak flexural strengths were about $60 \%$ higher than UHPC-S peak flexural strengths for both beam sizes. The smaller beams had higher peak flexural strengths due to fiber alignment for both materials.

Twenty-seven successful confined mechanical property tests were conducted with UHPC-S and compared to a historical data set for CorTuf. These tests consisted of two HC tests, three UC tests, 14 TXC tests, four DP tests, two UX tests, and two UX/CV tests. In addition to the mechanical property tests, nondestructive pulse-velocity measurements were performed on each specimen prior to testing.

The overall quality of the test data was good; little scatter was observed in the data over repeated loading paths. Creep was observed during the $\mathrm{HC}$ tests and the hydrostatic loading phases of the TXC tests. Results from the TXC tests exhibited a continuous increase in principal stress difference up to a mean normal stress of approximately $475 \mathrm{MPa}$, at which point the composite material was approaching a fully saturated state. A compression failure surface was developed from the results of TXC tests conducted at seven levels of confining pressure and from the results of the UC tests. High confining pressures are needed in order to define the material's brittle-to-ductile failure mode transition. A comparison of UHPC-S and CT concrete behaviors was conducted to evaluate any differences in mechanical properties. 


\section{References}

ACI (American Concrete Institute). 2018. ACI concrete terminology. ACI CT-18. Farmington Hills, MI: ACI.

ASTM (American Society for Testing and Materials International). 2008. Standard practices for preparing rock core as cylindrical test specimens and verifying conformance to dimensional and shape tolerances. Designation: D4543-08. West Conshohocken, PA: ASTM International. . 2010. Standard test methods for laboratory determination of water (moisture) content of soil and rock by mass. Designation: D2216-10. West Conshohocken, PA: ASTM International. . 2014. Standard test method for static modulus of elasticity and Poisson's ratio of concrete in compression. Designation: $\mathrm{C} 469 / \mathrm{C} 469 \mathrm{M}-14$. West Conshohocken, PA: ASTM International. . 2016. Standard test method for pulse velocity through concrete. Designation: C597-16. West Conshohocken, PA: ASTM International. . 2018a. Standard practice for making and curing concrete specimens in the laboratory. Designation: C192/C192M-18. West Conshohocken, PA: ASTM International.

. 2018b. Standard test method for compressive strength of cylindrical concrete specimens. Designation: C39/C39M-18. West Conshohocken, PA: ASTM International.

.2018c. Standard test method for obtaining and testing drilled cores and sawed beams of concrete. Designation: $\mathrm{C}_{42} / \mathrm{C} 42 \mathrm{M}-18$. West Conshohocken, PA: ASTM International.

. 2019a. Standard specification for mixing rooms, moist cabinets, moist rooms, and water storage tanks used in the testing of hydraulic cements and concrete. Designation: C511-19. West Conshohocken, PA: ASTM International.

. 2019b. Standard test method for flexural performance of fiber-reinforced concrete (using beam with third-point loading). Designation: C1609/C1609M19. West Conshohocken, PA: ASTM International.

BS (British Standard). 2009. Testing Hardened Concrete; Part 3: Compressive Strength of Test Specimens. Designation: EN 12390-3. London: British Standards Institution.

Bishop, A. W., and D. J. Henkel. 1962. The measurement of soil properties in the triaxial test. London: Edward Arnold, Ltd.

Green, B. H., R. D. Moser, D. A. Scott, and W. R. Long. 2015. Ultra-high performance concrete history and usage by the Corps of Engineers. Advances in Civil Engineering Materials 4(2):132-143. 
Roth, M. J., T. S. Rushing, O. G. Flores, D. K. Sham, and J. W. Stevens. 2010. Laboratory investigation of the characterization of Cor-Tufflexural and splitting tensile properties. ERDC/GSL-TR-10-46. Vicksburg, MS: U.S. Army Engineer Research and Development Center.

Williams, E. M., S. S. Graham, P. A. Reed, and T. S. Rushing. 2009. Laboratory characterization of Cor-Tuf concrete with and without steel fibers. ERDC/GSL TR-09-22. Vicksburg, MS: U.S. Army Engineer Research and Development Center. 


\title{
Acronyms and Abbreviations
}

\author{
Term Definition \\ $\mathrm{ACl} \quad$ American Concrete Institute \\ ARSR Axial-to-Radial-Strain Ratio \\ ASTM American Society for Testing and Materials \\ AWG American Wire Gauge \\ CTTSO Combating Terrorism Technical Support Office \\ CMB Concrete Materials Branch \\ CPF Copper Polyimide Film \\ CT Cor-Tuf \\ DP Direct Pull \\ DSTA Defence Science \& Technology Agency \\ ERDC U.S. Army Engineer Research and Development Center \\ ESMD Engineering Systems and Materials Division \\ GSL Geotechnical and Structures Laboratory \\ HBM Hottinger Baldwin Messtechnik \\ HC Hydrostatic Compression \\ IEEB Impact and Explosion Effects Branch \\ LVDT Linear Variable Differential Transformers \\ SATEC Scarborough Academy for Technological, Environmental, and Computer Education \\ SMB Structural Mechanics Branch \\ TXC Triaxial Compression \\ UC Unconfined Compression \\ UCS Unconfined Compressive Strength \\ UHPC Ultra-High-Performance Concrete \\ UHPC-S Ultra-High-Performance Concrete-Singapore \\ UHPFRC Ultra-High Performance Fiber Reinforced Concrete \\ UX Uniaxial Strain \\ UX/CV Uniaxial Strain/Constant Volumetric Strain
}




\section{Unit Conversion Factors}

\begin{tabular}{|l|c|l|}
\hline Multiply & By & To Obtain \\
\hline cubic feet & 0.02831685 & cubic meters \\
\hline cubic inches & $1.6387064 \mathrm{E}-05$ & cubic meters \\
\hline cubic yards & 0.7645549 & cubic meters \\
\hline degrees Fahrenheit & (F-32)/1.8 & degrees Celsius \\
\hline feet & 0.3048 & meters \\
\hline gallons (U.S. liquid) & $3.785412 \mathrm{E}-03$ & cubic meters \\
\hline inches & 0.0254 & meters \\
\hline pounds (force) & 4.448222 & newtons \\
\hline pounds (force) per square foot & 47.88026 & pascals \\
\hline pounds (force) per square inch & 6.894757 & kilopascals \\
\hline pounds (mass) & 0.45359237 & kilograms \\
\hline pounds (mass) per cubic foot & 16.01846 & kilograms per cubic meter \\
\hline pounds (mass) per cubic inch & $2.757990 \mathrm{E}+04$ & kilograms per cubic meter \\
\hline square feet & 0.09290304 & square meters \\
\hline square inches & $6.4516 \mathrm{E}-04$ & square meters \\
\hline yards & 0.9144 & meters \\
\hline
\end{tabular}




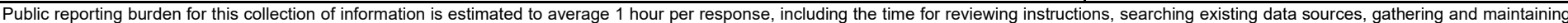

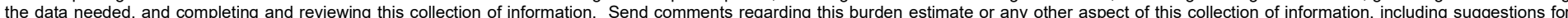

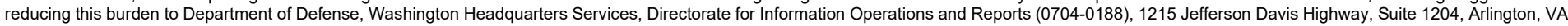

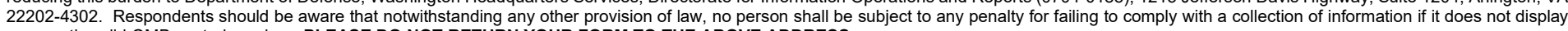
a currently valid OMB control number. PLEASE DO NOT RETURN YOUR FORM TO THE ABOVE ADDRESS.
1. REPORT DATE (DD-MM-YYYY) 2. REPORT TYPE
3. DATES COVERED (From - To)

March 2021 Final

\section{TITLE AND SUBTITLE}

Laboratory Characterization of Cor-Tuf Baseline and UHPC-S

5a. CONTRACT NUMBER

5b. GRANT NUMBER

5c. PROGRAM ELEMENT NUMBER

\section{AUTHOR(S)}

5d. PROJECT NUMBER

Dylan A. Scott, Steven S. Graham, Bradford P. Songer, Brian H. Green, Michael J. Grotke, and Tony N. Brogdon

5e. TASK NUMBER

5f. WORK UNIT NUMBER

\section{PERFORMING ORGANIZATION NAME(S) AND ADDRESS(ES)}

8. PERFORMING ORGANIZATION REPORT NUMBER

Geotechnical and Structures Laboratory

U.S. Army Engineer Research and Development Center

ERDC/GSL TR-21-7

3909 Halls Ferry Road

Vicksburg, MS 39180-6199

9. SPONSORING / MONITORING AGENCY NAME(S) AND ADDRESS(ES)

10. SPONSOR/MONITOR'S ACRONYM(S)

Combating Terrorism Technical Support Office

Washington, DC 20314-1000

11. SPONSOR/MONITOR'S REPORT NUMBER(S)

\section{DISTRIBUTION / AVAILABILITY STATEMENT}

Approved for public release; distribution is unlimited.

\section{SUPPLEMENTARY NOTES}

Project PS-3928, “Development of Ultra-High-Performance Concrete Tool,” MIPR N4175618MP00321

\section{ABSTRACT}

This experimental effort is part of a larger program entitled Development of Ultra-High-Performance Concrete Tools and Design Guidelines. This program operates in accordance with an agreement concerning combating terrorism research and development between the United States of America Department of Defense and the Republic of Singapore Ministry of Defence. The objective of the program is to develop a better understanding of the potential benefits that may be achieved from the application of ultra-highperformance concrete (UHPC) materials for protective structures. The specific effort detailed in this report will provide insight into laboratory-scale mechanical properties of Cor-Tuf and a proprietary material termed UHPC-Singapore (UHPC-S).

\begin{tabular}{|ll|}
\hline 15. SUBJECT TERMS & Material Characterization \\
Concrete & Materials-Compression testing \\
UHPC & Strains and stresses \\
\hline
\end{tabular}

16. SECURITY CLASSIFICATION OF:

\begin{tabular}{|l|l|}
\hline a. REPORT & b. ABSTRACT \\
Unclassified & Unclassified \\
\hline
\end{tabular}

17. LIMITATION OF ABSTRACT

c. THIS PAGE
Unclassified

High strength concrete-Testing

High strength concrete-Mechanical properties Stress-strain curves

\begin{tabular}{l|l}
$\begin{array}{l}\text { 18. NUMBER } \\
\text { OF PAGES }\end{array}$ & $\begin{array}{l}\text { 19a. NAME OF RESPONSIBLE } \\
\text { PERSON }\end{array}$
\end{tabular}

19b. TELEPHONE NUMBER (include

60 area code) 
